BNL-107612-2015-IR

\title{
Depth-dependent Vertical-to-Horizontal (V/H) Ratios of Free-Field Ground Motion Response Spectra for Deeply Embedded nuclear Structures
}

\author{
X. Wei, M. Miranda, M.E. Rosario, \\ C.J. Costantino, J. Braverman
}

February 2015

Nuclear Science \& Technology Department

Brookhaven National Laboratory

\section{U.S. Nuclear Regulatory Commission Office of New Reactors}

Notice: This manuscript has been authored by employees of Brookhaven Science Associates, LLC under Contract No. DE-AC02-98CH10886 with the U.S. Department of Energy. The publisher by accepting the manuscript for publication acknowledges that the United States Government retains a non-exclusive, paid-up, irrevocable, world-wide license to publish or reproduce the published form of this manuscript, or allow others to do so, for United States Government purposes. 


\section{DISCLAIMER}

This report was prepared as an account of work sponsored by an agency of the United States Government. Neither the United States Government nor any agency thereof, nor any of their employees, nor any of their contractors, subcontractors, or their employees, makes any warranty, express or implied, or assumes any legal liability or responsibility for the accuracy, completeness, or any third party's use or the results of such use of any information, apparatus, product, or process disclosed, or represents that its use would not infringe privately owned rights. Reference herein to any specific commercial product, process, or service by trade name, trademark, manufacturer, or otherwise, does not necessarily constitute or imply its endorsement, recommendation, or favoring by the United States Government or any agency thereof or its contractors or subcontractors. The views and opinions of authors expressed herein do not necessarily state or reflect those of the United States Government or any agency thereof. 


\title{
Depth-dependent Vertical-to-Horizontal (V/H) Ratios of Free-Field Ground Motion Response Spectra for Deeply Embedded Nuclear Structures
}

\author{
X. Wei ${ }^{1}$, M. Miranda ${ }^{2}$, M. E. Rosario ${ }^{3}$, C. J. Costantino ${ }^{4}$, and J. Braverman ${ }^{5}$ \\ ${ }^{1}$ Currently at WSP Group, ${ }^{2}$ Currently Assistant Professor at Hofstra University, \\ ${ }^{3}$ Visiting Research Associate at BNL from University of Puerto Rico at Mayaguez, \\ ${ }^{4}$ C.J. Costantino and Associates, ${ }^{5}$ Brookhaven National Laboratory
}

February 25, 2015

Nuclear Science and Technology Department

Brookhaven National Laboratory

Prepared for

Office of New Reactors

U.S. Nuclear Regulatory Commission 



\begin{abstract}
This report documents the results of a study to determine the depth-dependent $\mathrm{V} / \mathrm{H}$ ratios of ground motion response spectra in the free field. The $\mathrm{V} / \mathrm{H}$ ratios reported herein were developed from a worldwide database of surface and downhole acceleration recordings obtained from 45 vertical array stations. This database was specifically compiled for this project, and includes information from a diversity of active tectonic regions (California, Alaska, Taiwan, Japan), site conditions (rock to soft soil), ground motion intensity levels (PGAs between $0.01 \mathrm{~g}$ and $0.50 \mathrm{~g}$ ), magnitudes (between ML 2.78 and JMA 8.1), epicentral distances (between $3.2 \mathrm{~km}$ and 812 $\mathrm{km}$ ), and source depths (between $1.2 \mathrm{~km}$ and $112 \mathrm{~km}$ ), as well as sensors at surface and at a wide range of depths relevant to the project.

To study the significance of the depth effect, $\mathrm{V} / \mathrm{H}$ ratios from all the records were sorted into a number of depth bins relevant to the project, and statistics (average, standard deviation, coefficient of variation, 16th, 50th, and 84th percentiles) of the $\mathrm{V} / \mathrm{H}$ ratios within each bin were computed. Similar analyses were repeated, controlling for different site conditions, ground motion intensity levels, array locations, and source depths, to study their relative effect on the $\mathrm{V} / \mathrm{H}$ ratios.

Our findings confirm the importance of the depth effect on the $\mathrm{V} / \mathrm{H}$ ratios. The research findings in this report can be used to provide guidance on the significance of the depth effect, and the extent to which this effect should be considered in the seismic design of deeply embedded SMR structures and NPP structures in general.
\end{abstract}





\section{Table of Contents}

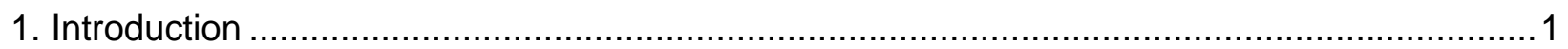

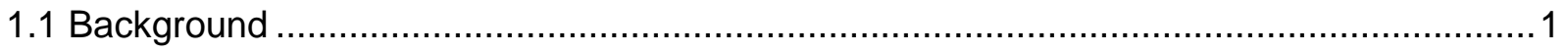

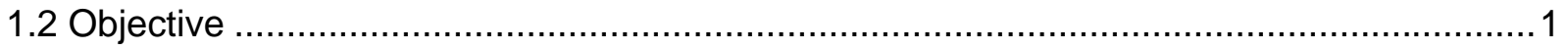

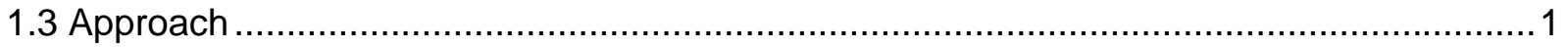

2. Collection of Vertical Seismic Array Data ............................................................

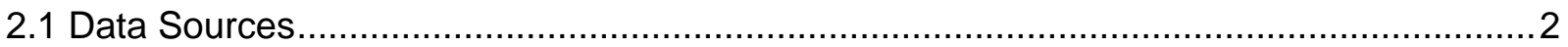

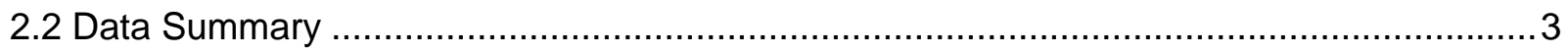

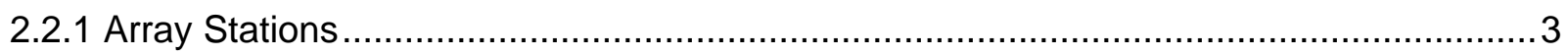

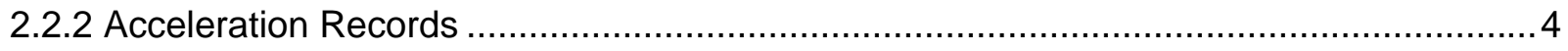

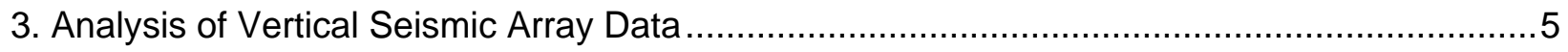

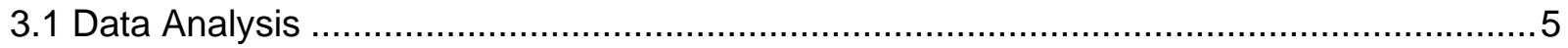

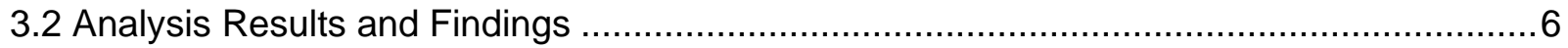

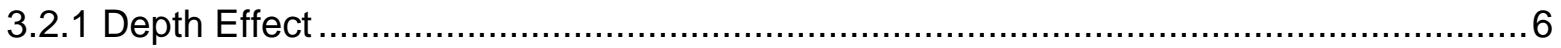

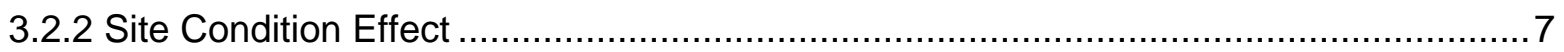

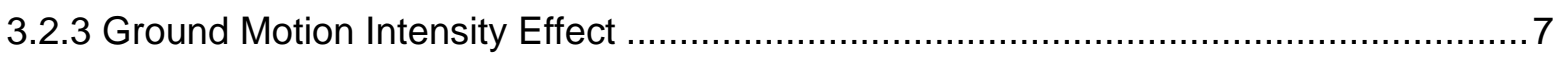

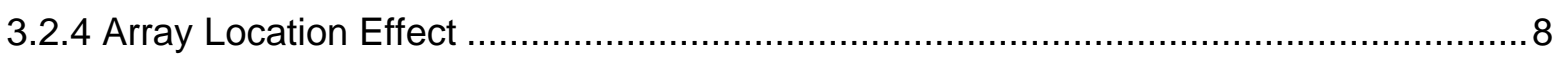

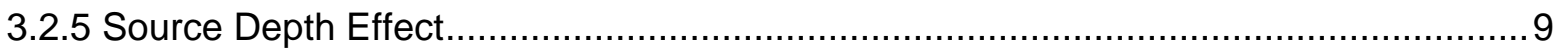

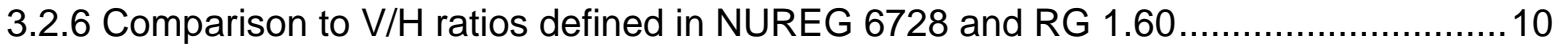

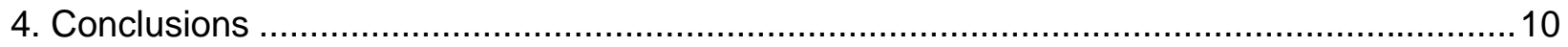

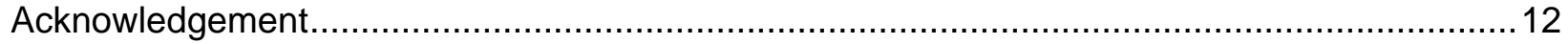

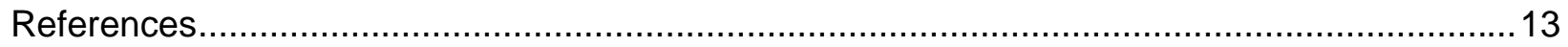

\section{List of Tables}

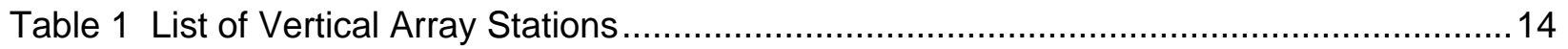

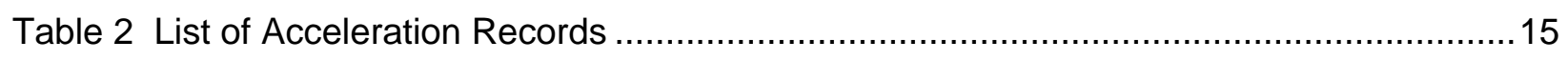

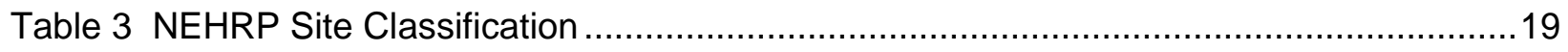

Table 4 Number of $\mathrm{V} / \mathrm{H}$ ratios obtained from arrays in class B, C, D1, D2, D3, and E sites......19

Table 5 Number of $\mathrm{V} / \mathrm{H}$ ratios obtained from events with PGAs in the ranges $0.01 \mathrm{~g}-0.1 \mathrm{~g}, 0.1 \mathrm{~g}$ -

$0.2 \mathrm{~g}$, and $0.2-0.5 \mathrm{~g}$ (from arrays in class $\mathrm{B}, \mathrm{C}$, and D1 sites only) ......................... 19 
Table 6 Number of V/H ratios obtained from CGS-CESMD and USGS-NSMP sites in California; NEES at UCSB sites in California; NEES at UCSB site in Anchorage, Alaska; Sendai District, Japan; and Taipei Basin, Taiwan (arrays in class B, C, and D sites only) ......20

\section{List of Figures}

Figure 1 Map of Vertical Array Stations 21

Figure $2 \mathrm{~V} / \mathrm{H}$ ratios of all records obtained from arrays in class $\mathrm{B}, \mathrm{C}$, and D1 site. Average $\mathrm{V} / \mathrm{H}$ ratios (top) and normalized average $\mathrm{V} / \mathrm{H}$ ratios (bottom) for each of the seven depth bins:.

Figure $3 \mathrm{~V} / \mathrm{H}$ ratios of all records obtained from arrays in class B, C, and D1 sites. Total of 521 $\mathrm{V} / \mathrm{H}$ ratios plotted in their corresponding depth bins:.

Figure $4 \mathrm{~V} / \mathrm{H}$ ratios of all records obtained from arrays in class $\mathrm{B}, \mathrm{C}$, and D1 sites. Coefficients of variation of the $\mathrm{V} / \mathrm{H}$ ratios within each of the seven depth bins: 24

Figure $5 \mathrm{~V} / \mathrm{H}$ ratios of all records obtained from arrays in class $\mathrm{B}, \mathrm{C}$, and D1 sites. Percentiles $\left(16^{\text {th }}, 50^{\text {th }}, 84^{\text {th }}\right)$ of the $\mathrm{V} / \mathrm{H}$ ratios within each of the seven depth bins:

Figure $6 \mathrm{~V} / \mathrm{H}$ ratios of all records obtained from arrays in class $\mathrm{B}$ and $\mathrm{C}$ sites. Average $\mathrm{V} / \mathrm{H}$ ratios (top) and normalized average $\mathrm{V} / \mathrm{H}$ ratios (bottom) for each of the six depth bins:

Figure $7 \mathrm{~V} / \mathrm{H}$ ratios of all records obtained from arrays in class $\mathrm{B}$ and $\mathrm{C}$ sites......... 27

Figure $8 \mathrm{~V} / \mathrm{H}$ ratios of all records obtained from arrays in class D1 sites. Average V/H ratios (top) and normalized average V/H ratios (bottom) for each of the seven depth bins: ..28

Figure $9 \mathrm{~V} / \mathrm{H}$ ratios of all records obtained from arrays in class D1 sites. Total of $297 \mathrm{~V} / \mathrm{H}$ ratios plotted in their corresponding depth bins:

Figure $10 \mathrm{~V} / \mathrm{H}$ ratios of all records obtained from arrays in class D2 sites. Average $\mathrm{V} / \mathrm{H}$ ratios (top) and normalized average $\mathrm{V} / \mathrm{H}$ ratios (bottom) for each of the seven depth bins:...30

Figure $11 \mathrm{~V} / \mathrm{H}$ ratios of all records obtained from arrays in class D2 sites. Total of $110 \mathrm{~V} / \mathrm{H}$ ratios plotted in their corresponding depth bins:

Figure $12 \mathrm{~V} / \mathrm{H}$ ratios of all records obtained from arrays in class D3 sites. Average $\mathrm{V} / \mathrm{H}$ ratios (top) and normalized average $\mathrm{V} / \mathrm{H}$ ratios (bottom) for each of the seven depth bins: ..32

Figure $13 \mathrm{~V} / \mathrm{H}$ ratios of all records obtained from arrays in class D3 sites. Total of $269 \mathrm{~V} / \mathrm{H}$ ratios plotted in their corresponding depth bins:.

Figure $14 \mathrm{~V} / \mathrm{H}$ ratios of all records obtained from arrays in class D (D1, D2, and D3) sites. Average $\mathrm{V} / \mathrm{H}$ ratios (top) and normalized average $\mathrm{V} / \mathrm{H}$ ratios (bottom) for each of the seven depth bins:

Figure $15 \mathrm{~V} / \mathrm{H}$ ratios of all records obtained from arrays in class D (D1, D2, and D3) sites. Total of $676 \mathrm{~V} / \mathrm{H}$ ratios plotted in their corresponding depth bins: 35 
Figure $16 \mathrm{~V} / \mathrm{H}$ ratios of all records obtained from arrays in class $\mathrm{E}$ sites. Average $\mathrm{V} / \mathrm{H}$ ratios (top) and normalized average $\mathrm{V} / \mathrm{H}$ ratios (bottom) for each of the seven depth bins: ..36

Figure $17 \mathrm{~V} / \mathrm{H}$ ratios of all records obtained from arrays in class $\mathrm{E}$ sites. Total of $65 \mathrm{~V} / \mathrm{H}$ ratios plotted in their corresponding depth bins:

Figure $18 \mathrm{~V} / \mathrm{H}$ ratios of all records obtained from events with PGA in the range 0.01-0.10 $\mathrm{g}$ (from arrays in class $\mathrm{B}, \mathrm{C}$, and D1 sites only). Average $\mathrm{V} / \mathrm{H}$ ratios (top) and normalized average $\mathrm{V} / \mathrm{H}$ ratios (bottom) for each of the seven depth bins:

Figure $19 \mathrm{~V} / \mathrm{H}$ ratios of all records obtained from events with PGA in the range 0.01-0.10 $\mathrm{g}$ (from arrays in class B, C, and D1 sites only). Total of $466 \mathrm{~V} / \mathrm{H}$ ratios plotted in their corresponding depth bins:

Figure $20 \mathrm{~V} / \mathrm{H}$ ratios of all records obtained from events with PGA in the range 0.10-0.20 $\mathrm{g}$ (from arrays in class $\mathrm{B}, \mathrm{C}$, and $\mathrm{D} 1$ sites only). Average $\mathrm{V} / \mathrm{H}$ ratios (top) and normalized average $\mathrm{V} / \mathrm{H}$ ratios (bottom) for each of the seven depth bins:

Figure $21 \mathrm{~V} / \mathrm{H}$ ratios of all records obtained from events with PGA in the range 0.10-0.20 $\mathrm{g}$ (from arrays in class $\mathrm{B}, \mathrm{C}$, and D1 sites only). Total of $30 \mathrm{~V} / \mathrm{H}$ ratios plotted in their corresponding depth bins:

Figure $22 \mathrm{~V} / \mathrm{H}$ ratios of all records obtained from events with PGA in the range $0.20-0.50 \mathrm{~g}$ (from arrays in class $\mathrm{B}, \mathrm{C}$, and $\mathrm{D} 1$ sites only). Average $\mathrm{V} / \mathrm{H}$ ratios (top) and normalized average $\mathrm{V} / \mathrm{H}$ ratios (bottom) for each of the seven depth bins:

Figure $23 \mathrm{~V} / \mathrm{H}$ ratios of all records obtained from events with PGA in the range $0.20-0.50 \mathrm{~g}$ (from arrays in class B, C, and D1 sites only). Total of $25 \mathrm{~V} / \mathrm{H}$ ratios plotted in their corresponding depth bins:

Figure $24 \mathrm{~V} / \mathrm{H}$ ratios of all records obtained from events with PGA in the range 0.10-0.50 $\mathrm{g}$ (from arrays in class $\mathrm{B}, \mathrm{C}$, and $\mathrm{D} 1$ sites only). Average $\mathrm{V} / \mathrm{H}$ ratios (top) and normalized average $\mathrm{V} / \mathrm{H}$ ratios (bottom) for each of the seven depth bins: .....

Figure $25 \mathrm{~V} / \mathrm{H}$ ratios of all records obtained from events with PGA in the range 0.10-0.50 $\mathrm{g}$ (from arrays in class B, C, and D1 sites only). Total of $55 \mathrm{~V} / \mathrm{H}$ ratios plotted in their corresponding depth bins:

Figure $26 \mathrm{~V} / \mathrm{H}$ ratios of all records obtained from CGS-CESMD and USGS-NSMP sites in California (arrays in class B, C, and D sites only). Average $\mathrm{V} / \mathrm{H}$ ratios (top) and normalized average $\mathrm{V} / \mathrm{H}$ ratios (bottom) for each of the seven depth bins:

Figure $27 \mathrm{~V} / \mathrm{H}$ ratios of all records obtained from CGS-CESMD and USGS-NSMP sites in California (arrays in class B, C, and D sites only). Total of $225 \mathrm{~V} / \mathrm{H}$ ratios plotted in their corresponding depth bins:

Figure $28 \mathrm{~V} / \mathrm{H}$ ratios of all records obtained from NEES at UCSB sites in California (arrays in class $\mathrm{C}$ and $\mathrm{D}$ sites only). Average $\mathrm{V} / \mathrm{H}$ ratios (top) and normalized average $\mathrm{V} / \mathrm{H}$ ratios (bottom) for each of the seven depth bins: 
Figure $29 \mathrm{~V} / \mathrm{H}$ ratios of all records obtained from NEES at UCSB sites in California (arrays in class $\mathrm{C}$ and $\mathrm{D}$ sites only). Total of $230 \mathrm{~V} / \mathrm{H}$ ratios plotted in their corresponding depth bins:

Figure $30 \mathrm{~V} / \mathrm{H}$ ratios of all records obtained from the NEES at UCSB site in Anchorage, Alaska (array in class $\mathrm{D}$ site). Average $\mathrm{V} / \mathrm{H}$ ratios (top) and normalized average $\mathrm{V} / \mathrm{H}$ ratios (bottom) for each of the seven depth bins: 50

Figure $31 \mathrm{~V} / \mathrm{H}$ ratios of all records obtained from the NEES at UCSB site in Anchorage, Alaska (array in class $\mathrm{D}$ site). Total of $55 \mathrm{~V} / \mathrm{H}$ ratios plotted in their corresponding depth bins:

Figure $32 \mathrm{~V} / \mathrm{H}$ ratios of all records obtained from the Sendai District, Japan (arrays in class B, $\mathrm{C}$, and $\mathrm{D}$ sites only). Average $\mathrm{V} / \mathrm{H}$ ratios (top) and normalized average $\mathrm{V} / \mathrm{H}$ ratios (bottom) for each of the seven depth bins:

Figure $33 \mathrm{~V} / \mathrm{H}$ ratios of all records obtained from the Sendai District, Japan (arrays in class B, $\mathrm{C}$, and $\mathrm{D}$ sites only). Total of $336 \mathrm{~V} / \mathrm{H}$ ratios plotted in their corresponding depth bins:

Figure $34 \mathrm{~V} / \mathrm{H}$ ratios of all records obtained from the Taipei Basin, Taiwan (arrays in class D sites only). Average $\mathrm{V} / \mathrm{H}$ ratios (top) and normalized average $\mathrm{V} / \mathrm{H}$ ratios (bottom) for each of the seven depth bins:

Figure $35 \mathrm{~V} / \mathrm{H}$ ratios of all records obtained from the Taipei Basin, Taiwan (arrays in class D sites only). Total of $54 \mathrm{~V} / \mathrm{H}$ ratios plotted in their corresponding depth bins:

Figure $36 \mathrm{~V} / \mathrm{H}$ ratios of all records obtained from events with source depths between $0 \mathrm{~km}$ and $40 \mathrm{~km}$, from the NEES at UCSB site in Anchorage, Alaska (class D site).... 56

Figure $37 \mathrm{~V} / \mathrm{H}$ ratios of all records obtained from events with source depths between $40 \mathrm{~km}$ and $70 \mathrm{~km}$, from the NEES at UCSB site in Anchorage, Alaska (class D site) ..................57

Figure 38 16th, 50th, and 84th percentiles of $\mathrm{V} / \mathrm{H}$ ratios of all records obtained from arrays in class $\mathrm{B}, \mathrm{C}$, and $\mathrm{D} 1$ sites, and comparison to $\mathrm{V} / \mathrm{H}$ ratios recommended in NUREG 6728 and RG 1.60 .....

Figure 39 16th, 50th, and 84th percentiles of $\mathrm{V} / \mathrm{H}$ ratios of all records obtained from arrays in class $\mathrm{B}, \mathrm{C}$, and D1 sites, and comparison to $\mathrm{V} / \mathrm{H}$ ratios recommended in NUREG 6728 and RG 1.60 . 


\section{Introduction}

\subsection{Background}

In the seismic design of nuclear power plant (NPP) structures, the vertical ground motion response spectra (RS) are typically developed by multiplying the horizontal ground motion RS with empirically-based, frequency-dependent, vertical-to-horizontal $(\mathrm{V} / \mathrm{H})$ spectral ratios. Since conventional NPP structures normally have shallow foundations (embedment less than $40 \mathrm{ft}$ ), the U.S. Nuclear Regulatory Commission (NRC) accepts the use of surface V/H ratios for such structures. Any uncertainties in the design ground motions, including uncertainties associated with the depth-dependence of the $\mathrm{V} / \mathrm{H}$ ratios, are judged to be compensated by the conservatism of the Soil Structure Interaction (SSI) analysis methodology typically followed in the site-specific seismic design of NPP structures.

In recent years, several Small Modular Reactor (SMR) designs have been submitted to the NRC for review and licensing approval. Currently proposed SMR structures are deeply embedded as much as $140 \mathrm{ft}$ from the ground surface, which is substantially deeper than the aforementioned shallow foundations of conventional NPP structures.

A review of the literature could only find a small number of studies performed to investigate the depth-dependence of the $\mathrm{V} / \mathrm{H}$ ratios $[1,2]$. It should also be noted that these studies were based on a relatively limited number of acceleration recordings from vertical (downhole) seismic arrays. Nevertheless, these studies indicate that the extrapolation of surface $\mathrm{V} / \mathrm{H}$ ratios to significantly greater depths may not be conservative in the frequency range of interest to the seismic design of SMR structures.

\subsection{Objective}

The objective of this project is to develop depth-dependent $\mathrm{V} / \mathrm{H}$ ratios of ground motion $\mathrm{RS}$ in the free field, based on available downhole acceleration recordings from a number of vertical arrays that have been instrumented to date. These depth-dependent $\mathrm{V} / \mathrm{H}$ ratios may then be used to characterize vertical motions in the seismic design of deeply embedded SMR structures.

The research results can also be used to provide guidance on the significance of the depth effect, and the extent to which this effect should be considered in the seismic design of NPP structures.

It should be emphasized that all recorded downhole acceleration records correspond to incolumn motions in the free field. It follows that any depth-dependent $\mathrm{V} / \mathrm{H}$ ratios derived from such records must also correspond to in-column motions, as opposed to outcrop motions. This important distinction should be taken into consideration in any application of empirically-based, depth-dependent $\mathrm{V} / \mathrm{H}$ ratios used for seismic design purposes.

\subsection{Approach}

The $\mathrm{V} / \mathrm{H}$ ratios reported herein were developed from a worldwide database of surface and downhole acceleration recordings obtained from a number of vertical array stations. This database was specifically compiled for this project, and includes information from a diversity of 
active tectonic regions, site conditions, ground motion intensity levels, earthquake magnitudes, epicentral distances, and sensors located at the ground surface and at a wide range of depths of interest to the project.

Each acceleration record at the surface and at depth includes three components: two horizontal and one vertical. For each acceleration record component, the corresponding 5\% damped response spectrum (RS) was calculated; the average horizontal RS was then computed as the geometric mean of the RS of the two horizontal components. Finally, the frequency-dependent $\mathrm{V} / \mathrm{H}$ ratios at the surface or at depth were calculated by dividing the vertical RS by the average horizontal RS.

Distinct $\mathrm{V} / \mathrm{H}$ ratios were calculated for each acceleration record set at the surface and at depth, for each seismic event recorded at a given array.

To study the significance of the depth effect, $\mathrm{V} / \mathrm{H}$ ratios from all the records were sorted into several depth bins, and statistics (average, standard deviation, coefficient of variation, $16^{\text {th }}, 50^{\text {th }}$, and $84^{\text {th }}$ percentiles) of the $\mathrm{V} / \mathrm{H}$ ratios within each bin were estimated. Similar analyses were repeated, controlling for different site conditions, ground motion intensity levels, array locations, and source depths, to study their relative effects on the $\mathrm{V} / \mathrm{H}$ ratios.

It should be noted that the same seismic event may be recorded at several array stations. Since accelerations recorded at different arrays, but corresponding to the same event, tend to have noticeable differences in amplitude and frequency content (due to differences in source-to-site paths, local site conditions, etc.) they are considered to originate form separate "events" for the purposes of the database. Statistical bias may be introduced by this approach if the same event is recorded by two arrays that have similar site conditions and are located relatively close to each other. Only 6 (out of 267) database events are judged to fall in this category, however, so that any such bias is likely to be very small.

\section{Collection of Vertical Seismic Array Data}

\subsection{Data Sources}

The study is based on downhole recordings in the free field with maximum surface peak ground accelerations (PGA) of at least $0.01 \mathrm{~g}$, and sensor depths ranging from near the surface to more than $300 \mathrm{ft}$ below grade.

To collect as many downhole recordings as possible, the authors performed an exhaustive search of electronic databases accessible through the internet, and contacted well-known researchers and private consultants. Major databases and institutions inquired include the following: Center for Engineering Strong Motion Data (CESMD) of the California Geological Survey (CGS), California Strong Motion Instrumentation Program (CSMIP); National StrongMotion Project (NSMP), U.S. Geological Survey (USGS); COSMOS Virtual Data Center; Pacific Earthquake Engineering Research (PEER) Center at the University of California, Berkeley; Pacific Engineering and Analysis, Inc.; Network for Earthquake Engineering Simulation at the University of California, Santa Barbara (NEES at UCSB); Southern California Earthquake 
Center (SCEC) at the University of Southern California; Northeastern University; KiK-net, Japan; Building Research Institute (BRI), Japan; Institute of Engineering Seismology and Earthquake Engineering, Institute of Earth Sciences (IES) at the Academia Sinica, Taiwan; and National Central University (NCU) of Taiwan.

Recordings meeting the project requirements (e.g., minimum PGA of $0.01 \mathrm{~g}$, recordings away from the influence of adjacent large/heavy structures, available site shear wave velocity, and available soil information) were obtained from the online data repositories of CGS-CESMD [3], USGS-NSMP [4], and NEES at UCSB [5]. In addition, researchers at BRI and NCU provided data from vertical arrays in Japan [6] and Taiwan [7], respectively, as well as corresponding site information.

\subsection{Data Summary}

\subsubsection{Array Stations}

The data used in this study were recorded at 45 different array stations located in California; Anchorage, Alaska; the Sendai District in Japan; and the Taipei Basin in Taiwan. Figure 1 shows a map of the different array stations considered. A summary of available information for each array station is provided in Table 1, which includes array station code, name, sensor depths, free field information, and local site information and site classification.

Sensor depths range from near the surface down to $1644 \mathrm{ft}$, although the study focuses primarily on depths representative of deeply embedded SMR designs; i.e. 0 to $200 \mathrm{ft}$. Records for depths greater than $200 \mathrm{ft}$ were included to illustrate trends in depth variation.

As indicated by the free field information in Table 1, all records were obtained from array stations that were judged to be representative of the free field; i.e., located sufficiently far away from adjacent heavy structures (e.g., dams).

Local site information, including a majority of shear wave velocity profiles, was obtained from the referenced data repositories, for the arrays located in California and Alaska, and from research reports for the arrays located in Japan and Taiwan.

Shear wave velocity profiles of 6 (out of 45 ) arrays could not be obtained. These arrays are: Alameda-Posey \& Webster, Crockett-Carquinez Bridge \#2, Vallejo-Highway 37/Napa River East, Seven Oaks Dam Downstream Array, and Superstition Mountain Peak in California; and Water Conservancy Bureau in Panchiao, Taiwan.

The Vs30 parameter shown in Table 1 for each array station corresponds to the average shear wave velocity of the rock or soil layers in the top $30 \mathrm{~m}$ at the site (equivalent-travel time). This parameter was obtained directly from the data repositories or was computed from the available shear wave velocity profiles. In only two cases, Vs30 was extrapolated from shear wave velocity profiles available for the vicinity of the site (Vs30 for Crockett-Carquinez Bridge \#2 was assumed to be similar to Crockett-Carquinez Bridge \#1 since the two stations are located $500 \mathrm{ft}$ apart in relatively flat terrain; Vs30 for Water Conservancy Bureau, Panchiao, Taiwan, was estimated from geotechnical studies of the Taipei basin $[8,9])$. 
In Table 1, local site conditions at each array station are categorized as rock (class B), soft rock or very dense soil (class C), stiff soil (class D), or soft soil (class E), according to the site classification defined in the well-known NEHRP provisions [10], which depends on the parameter Vs30. The full NEHRP site classification as a function of Vs30 is reproduced in Table 3. The number of arrays located in class B, C, D, and E sites are 2, 11, 28, and 4, respectively.

Since soft soil (class E) sites are unlikely to be considered for NPP construction, the V/H ratios obtained from arrays in class $E$ sites are provided only for the purpose of illustrating the trends in variation with respect to site conditions.

In some cases, even stiff soil (class D) sites may not be considered suitable for NPPs since the definition of competent foundation material for such structures is associated with a shear wave velocity of $1000 \mathrm{ft} / \mathrm{s}(305 \mathrm{~m} / \mathrm{s})$, which is in the middle of the Vs30 range for class D. Furthermore, a site classification more appropriate to deeply embedded SMRs would need to consider the average shear wave velocity of the layers in the top $60 \mathrm{~m}$, rather than $30 \mathrm{~m}$, at the site.

Therefore, for class D sites only, an additional sub-classification was implemented in this study in the following manner. First, a parameter Vs60 was defined as the average shear wave velocity of the rock or soil layers in the top $60 \mathrm{~m}$ at the site. If $\mathrm{Vs} 60$ is greater than approximately $350 \mathrm{~m} / \mathrm{s}$, the site was classified as D1. If Vs60 is less than approximately $250 \mathrm{~m} / \mathrm{s}$, the site was classified as D3. All remaining sites that are not D1 or D3 were classified as D2. The number of arrays in class D1, D2, and D3 sites are 13, 5, and 10, respectively, and are designated in Table 1 in parenthesis after the main site classification.

In light of the above discussions, the study focuses on $\mathrm{V} / \mathrm{H}$ ratios obtained from arrays in class $B, C$, and D1 sites.

\subsubsection{Acceleration Records}

Over 300 sets of downhole acceleration records from different seismic events recorded at the 45 vertical array stations were collected and processed as part of this study. V/H ratios were calculated and plotted for all these records. An initial review of the $\mathrm{V} / \mathrm{H}$ ratio plots resulted in the elimination of several sets of records because of obvious data errors. In addition, as discussed in the BRI report [6], several Japanese records are not reliable at frequencies below approximately $0.3 \mathrm{~Hz}$ because of the small amplitudes of components in the low frequency range. Based on the reliable frequency range recommended in the BRI report, as well as to avoid any numerical artifacts from the data processing or filtering, the RS used in the calculation of all the $\mathrm{V} / \mathrm{H}$ ratios were all truncated below $0.5 \mathrm{~Hz}$.

A total of 267 sets of downhole records were utilized in the final calculations reported herein. Since each set has records at two or more depths, the 267 sets result in 965 individual records at surface or at depth.

Table 2 provides detailed information of the 267 sets of records, including: data source; name and code of the array station; and seismic event information, including event name or ID, recording date and time, maximum surface PGA, magnitude, epicentral distance, and source 
depth. It is noted that the maximum surface PGA is the maximum peak ground acceleration of the three components recorded at the surface.

The number of records obtained from arrays in class B, C, D1, D2, D3, and E sites are 37, 187, $297,110,269$, and 65, respectively (a total of 965 ).

The data used in this study was recorded between 1987 and 2012. The 125 sets of records from the U.S. are fairly new, with $90 \%$ recorded within the last 10 years, 50\% recorded within the last 5 years, and the latest one recorded near the end of 2012. The 20 sets of records from Taiwan were recorded between 1994 and 1999, and the 122 sets of records from Japan were recorded between 1987 and 1998.

The magnitudes of the earthquakes shown in Table 2 are given in different scales; i.e., ML, Mw and JMA. Unit conversion was not performed because these scales are relatively similar in the range of magnitudes being considered in this study. Additional accuracy was not warranted because dependence on magnitude was not directly investigated. Magnitudes range between ML 2.78 and JMA 8.1.

Earthquake source depths range between $1.2 \mathrm{~km}$ and $112 \mathrm{~km}$. About $50 \%$ of the records correspond to earthquakes with source depths less than or equal to $14 \mathrm{~km}$, and about $80 \%$ of the records correspond to earthquakes with source depths less than $70 \mathrm{~km}$, which means that the majority of the records correspond to "shallow-focus" earthquakes. Epicentral distances range between $3.2 \mathrm{~km}$ and $812 \mathrm{~km}$; the percentages of records that correspond to epicentral distances less than $15 \mathrm{~km}, 50 \mathrm{~km}$, and $150 \mathrm{~km}$ are about 27\%, 49\%, and 80\%, respectively.

The largest PGA shown in Table 2 is $0.49 \mathrm{~g}$, recorded at the Los Angeles-La Cienega array during the 2001 West Hollywood earthquake. Of the 267 sets of records, about $50 \%$ have PGAs less than $0.032 \mathrm{~g}$, and about $87 \%$ have PGAs less than $0.10 \mathrm{~g}$.

In summary, as shown in Table 1 and Table 2, the records utilized in this study cover a diversity of active tectonic regions, site conditions, ground motion intensity levels, magnitudes, epicentral distances, and sensors at the surface and at a wide range of depths relevant to the project.

\section{Analysis of Vertical Seismic Array Data}

\subsection{Data Analysis}

As outlined in Section 1.3, each seismic event recorded at a given array generates acceleration records at or close to the surface, as well as at the various depths where the seismometers (sensors) of the array are embedded. Each acceleration record at the surface or at depth includes three components: two horizontal and one vertical. For each acceleration record component, the RS at 5\% damping was calculated; then, the average horizontal RS was computed as the geometric mean of the RS of the two horizontal components, using the equation given below.

$$
R S_{\text {hor.ave. }}=\sqrt{a_{\text {hor. } 1} \cdot a_{\text {hor. } 2}}
$$


Finally, the frequency-dependent $\mathrm{V} / \mathrm{H}$ ratios at the surface or at depth were calculated by dividing the vertical RS by the average horizontal RS.

As mentioned in the prior section, a total of 267 sets of downhole records were utilized in the final calculations reported herein. Since each set has records at two or more depths, the 267 sets result in 965 individual records at surface or at depth. Distinct V/H ratios were computed for each of these 965 individual records.

To study the significance of the depth effect, $\mathrm{V} / \mathrm{H}$ ratios from the records were sorted into several depth bins, and statistics (average, standard deviation, coefficient of variation, $16^{\text {th }}, 50^{\text {th }}$, and $84^{\text {th }}$ percentiles) of the ratios within each bin were estimated. Similar analyses were repeated, controlling for different site conditions, ground motion intensity levels, array locations, and source depths, to study their relative effects on the $\mathrm{V} / \mathrm{H}$ ratios.

\subsection{Analysis Results and Findings}

\subsubsection{Depth Effect}

The following bins were defined to study the depth effect: (1) depth 0-7 ft below grade (this bin is treated as representative of the surface); (2) depth 7-50 ft below grade; (3) depth 50-100 $\mathrm{ft}$ below grade; (4) depth 100-150 ft below grade; (5) depth 150-200 ft below grade; (6) depth 200$300 \mathrm{ft}$ below grade; and (7) depths greater than $300 \mathrm{ft}$ below grade.

Only $\mathrm{V} / \mathrm{H}$ ratios obtained from arrays in class $\mathrm{B}, \mathrm{C}$, and $\mathrm{D} 1$ sites were considered in the study of the depth effect. This reduced the total number of ratios from 965 to 521, which were distributed in the seven depth bins as follows: $154,71,81,65,62,57$, and 31 , from the shallowest to the deepest. Table 4 provides more detailed on how the data is distributed in terms of depth bins and site classes.

Statistics (average, standard deviation, coefficient of variation, $16^{\text {th }}, 50^{\text {th }}$, and $84^{\text {th }}$ percentiles) of the $\mathrm{V} / \mathrm{H}$ ratios within each depth bin were estimated using standard techniques. In addition, normalized average $\mathrm{V} / \mathrm{H}$ ratios for the six deeper bins were calculated by dividing their average $\mathrm{V} / \mathrm{H}$ ratios by the average $\mathrm{V} / \mathrm{H}$ ratios of the 0-7 ft bin. This information is presented in Figures 2 through 5.

As shown in Figure 2 (top), all average $\mathrm{V} / \mathrm{H}$ ratios for the various depth bins are less than 1.0, with the exception of ratios for the depth bin $>300 \mathrm{ft}$, which has a peak of approximately 1.17 at $1.2 \mathrm{~Hz}$. This peak is mainly due to data from Japan. Depths greater than $300 \mathrm{ft}$, however, are beyond the range of interest for this study.

Figure 2 (bottom) shows the normalized average $\mathrm{V} / \mathrm{H}$ ratios corresponding to the six deeper bins. This plot is used to illustrate how the frequency-dependent variation of the average $\mathrm{V} / \mathrm{H}$ ratios at depth differs from that at the surface. The plot shows that, for most frequencies below approximately $10 \mathrm{~Hz}$, the average $\mathrm{V} / \mathrm{H}$ ratios at depth are greater than the average $\mathrm{V} / \mathrm{H}$ ratios at the surface. In the frequency range of 1 to $6 \mathrm{~Hz}$, the average $\mathrm{V} / \mathrm{H}$ ratios at depth may be up to two times the average $\mathrm{V} / \mathrm{H}$ ratios at the surface. With the increase of depth, the peak of the 
normalized average $\mathrm{V} / \mathrm{H}$ ratios increase in magnitude and shift to the lower frequencies. For the depth bin 150-200 ft, which is of most interest for the seismic design of deeply embedded SMR structures, the average $\mathrm{V} / \mathrm{H}$ ratios are between 1.2 and 1.9 times the average $\mathrm{V} / \mathrm{H}$ ratios at the surface in the frequency range of 1 to $6 \mathrm{~Hz}$, and about the same at frequencies above $10 \mathrm{~Hz}$.

The depth effect illustrated in Figure 2 is generally consistent with previous findings by Darragh et al. [1], which were based on only 59 sets of records from 10 vertical arrays. The present findings also provide further validation to the explanation by Beresnev et al. [2], who indicate that the vertical component of ground motion increases with depth at low frequencies (below about $10 \mathrm{~Hz}$ ) where SV waves dominate, but not at high frequencies (above about $10 \mathrm{~Hz}$ ) where $P$ waves dominate.

\subsubsection{Site Condition Effect}

To study the effect of site conditions on the average $\mathrm{V} / \mathrm{H}$ ratios at depth, the analysis discussed in the preceding Section 3.2.1 was repeated, independently, for the $\mathrm{V} / \mathrm{H}$ ratios obtained from arrays in class B and C (combined), D1, D2, D3, D (D1, D2, and D3 combined), and E sites. The total number of ratios obtained from arrays in class B and C, D1, D2, D3, D, and E sites is $224,297,110,269,676$, and 65 , respectively. Table 4 provides more detailed information on how the data is distributed in terms of depth bins and site classes.

Figures 6 through 17 show average $\mathrm{V} / \mathrm{H}$ ratios and normalized average $\mathrm{V} / \mathrm{H}$ ratios computed for the various site conditions indicated above. Coefficients of variation and percentiles are not provided because, in several instances, the number of data in the depth bins is insufficient to yield meaningful statistics. In this regard, we note the following: in Figures 10 and 11 (class D2 sites), depth bin 7-50 ft has only 3 ratios and depth bin 150-200 ft has only 6 ratios; in Figures 12 and 13 (class D3 sites), depth bin 100-150 ft has only 6 ratios; and in Figures 16 and 17 (class $\mathrm{E}$ sites), depth bin 7-50 ft has only 5 ratios, depth bin 100-150 ft has only 6 ratios, depth bin 150-200 ft has only 2 ratios, and depth bin $>300 \mathrm{ft}$ has only 6 ratios. The reader is cautioned that the average $\mathrm{V} / \mathrm{H}$ ratios computed for such small sample sizes are probably lacking in statistical power; nevertheless, they are shown in the figures to illustrate trends and for completeness.

Comparisons of the normalized average $\mathrm{V} / \mathrm{H}$ ratios for the different site classes indicate that, with the decrease in site stiffness, from rock to soft soil, the ratio of the average $\mathrm{V} / \mathrm{H}$ ratios at depth relative to the ratios at the surface tends to increase, for most frequencies below approximately $10 \mathrm{~Hz}$. In the frequency range of 1 to $6 \mathrm{~Hz}$, the average $\mathrm{V} / \mathrm{H}$ ratios at depth may be up to 2.0, 2.5, and 3.9 times the average $\mathrm{V} / \mathrm{H}$ ratios at the surface for site classes $\mathrm{B}$ and $\mathrm{C}, \mathrm{D}$, and $\mathrm{E}$, respectively.

\subsubsection{Ground Motion Intensity Effect}

To study the effect of ground motion intensity on the average $\mathrm{V} / \mathrm{H}$ ratios at depth, the analysis discussed in the preceding sections was repeated, independently, for the $\mathrm{V} / \mathrm{H}$ ratios obtained from events with PGAs in the ranges $0.01-0.10 \mathrm{~g}, 0.10-0.20 \mathrm{~g}, 0.20-0.50 \mathrm{~g}$, and $0.10-0.50 \mathrm{~g}$ (0.10-0.20g and 0.20-0.50 g combined), from arrays in class B, C, and D1 sites only. The total 
number of ratios obtained from events with PGA ranges $0.01-0.10 \mathrm{~g}, 0.10-0.20 \mathrm{~g}, 0.20-0.50 \mathrm{~g}$, and $0.10-0.50 \mathrm{~g}$ is $466,30,25$, and 55 , respectively. Table 5 provides more detailed information on how the data is distributed in terms of depth bins and PGA ranges.

Figures 18 through 25 show average $\mathrm{V} / \mathrm{H}$ ratios and normalized average $\mathrm{V} / \mathrm{H}$ ratios computed for the various PGA ranges indicated above. Coefficients of variation and percentiles are not provided because, for PGAs above $0.10 \mathrm{~g}$, the number of data in the depth bins is insufficient to yield meaningful statistics. In this regard, we note the following: in Figures 20 and 21 (PGA range $0.10-0.20 \mathrm{~g}$ ), 6 out of 7 depth bins have 6 or fewer ratios, and 2 bins have only 2 ratios; in Figures 22 and 23 (PGA range $0.20-0.50 \mathrm{~g}$ ), 6 out of 7 depth bins have 6 or fewer ratios, and 2 bins have only 1 ratio; and in Figures 24 and 25 (PGA range 0.10-0.50 g), 4 out of 7 depth bins have 7 or fewer ratios. As indicated for previous cases, the reader is cautioned that the average $\mathrm{V} / \mathrm{H}$ ratios computed for such small sample sizes are probably lacking in statistical power; they are shown in the figures to illustrate trends and for completeness.

Direct comparisons of average $\mathrm{V} / \mathrm{H}$ ratios and normalized average $\mathrm{V} / \mathrm{H}$ ratios, for PGAs below $0.10 \mathrm{~g}$ (Figure 18) and above $0.10 \mathrm{~g}$ (Figure 24), are difficult because of the small sample sizes used to compute the latter. Comparisons between the data for depth bins 0-7 ft, 7-50 ft, 50-100 $\mathrm{ft}$, and 200-300 ft, all of which have at least 7 ratios, indicate a moderate increase of between $10 \%$ and $20 \%$ in the normalized average $\mathrm{V} / \mathrm{H}$ ratios for PGAs above $0.10 \mathrm{~g}$ relative to those below $0.10 \mathrm{~g}$, in the frequency range of 1 to $6 \mathrm{~Hz}$.

The differences identified above may suggest a possible trend but are not conclusive. To obtain more definitive results, it is necessary to obtain a substantial amount of additional records from events with PGAs greater than $0.10 \mathrm{~g}$ from arrays in class $\mathrm{B}, \mathrm{C}$, and D1 sites. It is noted again that $87 \%$ of the 267 sets of records compiled for this study have PGAs less than $0.10 \mathrm{~g}$.

\subsubsection{Array Location Effect}

To study the effect of array location on the average $\mathrm{V} / \mathrm{H}$ ratios at depth, the data from arrays in class B, C, and D sites was separated into five array location groups: CGS-CESMD and USGSNSMP sites in California; NEES at UCSB sites in California; NEES at UCSB site in Anchorage, Alaska; sites in the Sendai District, Japan; and sites in the Taipei Basin, Taiwan. Table 6 provides detailed information on how the data is distributed in terms of depth bins and array locations.

Figures 26 through 35 show average $\mathrm{V} / \mathrm{H}$ ratios and normalized average $\mathrm{V} / \mathrm{H}$ ratios computed for the various array locations indicated above. A review of these figures indicates that the normalized average $\mathrm{V} / \mathrm{H}$ ratios generally follow the same depth-dependent trends identified in Section 3.2.1 for the overall results (illustrated in Figure 2, bottom). In other words, there does not appear to be any location-specific characteristic that leads to significant deviations from the overall results for normalized average $\mathrm{V} / \mathrm{H}$ ratios, as discussed in Section 3.2.1.

However, Figures 28 and 29 (NEES at UCSB sites in California) show average V/H ratios significantly greater than 1.0 for the depth bin $0-7 \mathrm{ft}$, in frequency range of 20 to $30 \mathrm{~Hz}$. This does deviate from the overall results shown in Figure 2 (top), where average V/H ratios are less 
than 1.0 for all depth bins except for a small peak of 1.17 at a frequency of approximately $1.2 \mathrm{~Hz}$, for the depth bin $>300 \mathrm{ft}$. Similarly, Figures 30 and 31 (NEES at UCSB site in Anchorage, Alaska) show average $\mathrm{V} / \mathrm{H}$ ratios significantly greater than 1.0 for depth bins $0-7 \mathrm{ft}, 7-50 \mathrm{ft}$, and 200-300 ft, in the frequency range of 8 to $30 \mathrm{~Hz}$. It should be noted that these large averages appear to be caused by a relatively small number of $\mathrm{V} / \mathrm{H}$ ratios and do not have an impact on normalized average $\mathrm{V} / \mathrm{H}$ ratios.

The deviations described above may be due to events with relatively small epicentral distances. As indicated in NUREG 6728 [11], ground motions from events with near-source distances (less than $15 \mathrm{~km}$ ) tend to have vertical components that exceed the horizontal components at high frequencies. The average epicentral distance of events used in the study is: $60 \mathrm{~km}$ for CGSCESMD and USGS-NSMP sites in California; $26 \mathrm{~km}$ for NEES at UCSB sites in California; 34 $\mathrm{km}$ for NEES at UCSB site in Anchorage, Alaska; $163 \mathrm{~km}$ for sites in the Sendai District, Japan; and $77 \mathrm{~km}$ for sites in the Taipei Basin, Taiwan. This suggests that the impact of small epicentral distances is probably significant only for the average results from NEES at UCSB sites in California (average epicentral distance $26 \mathrm{~km}$ ) and Anchorage, Alaska (average epicentral distance $34 \mathrm{~km}$ ), which is in agreement with the data shown in Figures 26 through 35.

Additional research is necessary to investigate the relative impact of small epicentral distances on the overall trends discussed in Section 3.2.1. The epicentral distances of all events used in the study are listed in Table 2. Approximately $27 \%$ of all events correspond to epicentral distances of $15 \mathrm{~km}$ or less.

\subsubsection{Source Depth Effect}

To study the effect of earthquake source depth on the $\mathrm{V} / \mathrm{H}$ ratios, the data from the NEES at UCSB site in Anchorage, Alaska, was separated into two source depth ranges: 0-40 km and 40$70 \mathrm{~km}$. Figures 36 and 37 show average $\mathrm{V} / \mathrm{H}$ ratios and normalized average $\mathrm{V} / \mathrm{H}$ ratios computed for the two depth ranges. A comparison of the two figures indicates that source depth has a moderate effect on average $\mathrm{V} / \mathrm{H}$ ratios and a relatively minor effect on normalized average $\mathrm{V} / \mathrm{H}$ ratios, for all depth bins considered.

The comparison also indicates that the large average $\mathrm{V} / \mathrm{H}$ ratios at high frequencies noted in Section 3.2.4 tend to be more pronounced for the $0-40 \mathrm{~km}$ depth range. The reason for this trend may really be due to the effect of small epicentral distances since, for this particular array, events with source depths in the 0-40 km range also have an average epicentral distance of 18 $\mathrm{km}$, which is close to the near-source distance of $15 \mathrm{~km}$. In contrast, events with source depths in the $40-70 \mathrm{~km}$ range have an average epicentral distance of $44 \mathrm{~km}$.

The source depths of all events used in the study are listed in Table 2. As discussed in previous sections, the source depths of all events used in the study range between $1.2 \mathrm{~km}$ and $112 \mathrm{~km}$. About $50 \%$ of events correspond to source depths of $14 \mathrm{~km}$ or less, and about $80 \%$ of events correspond to source depths of $70 \mathrm{~km}$ or less, which means that the majority of the events correspond to "shallow-focus" earthquakes. 


\subsubsection{Comparison to V/H ratios defined in NUREG 6728 and RG 1.60}

The $16^{\text {th }}, 50^{\text {th }}$, and $84^{\text {th }}$ percentiles of the $\mathrm{V} / \mathrm{H}$ ratios obtained from all arrays in class $\mathrm{B}, \mathrm{C}$, and D1 sites, as discussed in Section 3.2.1, were compared to V/H ratios recommended by (a) NUREG 6728 for Western US soft rock (WUS-R) sites and PGAs less than $0.20 \mathrm{~g}$; (b) NUREG 6728 for Central and Eastern US rock (CEUS-R) sites and PGAs less than $0.20 \mathrm{~g}$; and (c) RG 1.60 [12]. These comparisons are illustrated in Figures 38 and 39 for each of the seven depth bins considered in the study. Recommendations for PGAs less than $0.20 \mathrm{~g}$ were used in light of the fact that $87 \%$ of the 267 sets of records compiled for this study have PGAs less than $0.10 \mathrm{~g}$.

For the depth bin 0-7ft (i.e., at or close to the surface), it is observed that the frequencydependent $\mathrm{V} / \mathrm{H}$ ratios recommended by NUREG 6728 for WUS-R sites follow the shape of the $50^{\text {th }}$ percentile curve reasonably closely, but are somewhat larger, for most frequencies between 0.5 and $50 \mathrm{~Hz}$. The V/H ratios recommended by NUREG 6728 for CEUS-R sites and by RG 1.60 are substantially different, in terms of the shape of the curve, from the $50^{\text {th }}$ percentile curve. This is to be expected since the data used to generate the $50^{\text {th }}$ percentile curve corresponds to the same depth and similar site conditions, PGA, and tectonic settings as the data used as basis for the NUREG 6728 recommendations for WUS-R sites.

In contrast, for all of the depth bins below the surface, it is observed that the frequencydependent $\mathrm{V} / \mathrm{H}$ ratios recommended by NUREG 6728 or RG 1.60 do not resemble the shape of the $50^{\text {th }}$ percentile curve. The discrepancies become more pronounced with increasing depth. For the depth bin 150-200 ft, which is of most interest for the seismic design of deeply embedded SMR structures, the $50^{\text {th }}$ percentile curve exceeds the $\mathrm{V} / \mathrm{H}$ ratios recommended by NUREG 6728 for WUS-R sites by a significant margin for frequencies below $7 \mathrm{~Hz}$ (by a factor of more than 2.0 at about $3 \mathrm{~Hz}$ ). On the other hand, the $\mathrm{V} / \mathrm{H}$ ratios recommended from $\mathrm{RG} 1.60$ envelope the $50^{\text {th }}$ percentile curve for all frequencies between 0.5 and $50 \mathrm{~Hz}$; however, even this conservative recommendation is exceeded by the $84^{\text {th }}$ percentile curve for frequencies below $6 \mathrm{~Hz}$.

\section{Conclusions}

This study focused on the development of depth-dependent $\mathrm{V} / \mathrm{H}$ ratios of ground motion response spectra in the free field. The $\mathrm{V} / \mathrm{H}$ ratios reported herein were developed from a worldwide database of surface and downhole acceleration recordings obtained from 45 vertical array stations. This database was specifically compiled for this project, and includes information from a diversity of active tectonic regions (California, Alaska, Taiwan, Japan), site conditions (rock to soft soil), ground motion intensity levels (PGAs between $0.01 \mathrm{~g}$ and $0.50 \mathrm{~g}$ ), magnitudes (between ML 2.78 and JMA 8.1), epicentral distances (between $3.2 \mathrm{~km}$ and $812 \mathrm{~km}$ ), and source depths (between $1.2 \mathrm{~km}$ and $112 \mathrm{~km}$ ), as well as sensors at surface and at a wide range of depths relevant to the project.

A total of 267 sets of downhole records were utilized in the final calculations. Since each set has records at two or more depths, the 267 sets result in 965 individual records at surface or at depth. 
To study the significance of the depth effect, $\mathrm{V} / \mathrm{H}$ ratios from all the records were sorted into seven depth bins relevant to the project, and statistics (average, standard deviation, coefficient of variation, 16th, 50th, and 84th percentiles) of the $\mathrm{V} / \mathrm{H}$ ratios within each bin were computed. Similar analyses were repeated, controlling for different site conditions, ground motion intensity levels, array locations, and source depths, to study their relative effect on the V/H ratios. Only $\mathrm{V} / \mathrm{H}$ ratios obtained from arrays in NEHRP class $\mathrm{B}, \mathrm{C}$, and a subset of D (designated as D1) sites were considered in the study of the depth effect and the ground motion intensity effect.

Our findings confirm the importance of the depth effect on the average $\mathrm{V} / \mathrm{H}$ ratios. For most frequencies below approximately $10 \mathrm{~Hz}$, the average $\mathrm{V} / \mathrm{H}$ ratios at depth are significantly greater than the average $\mathrm{V} / \mathrm{H}$ ratios at the surface. In the frequency range of 1 to $6 \mathrm{~Hz}$, the average $\mathrm{V} / \mathrm{H}$ ratios at depth may be up to two times the average $\mathrm{V} / \mathrm{H}$ ratios at the surface. With the increase of depth, the peak of the normalized average $\mathrm{V} / \mathrm{H}$ ratios seems to increase in magnitude and shift to the lower frequencies. For the depth bin 150-200 ft, which is of most interest for the seismic design of deeply embedded SMR structures, the average V/H ratios are between 1.2 and 1.9 times the average $\mathrm{V} / \mathrm{H}$ ratios at the surface in the frequency range of 1 to $6 \mathrm{~Hz}$, and about the same at frequencies above $10 \mathrm{~Hz}$.

Comparisons of average $\mathrm{V} / \mathrm{H}$ ratios for different site conditions indicate that, with the decrease in site stiffness from rock to soft soil, the normalized average $\mathrm{V} / \mathrm{H}$ ratios tends to increase for most frequencies below approximately $10 \mathrm{~Hz}$. In the frequency range of 1 to $6 \mathrm{~Hz}$, the average $\mathrm{V} / \mathrm{H}$ ratios at depth may be up to 2.0, 2.5, and 3.9 times the average $\mathrm{V} / \mathrm{H}$ ratios at the surface for NEHRP class B and C, D, and E sites, respectively.

Direct comparisons of average $\mathrm{V} / \mathrm{H}$ ratios for PGAs below $0.10 \mathrm{~g}$ and above $0.10 \mathrm{~g}$ are difficult because of the relative scarcity of records for the latter case. Limited comparisons indicate a moderate increase of between $10 \%$ and $20 \%$ in the normalized average $\mathrm{V} / \mathrm{H}$ ratios in the frequency range of 1 to $6 \mathrm{~Hz}$, for PGAs above $0.10 \mathrm{~g}$ relative to those below $0.10 \mathrm{~g}$. These differences suggest a possible trend but are not conclusive. To obtain more definitive results, it is necessary to obtain a substantial amount of additional records from events with PGA greater than $0.10 \mathrm{~g}$. It is noted that $87 \%$ of the records compiled for this study have PGA less than $0.10 \mathrm{~g}$.

Comparisons of average $\mathrm{V} / \mathrm{H}$ ratios for different array locations and source depths reveal a small to moderate effect on the average $\mathrm{V} / \mathrm{H}$ ratios in the frequency range of 8 to $30 \mathrm{~Hz}$, which appears to be linked to a number of events with small epicentral distances recorded at NEES at UCSB sites in California and Alaska. It has been previously observed (see, e.g., NUREG 6728) that ground motions from events with near-source distances (less than $15 \mathrm{~km}$ ) tend to have vertical components that exceed the horizontal components at high frequencies. Additional research is needed to investigate the relative impact of small epicentral distances on the overall trends identified in this study. It is noted that $27 \%$ of the records compiled for this study correspond to epicentral distances of $15 \mathrm{~km}$ or less.

The 16th, 50th, and 84th percentiles of the $\mathrm{V} / \mathrm{H}$ ratios used to study the depth effect were compared to V/H ratios recommended by (a) NUREG 6728 for WUS-R sites (PGA less than $0.20 \mathrm{~g}$ ); (b) NUREG 6728 for CEUS-R sites (PGA less than $0.20 \mathrm{~g}$ ); and (c) RG 1.60. 
For the depth bin closest to the surface, the $\mathrm{V} / \mathrm{H}$ ratios recommended by NUREG 6728 for WUS-R sites were found to be somewhat larger but generally following the shape of the 50th percentile curve, for most frequencies between 0.5 and $50 \mathrm{~Hz}$. In contrast, the V/H ratios recommended by NUREG 6728 for CEUS-R sites and by RG 1.60, in terms of the shape of the curves, were found to differ significantly from the 50th percentile curve. This is to be expected since the data used to generate the 50th percentile curve is similar to the data used as basis for the NUREG 6728 recommendations for WUS-R sites.

For the depth bins below the surface, the $\mathrm{V} / \mathrm{H}$ ratios recommended by NUREG 6728 and RG 1.60 were all found to differ significantly from the shape of the 50th percentile curve. This difference becomes more pronounced with increasing depth. For the depth bin 150-200 ft, which is of most interest for the seismic design of deeply embedded SMR structures, the 50th percentile curve exceeds the $\mathrm{V} / \mathrm{H}$ ratios recommended by NUREG 6728 for WUS-R sites by a large margin for frequencies below $7 \mathrm{~Hz}$ (by a factor of more than 2.0 at about $3 \mathrm{~Hz}$ ).

It is important to mention that the $\mathrm{V} / \mathrm{H}$ ratios recommended from $\mathrm{RG} 1.60$ do provide a conservative envelope of the 50th percentile curve for all depth bins from the surface down to the 150 - $200 \mathrm{ft}$ bin, which is the region of interest for the deeply embedded SMR structures. However, the $\mathrm{V} / \mathrm{H}$ ratios recommended from RG 1.60 are exceeded by the 84th percentile curve at some frequency range for all depth bins.

The research findings summarized above can be used to provide guidance on the significance of the depth effect, and the extent to which this effect should be considered in the seismic design of deeply embedded SMR structures and NPP structures in general.

Finally, the authors emphasize that all downhole acceleration records used in this study correspond to in-column motions in the free field. It follows that any depth-dependent V/H ratios derived from such records must also correspond to in-column motions, as opposed to outcrop motions. This important distinction should be taken into consideration in any application of empirically-based, depth-dependent $\mathrm{V} / \mathrm{H}$ ratios used for seismic design purposes.

\section{Acknowledgement}

This study was supported by the U.S. Nuclear Regulatory Commission, Office of New Reactors.

We gratefully acknowledge the following researchers for their generous support with the data collection: Dr. J. H. Steidl of the University of California, Santa Barbara; Prof. K-L. Wen and Mr. $\mathrm{J}-\mathrm{Y}$. Huang of the National Central University of Taiwan; and Mr. Toshihide Kashima of the International Institute of Seismology and Earthquake Engineering, Japan. 


\section{References}

[1] Darragh, R., W. Silva, and N. Gregor, "Bay Bridge Downhole Array Analyses." Final Report submitted to Earth Mechanics, Inc., Pacific Engineering and Analysis, 1999.

[2] Beresnev, I.A., A. M. Nightengale, and W. J. Silva, "Properties of Vertical Ground Motions." Bulletin of the Seismological Society of America, Vol. 92, No.8, pp. 3152-3164, 2002.

[3] California Strong Motion Instrumentation Program, California Geological Survey. Data repository available online at http://www.strongmotioncenter.org/

[4] National Strong Motion Project, U.S. Geological Survey. Data repository available online at http://nsmp.wr.usgs.gov/

[5] Network for Earthquake Engineering Simulation at the University of California, Santa Barbara. Data repository available online at http://www.nees.ucsb.edu/

[6] Sendai Dense Array Earthquake Observation, General Report, Building Research Institute and Japan Association for Building Research Promotion, December, 1999. Partial data repository (digital data for surface accelerations only) available online at http://smo.kenken.go.jp/smdb

[7] Taipei Basin Downhole Seismic Network, Institute of Earth Sciences, Academia Sinica, Taiwan. Descriptive information (no digital data) available online at http://www.earth.sinica.edu.tw/ smdmc

[8] Wang, C-Y., Y-H. Lee, M-L. Ger, and Y-L. Chen, "Investigating Subsurface Structures and P and $\mathrm{S}$ wave Velocities in the Taipei Basin." Terrestrial, Atmospheric and Oceanic Sciences, Vol. 15, No. 4, pp. 609-627, 2004.

[9] Huang, W-G., B-S. Huang, J-H. Wang, K-C. Chen, K-L. Wen, S-J. Tsao, Y-C. Hsieh, and C$\mathrm{H}$. Chen, "Seismic observations in the Taipei metropolitan area using the downhole network." Terrestrial, Atmospheric and Oceanic Sciences, Vol. 21, No. 3, pp. 615-625, 2010.

[10] BSSC, "NEHRP Recommended Provisions for Seismic Regulations for New Buildings and Other Structures (FEMA 450)." Building Seismic Safety Council, National Institute of Building Sciences, 2004.

[11] McGuire, R.K., W.J. Silva, and C. J. Costantino, "NUREG/CR-6728 Technical Basis for Revision of Regulatory Guidance on Design Ground Motions: Hazard and Risk Consistent Ground Motion Spectra Guidelines." Report to the U.S. Nuclear Regulatory Commission, 2001.

[12] U.S. NRC, "Regulatory Guide 1.60: Design Response Spectra of Nuclear Power Plants." U.S. Nuclear Regulatory Commission, 1973. 
Table 1 List of Vertical Array Stations

\begin{tabular}{|c|c|c|c|c|c|c|c|}
\hline Station Code & Station & Sensor Depths & Free Field Information & Site Geology & $V_{s}$ Profile & $\begin{array}{l}V_{s 30} \\
(\mathrm{~m} / \mathrm{s}, \text { appr. })\end{array}$ & Site Class \\
\hline 1794 & EI Centro - Meloland & $0,30,100,185 \mathrm{~m}(0,99,330,640 \mathrm{ft})$ & $140 \mathrm{ft}$ from a bridge abutment, $62 \mathrm{ft}$ from a highway & Deep alluvium & Yes & 186 & $\mathrm{D}(\mathrm{D} 3)$ \\
\hline 3192 & San Diego - Coronado East & $0,13,30,91 \mathrm{~m}(0,42,97,300 \mathrm{ft})$ & close to a bridge pier and two story building & Shallow alluvium over soft rock (sandstone) & Yes & 280 & $\mathrm{D}(\mathrm{D} 1)$ \\
\hline 3193 & San Diego - Coronado West & $0,11.6,22.9,40.1,103 \mathrm{~m}(0,38,75,138,358 \mathrm{ft})$ & $100 \mathrm{ft} \mathrm{from} \mathrm{a} \mathrm{bridge} \mathrm{pier}$ & Thin fill/alluvium over soft rock (sandstone) & Yes & 210 & $\mathrm{D}(\mathrm{D} 2)$ \\
\hline 13186 & Corona - 115/Hwy 91 & $0,7.9,21.6,41.8 \mathrm{~m}(0,28,71,137 \mathrm{ft})$ & about $100 \mathrm{ft}$ from bridge piers, $20 \mathrm{ft}$ from a highway & Shallow alluvium over rock (granodiorite) & Yes & 280 & $\mathrm{D}(\mathrm{D} 1)$ \\
\hline 14783 & Los Angeles - Vincent Thomas W1 & $0,30,91 \mathrm{~m}(0,100,300 \mathrm{ft})$ & about $120 \mathrm{ft}$ from a bridge pier & Deep alluvium & Yes & 200 & $\mathrm{D}(\mathrm{D} 3)$ \\
\hline 14784 & Los Angeles - Vincent Thomas W2 & $0,15,30 \mathrm{~m}(0,50,100 \mathrm{ft})$ & about $120 \mathrm{ft}$ from a bridge pier & Deep alluvium & Yes & 179 & E \\
\hline 14786 & Los Angeles - Vincent Thomas West & $0,30,91 \mathrm{~m}(0,100,300 \mathrm{ft})$ & about $120 \mathrm{ft}$ from a bridge pier & Deep alluvium & Yes & 200 & $\mathrm{D}(\mathrm{D} 3)$ \\
\hline 23792 & San Bernardino - I10/215 W & $0,10.7,35,92.1 \mathrm{~m}(0,35,115,302 \mathrm{ft})$ & $100 \mathrm{ft} \mathrm{from} \mathrm{a} \mathrm{bridge} \mathrm{pier}$ & Deep alluvium & Yes & 271 & $\mathrm{D}(\mathrm{D} 1)$ \\
\hline 24400 & Los Angeles - Obregon Park & $0,69.5 \mathrm{~m}(0,228 \mathrm{ft})$ & close to one story building & Deep alluvium over rock (sandstone) & Yes & 349 & $\mathrm{D}(\mathrm{D} 1)$ \\
\hline 24703 & Los Angeles - La Cienega & $0,18,100,252 \mathrm{~m}(0,60,330,827 \mathrm{ft})$ & next to highways & Deep alluvium & Yes & 260 & $\mathrm{D}(\mathrm{D} 2)$ \\
\hline 24764 & Tarzana-Cedar Hill B & $0,60 \mathrm{~m},(0,197 \mathrm{ft})$ & close to single family houses & Thin alluvium over shale & Yes & 411 & c \\
\hline 36520 & Parkfield - Turkey Flat \#2 & $0,11,23 \mathrm{~m}(0,35,77 \mathrm{ft})$ & free field & Shallow alluvium over rock (sandstone) & Yes & 492 & c \\
\hline 36529 & Parkfield - Turkey Flat \#1 & $0,24 \mathrm{~m}(0,79 \mathrm{ft})$ & free field & Rock (sandstone) & Yes & 907 & B \\
\hline 58137 & Alameda - Posey \& Webster & $0,5.2,12.2,36.6 \mathrm{~m}(0,17,40,120 \mathrm{ft})$ & free field & Deep alluvium & No & 208 & $\mathrm{D}(\mathrm{D} 3)$ \\
\hline 58204 & Oakland - Bay Bridge & $0,17,46,91,162 \mathrm{~m}(0,56,150,299,530 \mathrm{ft})$ & $50 \mathrm{ft}$ from a bridge pier & Alluvium (fill) & Yes & 150 & E \\
\hline 58642 & Treasure Island & $\begin{array}{l}0,7,16,31,44,104,122 \mathrm{~m} \\
(0,24,51,102,145,340,400 \mathrm{ft})\end{array}$ & close to a two story building & Shallow fill over deep alluvium (Bay mud) & Yes & 150 & E \\
\hline 58961 & San Francisco - Bay Bridge & $0,14,40 \mathrm{~m}(0,46,131 \mathrm{ft})$ & about $100 \mathrm{ft}$ from bridge a bridge pier & Fill over shallow alluvium over soft rock & Yes & 400 & c \\
\hline 58964 & Half Moon Bay - Tunitas & $0,5,12,45 \mathrm{~m}(0,17,39,147 \mathrm{ft})$ & next to a highway & Alluvium over soft rock (siltstone) & Yes & 353 & D (D1) \\
\hline 58968 & Foster City - San Mateo Bridge & $0,17.7,24,38.3 \mathrm{~m}(0,53,72,115 \mathrm{ft})$ & $90 \mathrm{ft}$ trom a highway, $10 \mathrm{ft}$ trom a local road & Shallow alluvium over rock (chert/greenstone) & Yes & 215 & D (D1) \\
\hline 68206 & Crockett- Carquinez Bridge \#1 & $0,45.7 \mathrm{~m},(0,150 \mathrm{ft})$ & about $50 \mathrm{ft}$ from a bridge pier, $20 \mathrm{ft}$ from a two story house & Shallow clay over rock (sed.) & Yes & 340 & $\mathrm{D}(\mathrm{D} 1)$ \\
\hline 68259 & Crockett - Carquinez Bridge \#2 & $0,61,125 \mathrm{~m}(0,201,410 \mathrm{ft})$ & $20 \mathrm{ft} \mathrm{from} \mathrm{a} \mathrm{bridge} \mathrm{pier}$ & Shallow clay over soft rock & No & 340 & $\mathrm{D}(\mathrm{D} 1)$ \\
\hline 68310 & Vallejo - Hwy 37/Napa River East & $0,17.9,44.5 \mathrm{~m}(0,59,146 \mathrm{ft})$ & $50 \mathrm{ft}$ from a bridge abutment & Bay mud & No & 552 & c \\
\hline 68323 & Benicia-Martinez Bridge South & $0,11,35 \mathrm{~m}(0,36,114 \mathrm{ft})$ & $50 \mathrm{ft}$ from a bridge pier & Thin alluvium over soft rock & Yes & 500 & c \\
\hline 89734 & Eureka & $0,19,33,56,136 \mathrm{~m}(0,62,109,185,446 \mathrm{ft})$ & $10 \mathrm{ft}$ from a highway & Deep alluvium & Yes & 220 & $\mathrm{D}(\mathrm{D} 2)$ \\
\hline \multicolumn{8}{|c|}{ USGS-NSMP (National Strong-Motion Project) } \\
\hline Station Code & Station & Sensor Depths & Free Field Information & Site Geology & $V_{s}$ Profile & $\begin{array}{c}V_{s 30} \\
(\mathrm{~m} / \mathrm{s}, \text { appr. })\end{array}$ & Site Class \\
\hline 5300 & $\begin{array}{l}\text { Seven Oaks Dam Downstream Array, } \\
\text { Redlands, CA }\end{array}$ & $0,16.2 \mathrm{~m}(0,53 \mathrm{ft})$ & about $1500 \mathrm{ft}$ from Seven Oaks Dam & Rock & No & 685 & c \\
\hline 286 & Superstition Mtn. Pk., Imperial Valley, CA & $0,35.7 \mathrm{~m}(0,117 \mathrm{ft})$ & free field & & No & 362 & Ic \\
\hline \multicolumn{8}{|l|}{ NEES at UCSB } \\
\hline Station Code & Station & Sensor Depths & Free Field Information & Site Geology & $V_{s}$ Profile & $\begin{array}{c}\mathrm{V}_{\mathrm{s} 30} \\
(\mathrm{~m} / \mathrm{s}, \text { appr.) }\end{array}$ & Site Class \\
\hline GVDA & Garner Valley Downhole Array, CA & $0,6,15,22,50,150,501 \mathrm{~m}(0,20,49,72,164,492,1644 \mathrm{ft})$ & $200 \mathrm{ftt}$ trom highway and one story building & Alluvium (0-18 to $25 \mathrm{~m}$ ) over rock (granite) & Yes & 260 & $\mathrm{D}(\mathrm{D} 1)$ \\
\hline HEO & Hollister Earthquake Observatory, CA & $0,53 \mathrm{~m}(0,174 \mathrm{ft})$ & free field at remote rock site (not the main site) & Rock (granite) & Yes & 600 & c \\
\hline WLA & Wildlife Liquefaction Array, CA & $0,2.5,5.5,7.7,30,100 \mathrm{~m}(0,8,18,25,98,328 \mathrm{ft})$ & free field & Silty clay $(0-3 \mathrm{~m})$, silty sand $(3-7 \mathrm{~m})$, clay $(7-12 \mathrm{~m})$ & Yes & 200 & $\mathrm{D}(\mathrm{D} 3)$ \\
\hline 8040 & $\begin{array}{l}\begin{array}{l}\text { Delaney Park Downhole Array, Anchorage, } \\
\text { AK }\end{array} \\
\end{array}$ & $\begin{array}{l}0,4.6,10.7,18.3,30.5,45.4,61 \mathrm{~m} \\
(0,15,35,60,100,150,200 \mathrm{ft})\end{array}$ & $200 \mathrm{ft}$ from two story building, $600 \mathrm{ft}$ from high rise building & \begin{tabular}{|l} 
Soft clay (outwash [0-40 ff], transition [40-60 ft], \\
bootlegger cove formation [60-160 ft]) over till
\end{tabular} & Yes & 300 & $\mathrm{D}(\mathrm{D} 1)$ \\
\hline \multicolumn{8}{|c|}{ Taipei Basin Downhole Seismic Network, Institute of Earth Sciences, Academia Sinica, Taiwan (data from Prof. Wen Kuo-Liang) } \\
\hline Station Code & Station & Sensor Depths & Free Field Information & Site Geology & Vs Profile & 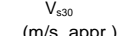 & Site Class \\
\hline BS & Water Conservancy Bureau, Panchiao & $0,25,59 \mathrm{~m}$ & & Deep alluvium & No & $\frac{1 \mathrm{mls}}{200}$ & $\mathrm{D}(\mathrm{D} 3)$ \\
\hline SS & Songshan Tobacco Plant & $0,30,49 \mathrm{~m}$ & away from large buildings & Deep alluvium, tertiary rock at $150 \mathrm{~m}$ depth & Yes & 200 & $\mathrm{D}(\mathrm{D} 3)$ \\
\hline TF & Vocational Advisory Committee for & $0,60 \mathrm{~m}$ & in the backyard of a two story building & Deep alluvium, tertiary rock at $300 \mathrm{~m}$ depth & Yes & 215 & $\mathrm{D}(\mathrm{D} 3)$ \\
\hline WK & $\begin{array}{l}\text { Retried Servicemen, Panchiao } \\
\text { Sewage Disposal Plant, Wuku } \\
\end{array}$ & $0,30,60 \mathrm{~m}$ & away from large buildings & Deep alluvium & Yes & 200 & $\mathrm{D}(\mathrm{D} 3)$ \\
\hline \multicolumn{8}{|c|}{ Sendai Dense Array Earthquake Observation Project, Building Research Institute, Japan (data from Mr. Toshihide Kashima) } \\
\hline Station Code & Station & Sensor Depths & Free Field Information & Site Geology & $V_{s}$ Profile & $\begin{array}{c}\mathrm{V}_{\mathrm{s} 30} \\
(\mathrm{~m} / \mathrm{s}, \text { appr. }\end{array}$ & Site Class \\
\hline MIYA & Miyagino & $1,22,54 \mathrm{~m}$ & in elementary school, away from building & Alluvium $(0-26 \mathrm{~m})$ over sedimentary rock & Yes & 443 & c \\
\hline NAGA & Nagamachi & $1,29,81 \mathrm{~m}$ & in elementary school, away from building & Alluvium $(0-57 \mathrm{~m})$ over sedimentary rock & Yes & 192 & D (D2) \\
\hline NAKA & Nakano & $1,30,61 \mathrm{~m}$ & in elementary school, away from building & Alluvium $(0-58 \mathrm{~m})$ over sedimentary rock & Yes & 183 & $\mathrm{D}(\mathrm{D} 3)$ \\
\hline OKIN & Okino & $1,17,62 \mathrm{~m}$ & in elementary school, away from building & Alluvium $(0-50 \mathrm{~m})$ over sedimentary rock & Yes & 267 & $\mathrm{D}(\mathrm{D} 1)$ \\
\hline ORID & Oridate & $1,57,76 \mathrm{~m}$ & in elementary school, away from building & Soft sedimentary rock over andesite & Yes & 460 & $\mathrm{c}$ \\
\hline SHIR & Shiromaru & $1,20,76 \mathrm{~m}$ & in elementary school, away from building & Alluvium $(0-50 \mathrm{~m})$ over sedimentary rock & Yes & 271 & $\mathrm{D}(\mathrm{D} 1)$ \\
\hline TAMA & Tamagawa & $2,11,33 \mathrm{~m}$ & in junior high school, away from building & Sedimentary rock & Yes & 739 & c \\
\hline TRGA & Tsurugaya & $2,37,62 \mathrm{~m}$ & in elementary school, away from building & Sedimentary rock & Yes & 816 & $B$ \\
\hline TRMA & Tsurumaki & $1,25,79 \mathrm{~m}$ & in elementary school, away from building & Alluvium $(0-80 \mathrm{~m})$ over sedimentary rock & Yes & 177 & E \\
\hline TSUT & Tsutsujigaoka & $1,36,59 \mathrm{~m}$ & in elementary school, a & Alluvium $(0-5 \mathrm{~m})$ over sedimentary rock & Yes & 323 & $\mathrm{D}(\mathrm{D} 1)$ \\
\hline ARAH & Arahama & $1,31,76 \mathrm{~m}$ & in elementary school, away from building & Alluvium $(0-35 \mathrm{~m})$ over sedimentary rock & Yes & 189 & D (D2) \\
\hline
\end{tabular}


Table 2 List of Acceleration Records

CGS-CSMIP (California Strong Motion Instrumentation Program)

\begin{tabular}{|c|c|c|c|c|c|c|c|c|c|c|}
\hline $\begin{array}{l}\text { Station } \\
\text { Code }\end{array}$ & Station & Earthquake & Year & Month & Day & HRMN & $\begin{array}{l}\text { Max. PGA } \\
\text { (g) }\end{array}$ & Magnitude & $\begin{array}{l}\text { Epicentral } \\
\text { Dist. }(\mathrm{km})\end{array}$ & $\begin{array}{c}\text { Source } \\
\text { Depth }(\mathrm{km})\end{array}$ \\
\hline \multirow[t]{4}{*}{1794} & El Centro - Meloland & Calexico & 2010 & Apr & 4 & & 0.230 & $\mathrm{Mw} 7.2$ & 59.1 & 32.3 \\
\hline & " & Calexico & 2010 & May & 22 & & 0.032 & Mw 4.9 & 35.1 & 5.4 \\
\hline & $"$ & Ocotillo & 2010 & Jun & 14 & & 0.033 & ML 5.7 & 45.3 & 6.9 \\
\hline & " & Borrego Springs & 2010 & Jul & 7 & & 0.011 & ML 5.4 & 120.7 & 14.0 \\
\hline 3192 & San Diego - Coronado East & San Clemente Island & 2004 & Jun & 15 & & 0.027 & ML 5.2 & 75.1 & 7.0 \\
\hline \multirow[t]{3}{*}{3193} & San Diego - Coronado West & San Clemente Island & 2004 & Jun & 15 & & 0.058 & ML 5.2 & 73 & 7.0 \\
\hline & " & San Ysidro & 2003 & Oct & 7 & & 0.016 & ML 3.6 & 15.8 & 16.4 \\
\hline & " & Chino Hills & 2008 & Jul & 29 & & 0.016 & Mw 5.4 & 151.2 & 13.6 \\
\hline \multirow[t]{2}{*}{13186} & Corona - I15/Hwy 91 & Anza & 2005 & Jun & 12 & & 0.035 & ML 5.2 & 98.8 & 13.5 \\
\hline & " & Chino Hills & 2008 & Jul & 29 & & 0.157 & Mw 5.4 & 21.6 & 13.6 \\
\hline \multirow[t]{2}{*}{14783} & Los Angeles - Vincent Thomas W1 & Inglewood & 2009 & May & 17 & & 0.051 & Mw 4.7 & 21.7 & 15 \\
\hline & " & Calexico & 2010 & Apr & 04 & & 0.014 & $\mathrm{Mw} 7.2$ & 324.5 & 32.3 \\
\hline \multirow[t]{2}{*}{14784} & Los Angeles - Vincent Thomas W2 & Inglewood & 2009 & May & 17 & & 0.060 & Mw 4.7 & 21.6 & 15 \\
\hline & " & Calexico & 2010 & Apr & 4 & & 0.017 & $\mathrm{Mw} 7.2$ & 324.8 & 32.3 \\
\hline 14786 & Los Angeles - Vincent Thomas West & Hector Mine & 1999 & Oct & 16 & & 0.030 & ML 7.1 & 207.9 & 6.0 \\
\hline \multirow[t]{4}{*}{23792} & San Bernardino - I10/215 W & Chino Hills & 2008 & Jul & 29 & & 0.049 & Mw 5.4 & 44.8 & 13.6 \\
\hline & " & Inglewood & 2009 & May & 17 & & 0.010 & Mw 4.7 & 97.7 & 15 \\
\hline & " & Calexico & 2010 & Apr & 4 & & 0.022 & Mw 7.2 & 274.3 & 32.3 \\
\hline & " & Beaumont & 2011 & Sep & 14 & & 0.024 & ML 4.1 & 23.9 & 16.9 \\
\hline \multirow[t]{3}{*}{24400} & Los Angeles - Obregon Park & Chino Hills & 2008 & Jul & 29 & & 0.185 & Mw 5.4 & 39.2 & 13.6 \\
\hline & " & Whittier Narrows & 2010 & Mar & 16 & & 0.113 & ML 4.4 & 10.7 & 18 \\
\hline & " & Calexico & 2010 & Apr & 4 & & 0.013 & $\mathrm{Mw} 7.2$ & 334 & 32.3 \\
\hline \multirow[t]{7}{*}{24703} & Los Angeles - La Cienega & Hector Mine & 1999 & Oct & 16 & & 0.035 & ML 7.1 & 203.9 & 6.0 \\
\hline & " & West Hollywood & 2001 & Sep & 9 & & 0.490 & ML 4.2 & 4.3 & 7.9 \\
\hline & " & Chino Hills & 2008 & Jul & 29 & & 0.030 & Mw 5.4 & 57.3 & 13.6 \\
\hline & " & Marina Del Rey & 2009 & Jan & 23 & & 0.012 & ML 3.4 & 10.3 & 7 \\
\hline & " & Inglewood & 2009 & May & 17 & & 0.111 & Mw 4.7 & 11.4 & 15 \\
\hline & " & Whittier Narrows & 2010 & Mar & 16 & & 0.016 & ML 4.4 & 28.6 & 18 \\
\hline & " & Calexico & 2010 & Apr & 4 & & 0.010 & Mw 7.2 & 349.3 & 32.3 \\
\hline 24764 & Tarzana- Cedar Hill B & West Hollywood & 2001 & Sep & 9 & & 0.028 & ML 4.2 & 17.2 & 7.9 \\
\hline 36520 & Parkfield - Turkey Flat \#2 & Parkfield & 2004 & Sep & 28 & & 0.294 & ML 6.0 & 7.7 & 7.9 \\
\hline \multirow[t]{2}{*}{36529} & Parkfield - Turkey Flat \#1 & Parkfield & 2007 & May & 22 & & 0.035 & Mw 4.0 & 5.4 & 9.2 \\
\hline & " & Parkfield & 2004 & Sep & 28 & & 0.244 & ML 6.0 & 7.1 & 7.9 \\
\hline \multirow[t]{3}{*}{58137} & Alameda - Posey \& Webster & Piedmont & 2007 & Jul & 20 & & 0.053 & $\mathrm{Mw} 4.2$ & 8.1 & 5.8 \\
\hline & " & Alamo & 2008 & Sep & 5 & & 0.018 & Mw 4.0 & 26.1 & 16.2 \\
\hline & " & Alum Rock & 2007 & Oct & 30 & & 0.011 & Mw 5.4 & 59.4 & 9.2 \\
\hline \multirow[t]{2}{*}{58204} & Oakland - Bay Bridge & Berkeley & 2011 & Oct & 20 & & 0.029 & Mw 4.0 & 8.3 & 9.8 \\
\hline & " & El Cerrito & 2012 & Mar & 5 & & 0.017 & Ml 4.0 & 12.1 & 9.2 \\
\hline \multirow[t]{3}{*}{58642} & Treasure Island & Piedmont Area & 2006 & Dec & 20 & & 0.020 & ML 3.7 & 12.7 & 9 \\
\hline & " & Alum Rock & 2007 & Oct & 30 & & 0.012 & Mw 5.4 & 68.5 & 9.2 \\
\hline & " & Gilroy & 1993 & Jan & 15 & & 0.014 & ML 5.3 & 120.3 & 5.0 \\
\hline 58961 & San Francisco - Bay Bridge & Berkeley & 2011 & Oct & 20 & & 0.023 & Mw 4.0 & 14.9 & 9.8 \\
\hline 58964 & Half Moon Bay - Tunitas & Gilroy & 2002 & May & 13 & & 0.027 & ML 4.9 & 83.1 & 7.6 \\
\hline 58968 & Foster City - San Mateo Bridge & Alum Rock & 2007 & Oct & 30 & & 0.010 & Mw 5.4 & 45.9 & 9.2 \\
\hline 68206 & Crockett - Carquinez Bridge \#1 & El Cerrito & 2012 & Mar & 5 & & 0.043 & MI 4.0 & 15.5 & 9.2 \\
\hline 68259 & Crockett - Carquinez Bridge \#2 & El Cerrito & 2012 & Mar & 5 & & 0.018 & Ml 4.0 & 15.6 & 9.2 \\
\hline \multirow[t]{3}{*}{68310} & Vallejo - Hwy 37/Napa River East & Crockett & 2012 & Feb & 15 & & 0.020 & ML 3.6 & 6.4 & 9.3 \\
\hline & " & Crockett & 2012 & Feb & 16 & & 0.020 & ML 3.5 & 6 & 8.3 \\
\hline & " & El Cerrito & 2012 & Mar & 5 & & 0.012 & Ml 4.0 & 21.5 & 9.2 \\
\hline 68323 & Benicia - Martinez Bridge South & El Cerrito & 2012 & Mar & 5 & & 0.009 & Ml 4.0 & 20.1 & 9.2 \\
\hline 89734 & Eureka & Ferndale & 2007 & Feb & 26 & & 0.010 & ML 5.4 & 62.6 & - \\
\hline & " & Ferndale & 2010 & Jan & 9 & & 0.197 & Mw 6.5 & 54 & 21.7 \\
\hline & " & Ferndale & 2010 & Feb & 4 & & 0.025 & Mw 5.9 & 77.6 & 11.2 \\
\hline & " & Eureka Offshore & 2000 & Sep & 22 & & 0.011 & ML 4.4 & 24.4 & 13.9 \\
\hline & " & Weitchpec & 2012 & Feb & 13 & & 0.038 & Mw 5.6 & 47.9 & 28.2 \\
\hline & " & Blue Lake & 2012 & Oct & 21 & & 0.017 & ML 3.5 & 22.2 & 21.7 \\
\hline
\end{tabular}

USGS-NSMP (National Strong-Motion Project)

\begin{tabular}{|c|c|c|c|c|c|c|c|c|c|c|}
\hline $\begin{array}{l}\text { Station } \\
\text { Code }\end{array}$ & Station & Earthquake & Year & Month & Day & HRMN & $\begin{array}{l}\text { Max. PGA } \\
(\mathrm{g})\end{array}$ & Magnitude & $\begin{array}{l}\text { Epicentral } \\
\text { Dist. }(\mathrm{km})\end{array}$ & $\begin{array}{c}\text { Source } \\
\text { Depth }(\mathrm{km})\end{array}$ \\
\hline \multirow[t]{10}{*}{5300} & $\begin{array}{l}\text { Seven Oaks Dam Downstream Array, } \\
\text { Redlands. CA }\end{array}$ & Big Bear City & 2000 & 12 & 2 & 0828 UTC & 0.018 & ML 4.1 & 34 & 2.7 \\
\hline & $"$ & Big Bear Lake & 2001 & 2 & 10 & 21:05 UTC & 0.06 & ML 5.1 & 24.8 & 5.9 \\
\hline & " & Big Bear City & 2003 & 2 & 22 & 12:19 UTC & 0.04 & ML 5.4 & 32 & 1.2 \\
\hline & $"$ & Big Bear City & 2004 & 11 & 13 & 17:39 UTC & 0.01 & Mw 3.9 & 35.6 & 9.6 \\
\hline & " & Anza & 2005 & 6 & 12 & 15:41 UTC & 0.02 & Mw 5.2 & 80.2 & 14.1 \\
\hline & " & Yucaipa & 2005 & 6 & 16 & 20:53 UTC & 0.295 & Mw 4.9 & 10 & 11.8 \\
\hline & " & Big Bear City & 2005 & 12 & 3 & 07:49 UTC & 0.014 & Mw 3.9 & 34.4 & 5.1 \\
\hline & " & Big Bear Lake & 2007 & 12 & 19 & 12:14 UTC & 0.04 & Ml 4.0 & 12 & 10.2 \\
\hline & $"$ & Yucaipa & 2008 & 10 & 2 & 09:41 UTC & 0.10 & Mw 3.8 & 12.4 & 12.5 \\
\hline & " & San Bernardino & 2009 & 1 & 9 & 03:49 UTC & 0.07 & Mw 4.5 & 19 & 14.1 \\
\hline 286 & Superstition Mtn. Pk., Imperial Valley, CA & Obsidian Butte & 2005 & 9 & 2 & 01:27 UTC & 0.02 & Mw 5.1 & 28.7 & 9.7 \\
\hline
\end{tabular}


Table 2 List of Acceleration Records (continued)

NEES at UCSB

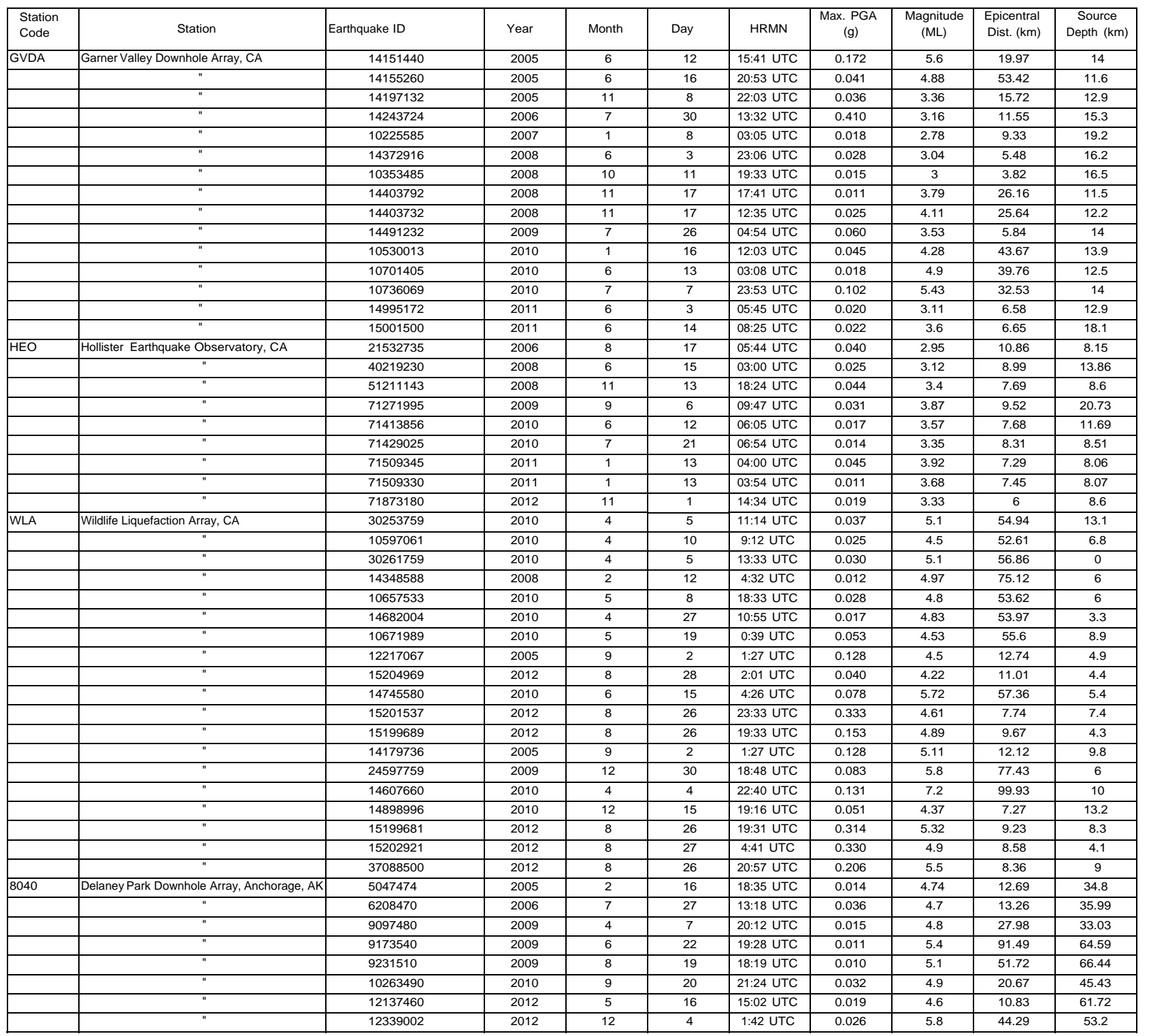

Taipei Basin Downhole Seismic Network, Institute of Earth Sciences, Academia Sinica, Taiwan (data from Prof. Wen Kuo-Liang)

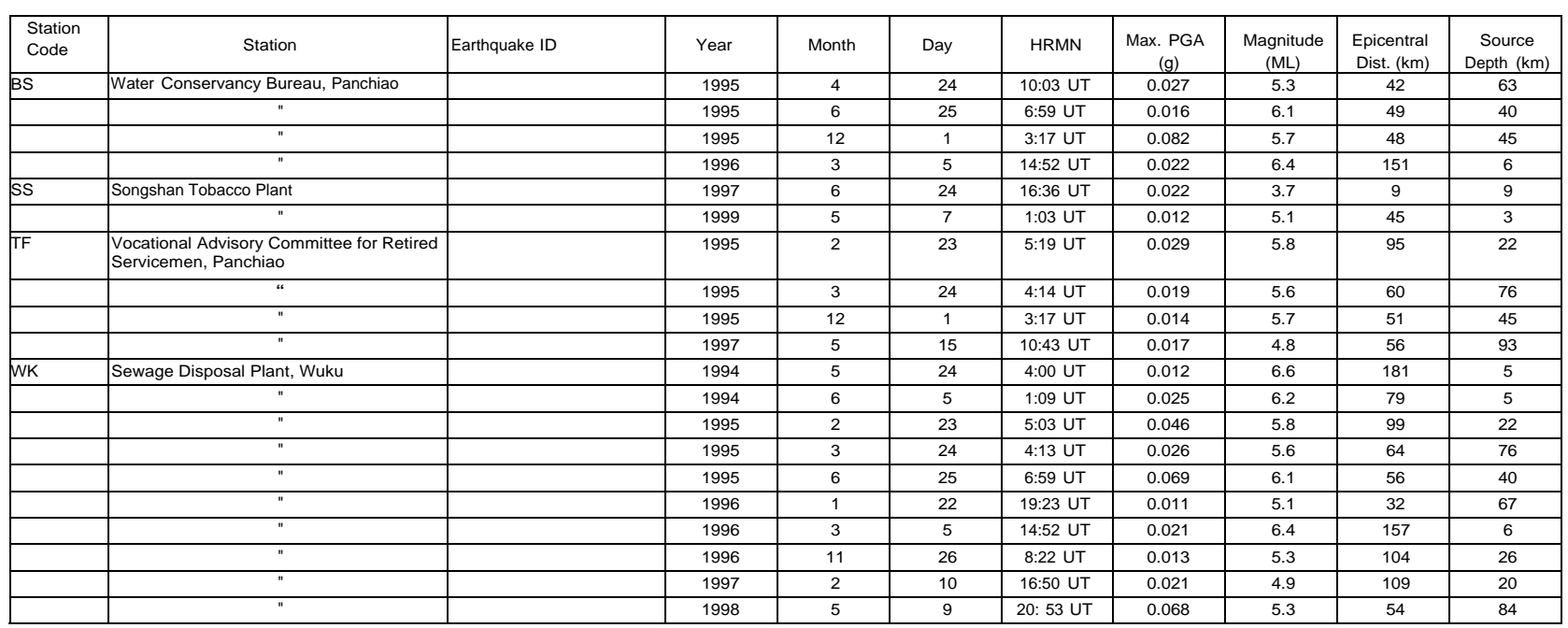


Table 2 List of Acceleration Records (continued)

Sendai Dense Array Earthquake Observation Project, Building Research Institute, Japan (data from Mr. Toshihide Kashima)

\begin{tabular}{|c|c|c|c|c|c|c|c|c|c|c|}
\hline $\begin{array}{l}\text { Station } \\
\text { code }\end{array}$ & Station & Earthquake ID & Year & Month & Day & HRMN & $\begin{array}{l}\text { Max. PGA } \\
\text { (g) }\end{array}$ & $\begin{array}{c}\text { Magnitude } \\
(\mathrm{JMA})\end{array}$ & $\begin{array}{l}\text { Epicentral } \\
\text { Dist. }(\mathrm{km})\end{array}$ & $\begin{array}{c}\text { Source } \\
\text { Depth }(\mathrm{km})\end{array}$ \\
\hline \multirow{3}{*}{ ARAH } & Arahama & EQ9234 & 1992 & 12 & 28 & $1: 21$ & 0.026 & 5.9 & 157 & 34 \\
\hline & " & EQ9305 & 1993 & 1 & 15 & $20: 07$ & 0.026 & 7.8 & 595 & 101 \\
\hline & " & EQ9327 & 1993 & 11 & 27 & $15: 11$ & 0.094 & 5.9 & 51 & 112 \\
\hline \multirow[t]{13}{*}{ MIYA } & Miyagino & EQ8701 & 1987 & 1 & 9 & $15: 15$ & 0.022 & 6.6 & 190 & 72 \\
\hline & " & EQ8704 & 1987 & 1 & 21 & $8: 36$ & 0.028 & 5.5 & 113 & 50 \\
\hline & " & EQ8709 & 1987 & 2 & 6 & $22: 16$ & 0.030 & 6.4 & 168 & 30 \\
\hline & " & EQ8719 & 1987 & 4 & 7 & 9:41 & 0.032 & 6.6 & 135 & 44 \\
\hline & $"$ & EQ8740 & 1987 & 10 & 4 & $19: 27$ & 0.027 & 5.8 & 129 & 42 \\
\hline & $"$ & EQ8915 & 1989 & 6 & 24 & $4: 59$ & 0.038 & 4.1 & 9 & 14 \\
\hline & " & EQ9234 & 1992 & 12 & 28 & $1: 21$ & 0.013 & 5.9 & 160 & 34 \\
\hline & $"$ & EQ9305 & 1993 & 1 & 15 & $20: 07$ & 0.019 & 7.8 & 594 & 101 \\
\hline & $"$ & EQ9602 & 1996 & 2 & 17 & $0: 23$ & 0.041 & 6.5 & 179 & 6 \\
\hline & " & EQ9712 & 1997 & 12 & 7 & $12: 50$ & 0.025 & 5.3 & 97 & 83 \\
\hline & " & EQ9819 & 1998 & 9 & 15 & $16: 18$ & 0.027 & 3.6 & 13 & 13 \\
\hline & $"$ & EQ9820 & 1998 & 9 & 15 & $16: 24$ & 0.145 & 5.0 & 13 & 13 \\
\hline & $"$ & EQ9826 & 1998 & 9 & 15 & $17: 56$ & 0.037 & 4.0 & 13 & 13 \\
\hline \multirow[t]{11}{*}{ NAGA } & Nagamachi & EQ9234 & 1992 & 12 & 28 & $1: 21$ & 0.023 & 5.9 & 164 & 34 \\
\hline & $"$ & EQ9305 & 1993 & 1 & 15 & $20: 07$ & 0.036 & 7.8 & 598 & 101 \\
\hline & $"$ & EQ9327 & 1993 & 11 & 27 & $15: 11$ & 0.092 & 5.9 & 56 & 112 \\
\hline & " & EQ9602 & 1996 & 2 & 17 & $0: 23$ & 0.108 & 6.5 & 179 & 6 \\
\hline & " & EQ9604 & 1996 & 4 & 23 & $13: 08$ & 0.031 & 5.2 & 121 & 76 \\
\hline & " & EQ9701 & 1997 & 2 & 20 & $5: 22$ & 0.053 & 5.3 & 97 & 88 \\
\hline & $"$ & EQ9712 & 1997 & 12 & 7 & $12: 50$ & 0.052 & 5.3 & 97 & 83 \\
\hline & " & EQ9819 & 1998 & 9 & 15 & $16: 18$ & 0.038 & 3.6 & 11 & 13 \\
\hline & $"$ & EQ9820 & 1998 & 9 & 15 & $16: 24$ & 0.181 & 5.0 & 11 & 13 \\
\hline & $"$ & EQ9826 & 1998 & 9 & 15 & $17: 56$ & 0.042 & 4.0 & 10 & 13 \\
\hline & " & EQ9839 & 1998 & 11 & 24 & 4:48 & 0.045 & 5.1 & 67 & 82 \\
\hline \multirow[t]{12}{*}{ NAKA } & Nakano & EQ8701 & 1987 & 1 & 9 & $15: 15$ & 0.044 & 6.6 & 188 & 72 \\
\hline & " & EQ8704 & 1987 & 1 & 21 & $8: 36$ & 0.050 & 5.5 & 106 & 50 \\
\hline & $"$ & EQ8709 & 1987 & 2 & 6 & $22: 16$ & 0.096 & 6.4 & 164 & 30 \\
\hline & $"$ & EQ8719 & 1987 & 4 & 7 & $9: 41$ & 0.081 & 6.6 & 131 & 44 \\
\hline & $"$ & EQ8724 & 1987 & 4 & 23 & $5: 13$ & 0.111 & 6.5 & 141 & \\
\hline & " & EQ8740 & 1987 & 10 & 4 & $19: 27$ & 0.070 & 5.8 & 125 & 42 \\
\hline & $"$ & EQ8915 & 1989 & 6 & 24 & $4: 59$ & 0.039 & 4.1 & 16 & 14 \\
\hline & $"$ & EQ9413 & 1994 & 10 & 4 & $22: 24$ & 0.054 & 8.1 & 801 & 23 \\
\hline & $"$ & EQ9602 & 1996 & 2 & 17 & $0: 23$ & 0.073 & 6.5 & 172 & 6 \\
\hline & $"$ & EQ9701 & 1997 & 2 & 20 & $5: 22$ & 0.026 & 5.3 & 98 & 88 \\
\hline & " & EQ9712 & 1997 & 12 & 7 & $12: 50$ & 0.041 & 5.3 & 91 & 83 \\
\hline & $"$ & EQ9839 & 1998 & 11 & 24 & $4: 48$ & 0.072 & 5.1 & 59 & 82 \\
\hline OKIN & Okino & EQ8915 & 1989 & 6 & 24 & $4: 59$ & 0.037 & 4.1 & 11 & 14 \\
\hline & " & EQ9234 & 1992 & 12 & 28 & $1: 21$ & 0.028 & 5.9 & 162 & 34 \\
\hline & $"$ & EQ9305 & 1993 & 1 & 15 & $20: 07$ & 0.026 & 7.8 & 597 & 101 \\
\hline & " & EQ9327 & 1993 & 11 & 27 & $15: 11$ & 0.127 & 5.9 & 54 & 112 \\
\hline & $"$ & EQ9602 & 1996 & 2 & 17 & $0: 23$ & 0.257 & 6.5 & 177 & 6 \\
\hline & $"$ & EQ9701 & 1997 & 2 & 20 & $5: 22$ & 0.046 & 5.3 & 96 & 88 \\
\hline & $"$ & EQ9819 & 1998 & 9 & 15 & $16: 18$ & 0.022 & 3.6 & 14 & 13 \\
\hline & " & EQ9820 & 1998 & 9 & 15 & $16: 24$ & 0.157 & 5.0 & 14 & 13 \\
\hline & $"$ & EQ9826 & 1998 & 9 & 15 & $17: 56$ & 0.048 & 4.0 & 13 & 13 \\
\hline & " & EQ9839 & 1998 & 11 & 24 & $4: 48$ & 0.041 & 5.1 & 64 & 82 \\
\hline ORID & Oridate & EQ8719 & 1987 & 4 & 7 & $9: 41$ & 0.058 & 6.6 & 142 & 44 \\
\hline & $"$ & EQ8724 & 1987 & 4 & 23 & $5: 13$ & 0.081 & 6.5 & 149 & \\
\hline & $"$ & EQ8740 & 1987 & 10 & 4 & $19: 27$ & 0.038 & 5.8 & 135 & 42 \\
\hline & $"$ & EQ8915 & 1989 & 6 & 24 & $4: 59$ & 0.031 & 4.1 & 4 & 14 \\
\hline & " & EQ9234 & 1992 & 12 & 28 & $1: 21$ & 0.009 & 5.9 & 169 & 34 \\
\hline & " & EQ9305 & 1993 & 1 & 15 & $20: 07$ & 0.022 & 7.8 & 598 & 101 \\
\hline & " & EQ9327 & 1993 & 11 & 27 & $15: 11$ & 0.046 & 5.9 & 58 & 112 \\
\hline & $"$ & EQ9413 & 1994 & 10 & 4 & $22: 24$ & 0.022 & 8.1 & 812 & 23 \\
\hline & " & EQ9712 & 1997 & 12 & 7 & $12: 50$ & 0.030 & 5.3 & 104 & 83 \\
\hline & " & EQ9819 & 1998 & 9 & 15 & $16: 18$ & 0.026 & 3.6 & 4 & 13 \\
\hline & $"$ & EQ9820 & 1998 & 9 & 15 & $16: 24$ & 0.269 & 5.0 & 4 & 13 \\
\hline & $"$ & EQ9826 & 1998 & 9 & 15 & $17: 56$ & 0.028 & 4.0 & 3 & 13 \\
\hline & " & EQ9839 & 1998 & 11 & 24 & $4: 48$ & 0.059 & 5.1 & 74 & 82 \\
\hline SHIR & Shiromaru & EQ8915 & 1989 & 6 & 24 & $4: 59$ & 0.028 & 4.1 & 13 & 14 \\
\hline & " & EQ9234 & 1992 & 12 & 28 & $1: 21$ & 0.018 & 5.9 & 164 & 34 \\
\hline & $"$ & EQ9305 & 1993 & 1 & 15 & $20: 07$ & 0.031 & 7.8 & 600 & 101 \\
\hline & $"$ & EQ9327 & 1993 & 11 & 27 & $15: 11$ & 0.084 & 5.9 & 57 & 112 \\
\hline & $"$ & EQ9602 & 1996 & 2 & 17 & $0: 23$ & 0.086 & 6.5 & 175 & 6 \\
\hline & $"$ & EQ9701 & 1997 & 2 & 20 & $5: 22$ & 0.048 & 5.3 & 93 & 88 \\
\hline & $"$ & EQ9712 & 1997 & 12 & 7 & $12: 50$ & 0.094 & 5.3 & 93 & 83 \\
\hline & $"$ & EQ9805 & 1998 & 4 & 9 & $17: 45$ & 0.043 & 5.4 & 140 & 93 \\
\hline
\end{tabular}


Table 2 List of Acceleration Records (continued)

Sendai Dense Array Earthquake Observation Project, Building Research Institute, Japan (data from Mr. Toshihide Kashima)

\begin{tabular}{|c|c|c|c|c|c|c|c|c|c|c|}
\hline $\begin{array}{l}\text { Station } \\
\text { code }\end{array}$ & Station & Earthquake ID & Year & Month & Day & HRMN & $\begin{array}{l}\text { Max. PGA } \\
\text { (g) }\end{array}$ & $\begin{array}{l}\text { Magnitude } \\
\text { (JMA) }\end{array}$ & $\begin{array}{l}\text { Epicentral } \\
\text { Dist.(km) }\end{array}$ & $\begin{array}{c}\text { Source } \\
\text { Depth }(\mathrm{km})\end{array}$ \\
\hline \multirow[t]{12}{*}{ TAMA } & Tamagawa & EQ8701 & 1987 & 1 & 9 & $15: 15$ & 0.011 & 6.6 & 181 & 72 \\
\hline & " & EQ8704 & 1987 & 1 & 21 & $8: 36$ & 0.017 & 5.5 & 103 & 50 \\
\hline & $"$ & EQ8709 & 1987 & 2 & 6 & $22: 16$ & 0.033 & 6.4 & 170 & 30 \\
\hline & $"$ & EQ8719 & 1987 & 4 & 7 & 9:41 & 0.035 & 6.6 & 136 & 44 \\
\hline & " & EQ8724 & 1987 & 4 & 23 & $5: 13$ & 0.033 & 6.5 & 147 & \\
\hline & $"$ & EQ9234 & 1992 & 12 & 28 & $1: 21$ & 0.018 & 5.9 & 150 & 34 \\
\hline & " & EQ9305 & 1993 & 1 & 15 & $20: 07$ & 0.014 & 7.8 & 584 & 101 \\
\hline & " & EQ9413 & 1994 & 10 & 4 & $22: 24$ & 0.021 & 8.1 & 795 & 23 \\
\hline & $"$ & EQ9602 & 1996 & 2 & 17 & $0: 23$ & 0.042 & 6.5 & 176 & 6 \\
\hline & $"$ & EQ9701 & 1997 & 2 & 20 & $5: 22$ & 0.351 & 5.3 & 105 & 88 \\
\hline & $"$ & EQ9712 & 1997 & 12 & 7 & $12: 50$ & 0.036 & 5.3 & 95 & 83 \\
\hline & " & EQ9820 & 1998 & 9 & 15 & $16: 24$ & 0.038 & 5.0 & 21 & 13 \\
\hline \multirow[t]{10}{*}{ TRGA } & Tsurugaya & EQ8915 & 1989 & 6 & 24 & 4:59 & 0.021 & 4.1 & 7 & 14 \\
\hline & " & EQ9234 & 1992 & 12 & 28 & $1: 21$ & 0.012 & 5.9 & 159 & 34 \\
\hline & $"$ & EQ9305 & 1993 & 1 & 15 & $20: 07$ & 0.014 & 7.8 & 591 & 101 \\
\hline & " & EQ9327 & 1993 & 11 & 27 & $15: 11$ & 0.041 & 5.9 & 49 & 112 \\
\hline & $"$ & EQ9602 & 1996 & 2 & 17 & $0: 23$ & 0.043 & 6.5 & 181 & 6 \\
\hline & $"$ & EQ9701 & 1997 & 2 & 20 & $5: 22$ & 0.025 & 5.3 & 103 & 88 \\
\hline & $"$ & EQ9712 & 1997 & 12 & 7 & $12: 50$ & 0.022 & 5.3 & 99 & 83 \\
\hline & $"$ & EQ9820 & 1998 & 9 & 15 & $16: 24$ & 0.081 & 5.0 & 13 & 13 \\
\hline & $"$ & EQ9826 & 1998 & 9 & 15 & $17: 56$ & 0.015 & 4.0 & 12 & 13 \\
\hline & " & EQ9839 & 1998 & 11 & 24 & $4: 48$ & 0.052 & 5.1 & 68 & 82 \\
\hline \multirow[t]{10}{*}{ TRMA } & Tsurumaki & EQ8915 & 1989 & 6 & 24 & $4: 59$ & 0.046 & 4.1 & 13 & 14 \\
\hline & " & EQ9234 & 1992 & 12 & 28 & $1: 21$ & 0.042 & 5.9 & 156 & 34 \\
\hline & $"$ & EQ9305 & 1993 & 1 & 15 & $20: 07$ & 0.037 & 7.8 & 591 & 101 \\
\hline & $"$ & EQ9327 & 1993 & 11 & 27 & $15: 11$ & 0.090 & 5.9 & 48 & 112 \\
\hline & " & EQ9602 & 1996 & 2 & 17 & $0: 23$ & 0.096 & 6.5 & 175 & 6 \\
\hline & $"$ & EQ9701 & 1997 & 2 & 20 & $5: 22$ & 0.029 & 5.3 & 99 & 88 \\
\hline & $"$ & EQ9712 & 1997 & 12 & 7 & $12: 50$ & 0.053 & 5.3 & 94 & 83 \\
\hline & " & EQ9819 & 1998 & 9 & 15 & $16: 18$ & 0.035 & 3.6 & 18 & 13 \\
\hline & $"$ & EQ9820 & 1998 & 9 & 15 & $16: 24$ & 0.101 & 5.0 & 18 & 13 \\
\hline & $"$ & EQ9826 & 1998 & 9 & 15 & $17: 56$ & 0.036 & 4.0 & 17 & 13 \\
\hline \multirow[t]{7}{*}{ TSUT } & Tsutsujigaoka & EQ8915 & 1989 & 6 & 24 & 4:59 & 0.033 & 4.1 & 7 & 14 \\
\hline & " & EQ9234 & 1992 & 12 & 28 & $1: 21$ & 0.018 & 5.9 & 162 & 34 \\
\hline & " & EQ9602 & 1996 & 2 & 17 & $0: 23$ & 0.075 & 6.5 & 181 & 6 \\
\hline & $"$ & EQ9712 & 1997 & 12 & 7 & $12: 50$ & 0.034 & 5.3 & 99 & 83 \\
\hline & $"$ & EQ9819 & 1998 & 9 & 15 & $16: 18$ & 0.016 & 3.6 & 11 & 13 \\
\hline & $"$ & EQ9820 & 1998 & 9 & 15 & $16: 24$ & 0.115 & 5.0 & 11 & 13 \\
\hline & $"$ & EQ9826 & 1998 & 9 & 15 & $17: 56$ & 0.021 & 4.0 & 10 & 13 \\
\hline
\end{tabular}


Table 3 NEHRP Site Classification

\begin{tabular}{c|l|l}
\hline Classification & \multicolumn{1}{|c}{ Description } & $\mathbf{V}_{\mathbf{s 3 0}}(\mathbf{m} / \mathbf{s})$ \\
\hline A & hard rock & $>1500$ \\
\hline B & rock & $760-1500$ \\
\hline C & very dense soil/soft rock & $360-760$ \\
\hline D & stiff soil & $180-360$ \\
\hline E & soft soil & $<180$ \\
\hline F & $\begin{array}{l}\text { special soils requiring site- } \\
\text { specific evaluation }\end{array}$ & \\
\hline
\end{tabular}

Table 4 Number of V/H ratios obtained from arrays in class B, C, D1, D2, D3, and E sites

\begin{tabular}{c|c|c|c|c|c|c|c}
\hline \hline \multirow{2}{*}{ Soil Class } & \multicolumn{7}{c}{ Depth Bin } \\
\cline { 2 - 8 } & $0-7 \mathrm{ft}$ & $7-50 \mathrm{ft}$ & $50-100 \mathrm{ft}$ & $100-150 \mathrm{ft}$ & $150-200 \mathrm{ft}$ & $200-300 \mathrm{ft}$ & $>300 \mathrm{ft}$ \\
\hline \multirow{2}{*}{$\mathrm{B}$} & 13 & 0 & 2 & 11 & 0 & 11 & 0 \\
$\mathrm{C}$ & 70 & 16 & 31 & 19 & 38 & 13 & 0 \\
D1 & 71 & 55 & 48 & 35 & 24 & 33 & 31 \\
D2 & 30 & 3 & 27 & 12 & 6 & 19 & 19 \\
D3 & 69 & 69 & 58 & 6 & 6 & 29 \\
E & 17 & 5 & 17 & 6 & & 6 \\
\hline \hline
\end{tabular}

Table 5 Number of $\mathrm{V} / \mathrm{H}$ ratios obtained from events with PGAs in the ranges $0.01 \mathrm{~g}-0.1 \mathrm{~g}$,

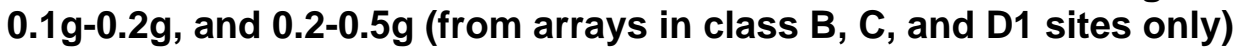

\begin{tabular}{c|c|c|c|c|c|c|c}
\hline \hline \multirow{2}{*}{ PGA (g) } & \multicolumn{7}{c}{ Depth Bin } \\
\cline { 2 - 8 } & $0-7 \mathrm{ft}$ & $7-50 \mathrm{ft}$ & $50-100 \mathrm{ft}$ & $100-150 \mathrm{ft}$ & $150-200 \mathrm{ft}$ & $200-300 \mathrm{ft}$ & $>300 \mathrm{ft}$ \\
\hline $0.01-0.10$ & 137 & 63 & 69 & 62 & 57 & 50 & 28 \\
$0.10-0.20$ & 9 & 4 & 6 & 2 & 3 & 4 & 2 \\
$0.20-0.50$ & 8 & 4 & 6 & 1 & 2 & 3 & 1 \\
\hline \hline
\end{tabular}


Table 6 Number of V/H ratios obtained from CGS-CESMD and USGS-NSMP sites in California; NEES at UCSB sites in California; NEES at UCSB site in Anchorage, Alaska; Sendai District, Japan; and Taipei Basin, Taiwan (arrays in class B, C, and D sites only)

\begin{tabular}{c|c|c|c|c|c|c|c}
\hline \hline \multirow{2}{*}{ Array Location } & \multicolumn{7}{c}{ Depth Bin } \\
\cline { 2 - 8 } & $0-7 \mathrm{ft}$ & $7-50 \mathrm{ft}$ & $50-100 \mathrm{ft}$ & $100-150 \mathrm{ft}$ & $150-200 \mathrm{ft}$ & $200-300 \mathrm{ft}$ & $>300 \mathrm{ft}$ \\
\hline California CGS-CESMD & 68 & 28 & 48 & 31 & 7 & 9 & 34 \\
and USGS-NSMP & 43 & 86 & 34 & 0 & 23 & 0 & 44 \\
California NEES at UCSB & 8 & 16 & 8 & 15 & 0 & 8 & 0 \\
Anchorage, Alaska & 114 & 13 & 61 & 37 & 38 & 73 & 0 \\
Sendai District, Japan & 20 & 0 & 15 & 0 & 19 & 0 & 0 \\
Taipei Basin, Taiwan &
\end{tabular}




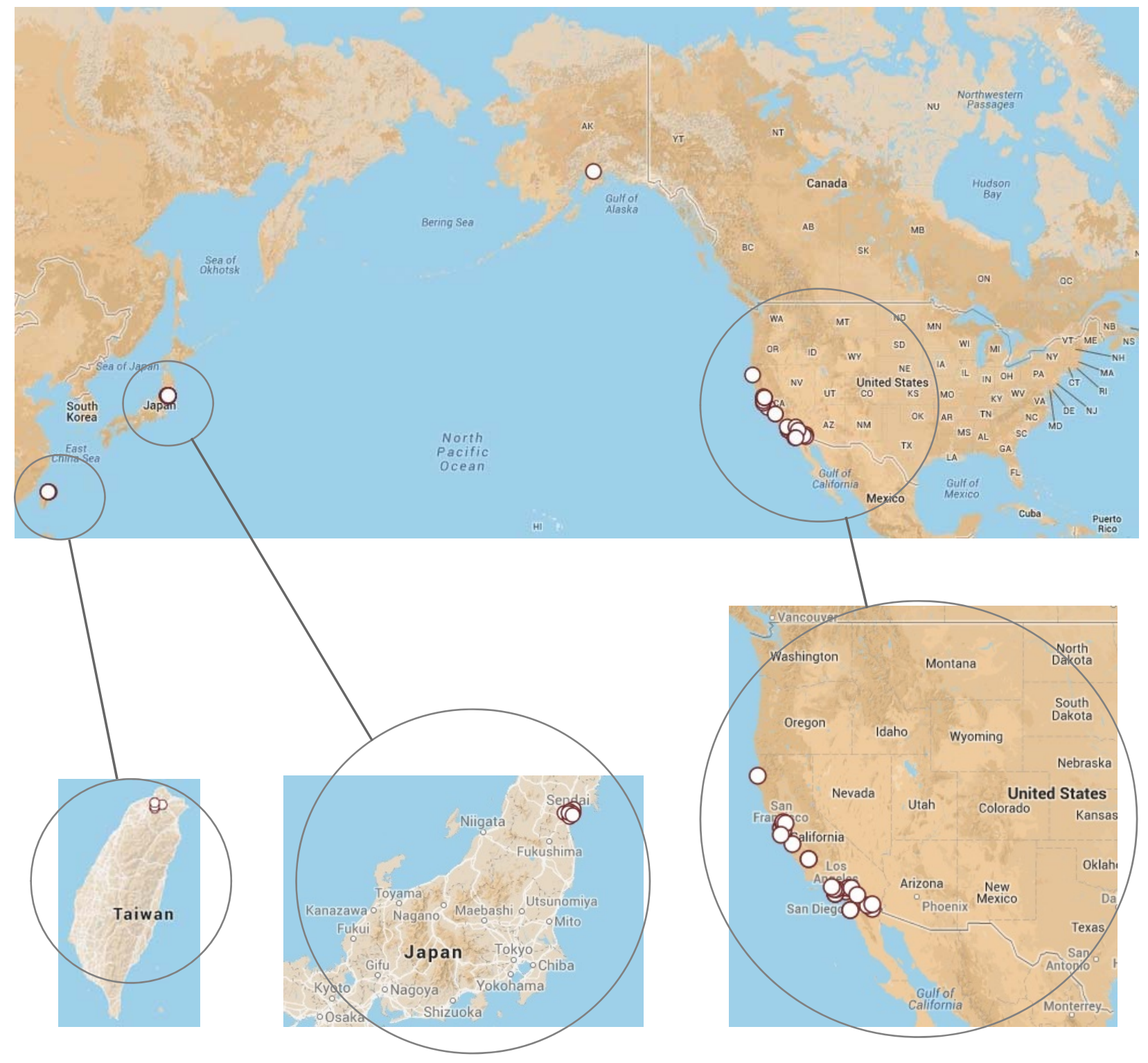

Figure 1 Map of Vertical Array Stations 

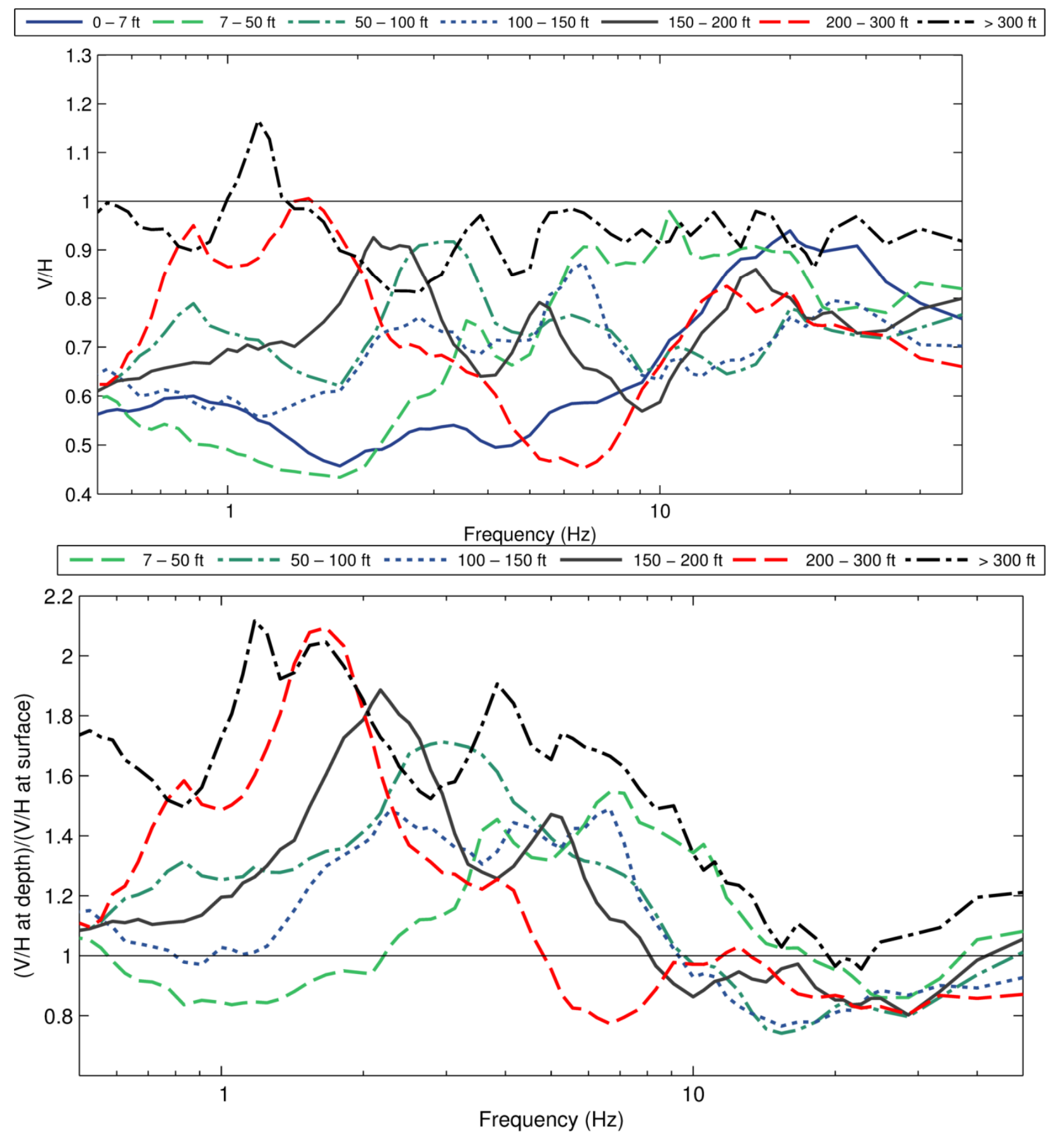

Figure $2 \mathrm{~V} / \mathrm{H}$ ratios of all records obtained from arrays in class B, C, and D1 site. Average $\mathrm{V} / \mathrm{H}$ ratios (top) and normalized average $\mathrm{V} / \mathrm{H}$ ratios (bottom) for each of the seven depth bins:

0-7 ft (154 ratios), 7-50 ft (71 ratios), 50-100 ft (81 ratios), 100-150 ft (65 ratios), 150-200 ft (62 ratios), $200-300 \mathrm{ft}$ (57 ratios), and $>300 \mathrm{ft}$ (31 ratios). 


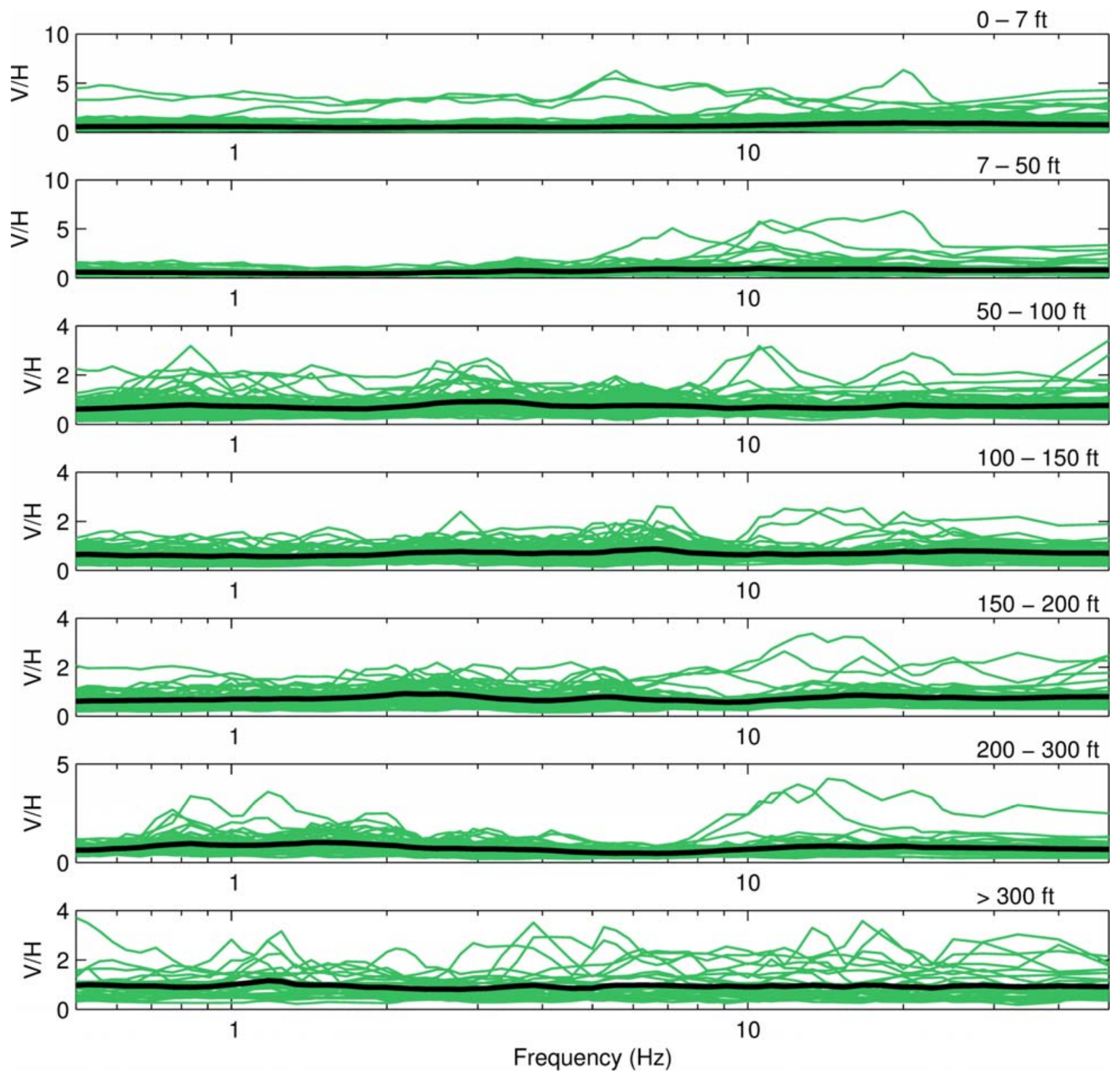

Figure $3 \mathrm{~V} / \mathrm{H}$ ratios of all records obtained from arrays in class B, C, and D1 sites. Total of $521 \mathrm{~V} / \mathrm{H}$ ratios plotted in their corresponding depth bins:

0-7 ft (154 ratios), 7-50 ft (71 ratios), 50-100 ft (81 ratios), 100-150 ft (65 ratios), 150-200 ft (62 ratios), $200-300 \mathrm{ft}$ (57 ratios), and $>300 \mathrm{ft}$ (31 ratios). The thick black lines correspond to the averages for each bin. 

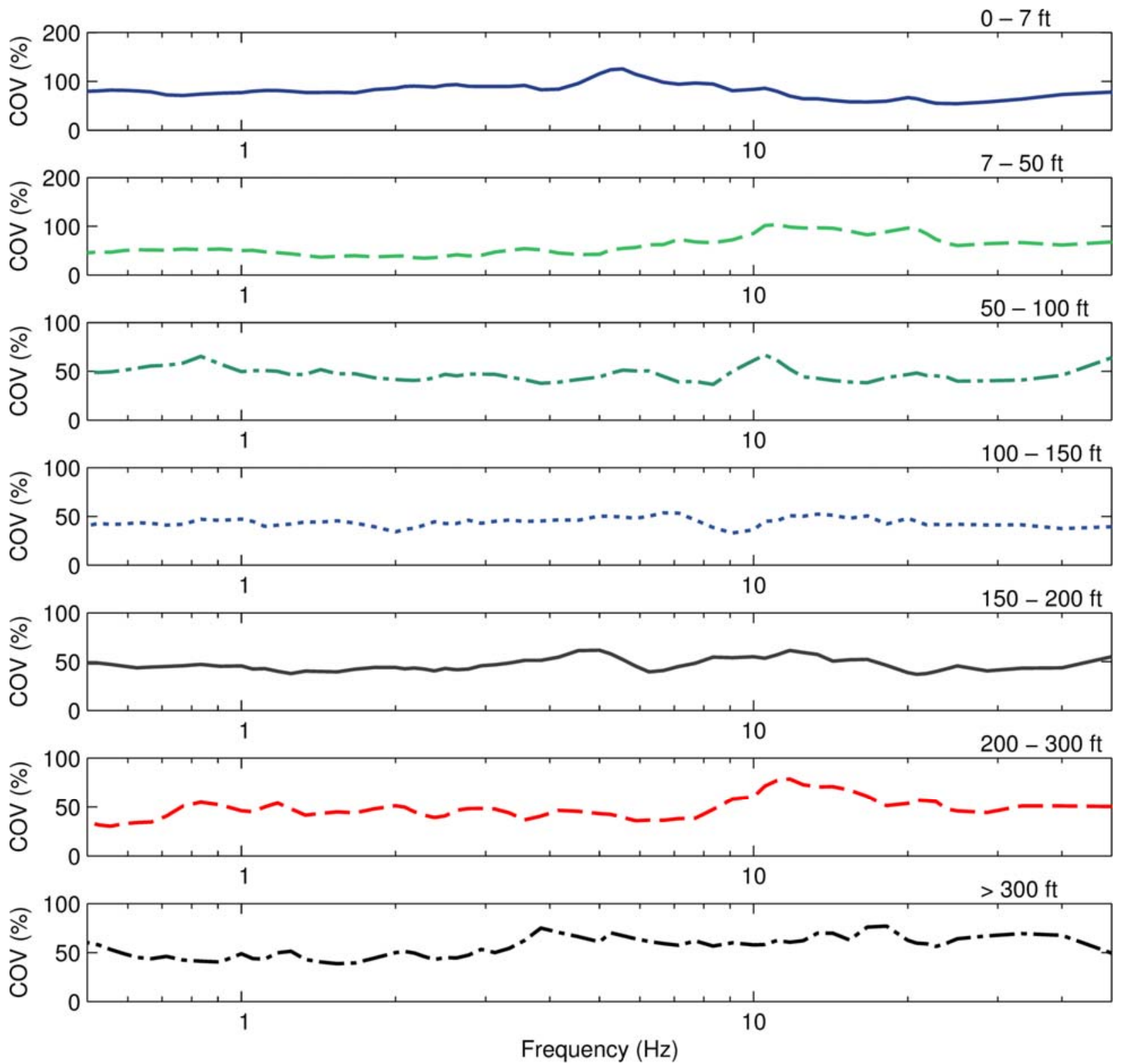

Figure $4 \mathrm{~V} / \mathrm{H}$ ratios of all records obtained from arrays in class B, C, and D1 sites. Coefficients of variation of the $\mathrm{V} / \mathrm{H}$ ratios within each of the seven depth bins:

0-7 ft (154 ratios), 7-50 ft (71 ratios), 50-100 ft (81 ratios), 100-150 ft (65 ratios), 150-200 ft (62 ratios), $200-300 \mathrm{ft}$ (57 ratios), and $>300 \mathrm{ft}$ (31 ratios). 

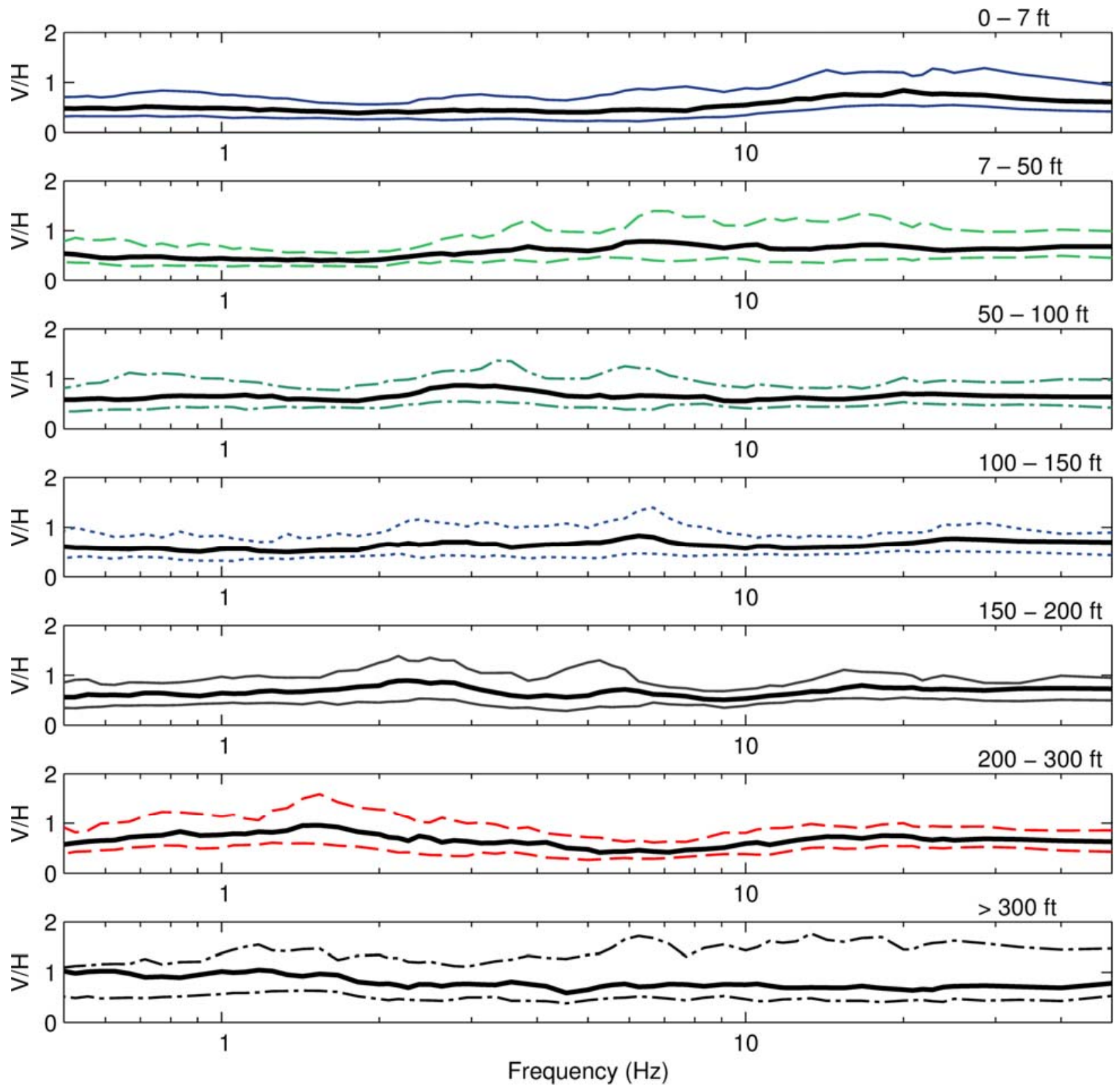

Figure $5 \mathrm{~V} / \mathrm{H}$ ratios of all records obtained from arrays in class $\mathrm{B}, \mathrm{C}$, and D1 sites. Percentiles $\left(16^{\text {th }}, 50^{\text {th }}, 84^{\text {th }}\right)$ of the V/H ratios within each of the seven depth bins:

0-7 ft (154 ratios), 7-50 ft (71 ratios), 50-100 ft (81 ratios), 100-150 ft (65 ratios), 150-200 ft (62 ratios), $200-300 \mathrm{ft}$ (57 ratios), and $>300 \mathrm{ft}$ (31 ratios). The thick black lines correspond to $50^{\text {th }}$ percentiles for each bin. 

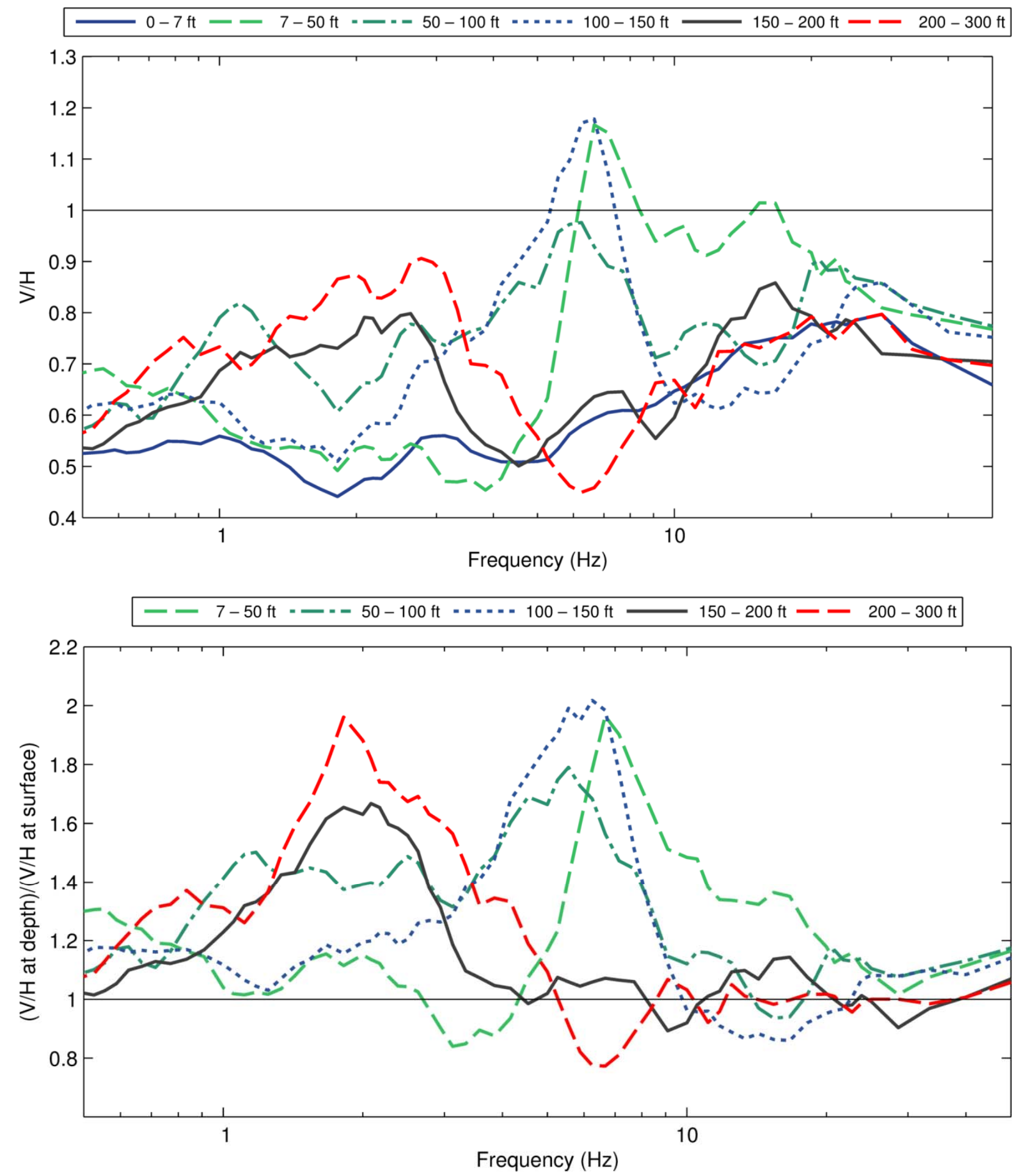

Figure $6 \mathrm{~V} / \mathrm{H}$ ratios of all records obtained from arrays in class B and C sites. Average $\mathrm{V} / \mathrm{H}$ ratios (top) and normalized average $\mathrm{V} / \mathrm{H}$ ratios (bottom) for each of the six depth bins:

0-7 ft (83 ratios), 7-50 ft (16 ratios), 50-100 ft (33 ratios), 100-150 ft (30 ratios), 150-200 ft (38 ratios), and $200-300 \mathrm{ft}$ (24 ratios). There was no data in depth bin $>300 \mathrm{ft}$. 

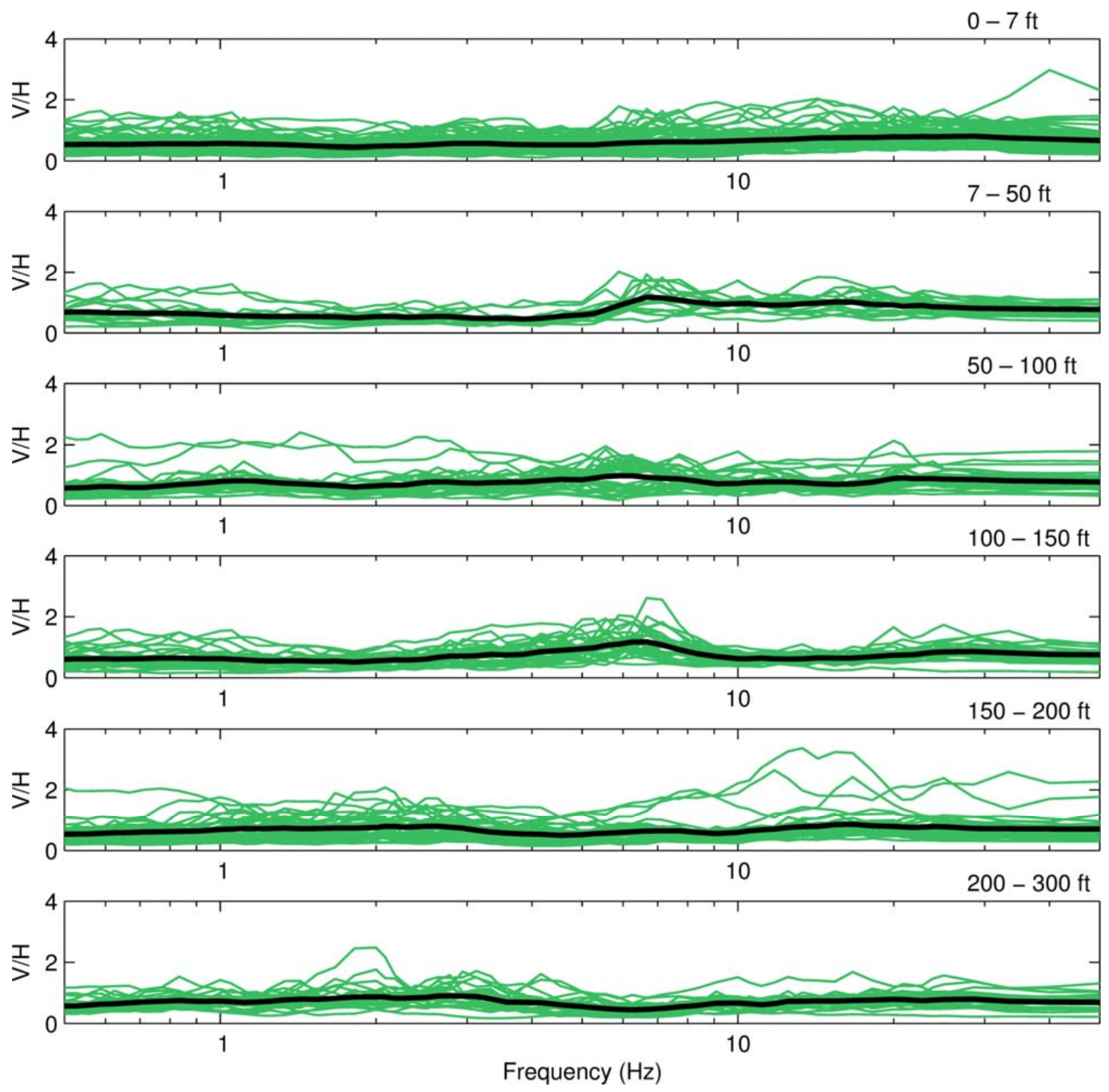

Figure $7 \mathrm{VIH}$ ratios of all records obtained from arrays in class B and C sites

Total of $224 \mathrm{~V} / \mathrm{H}$ ratios plotted in their corresponding depth bins: 0-7 ft (83 ratios), 7-50 ft (16 ratios), 50-100 ft (33 ratios), 100-150 ft (30 ratios), 150-200 ft (38 ratios), and 200-300 ft (24 ratios). There was no data in depth bin $>300 \mathrm{ft}$. The thick black lines correspond to the averages for each bin. 

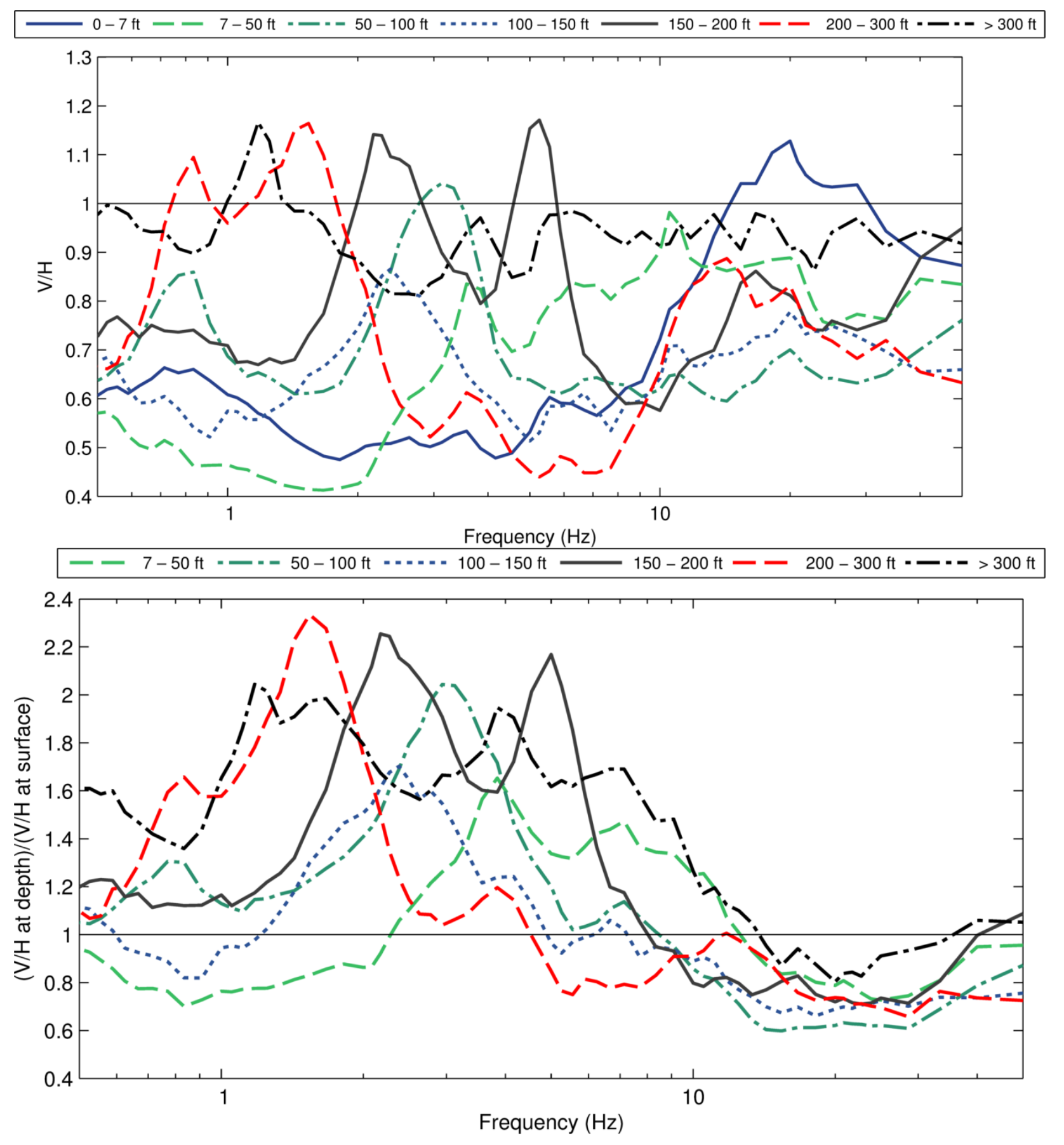

Figure $8 \mathrm{~V} / \mathrm{H}$ ratios of all records obtained from arrays in class D1 sites. Average V/H ratios (top) and normalized average V/H ratios (bottom) for each of the seven depth bins:

0-7 ft (71 ratios), 7-50 ft (55 ratios), 50-100 ft (48 ratios), 100-150 ft (35 ratios), 150-200 ft (24 ratios), 200-300 ft (33 ratios), and $>300 \mathrm{ft}$ (31 ratios). 

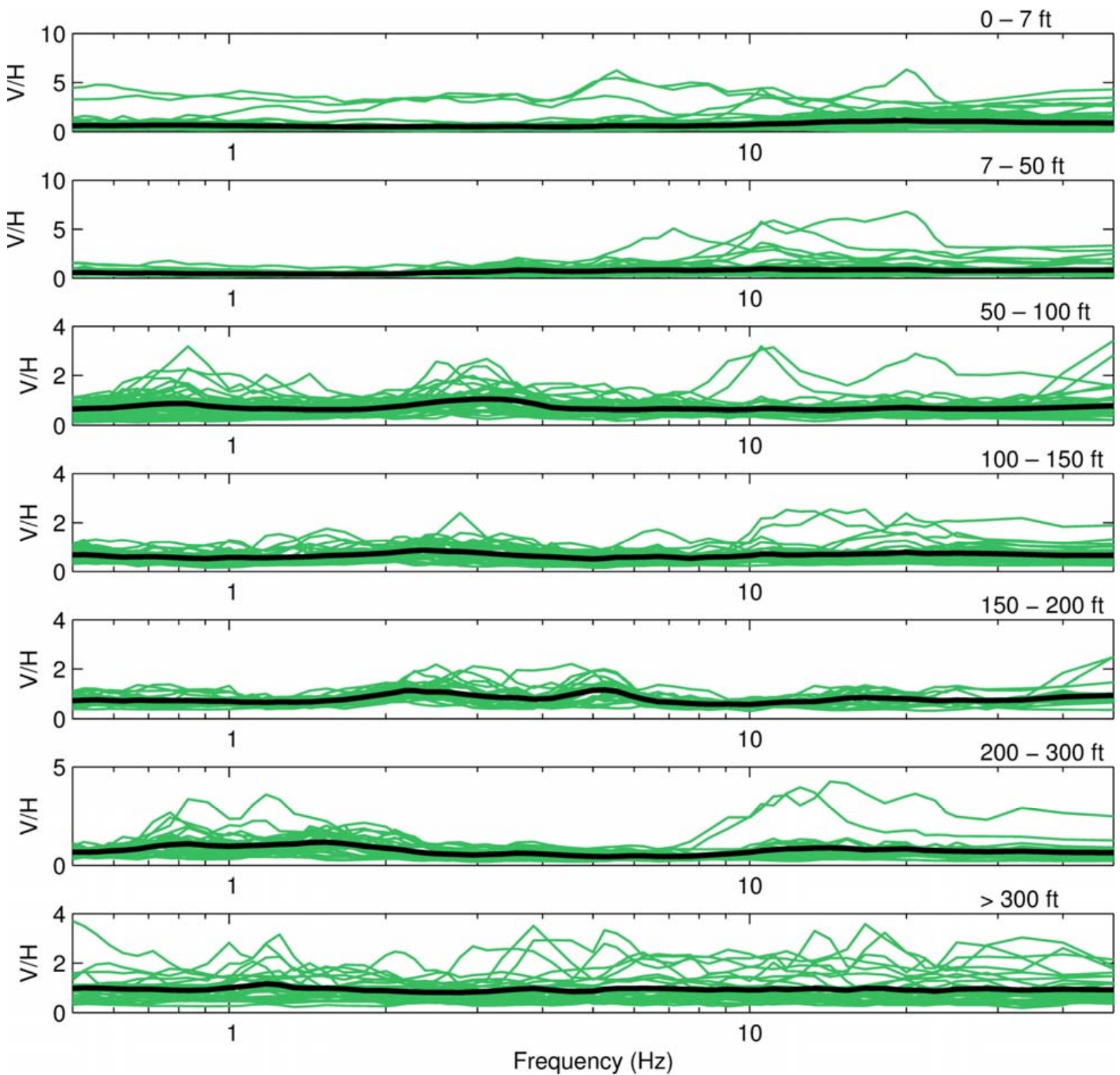

Figure $9 \mathrm{~V} / \mathrm{H}$ ratios of all records obtained from arrays in class D1 sites. Total of $297 \mathrm{~V} / \mathrm{H}$ ratios plotted in their corresponding depth bins:

0-7 ft (71 ratios), 7-50 ft (55 ratios), 50-100 ft (48 ratios), 100-150 ft (35 ratios), 150-200 ft (24 ratios), $200-300 \mathrm{ft}$ (33 ratios), and $>300 \mathrm{ft}$ (31 ratios). The thick black lines correspond to the averages for each bin. 

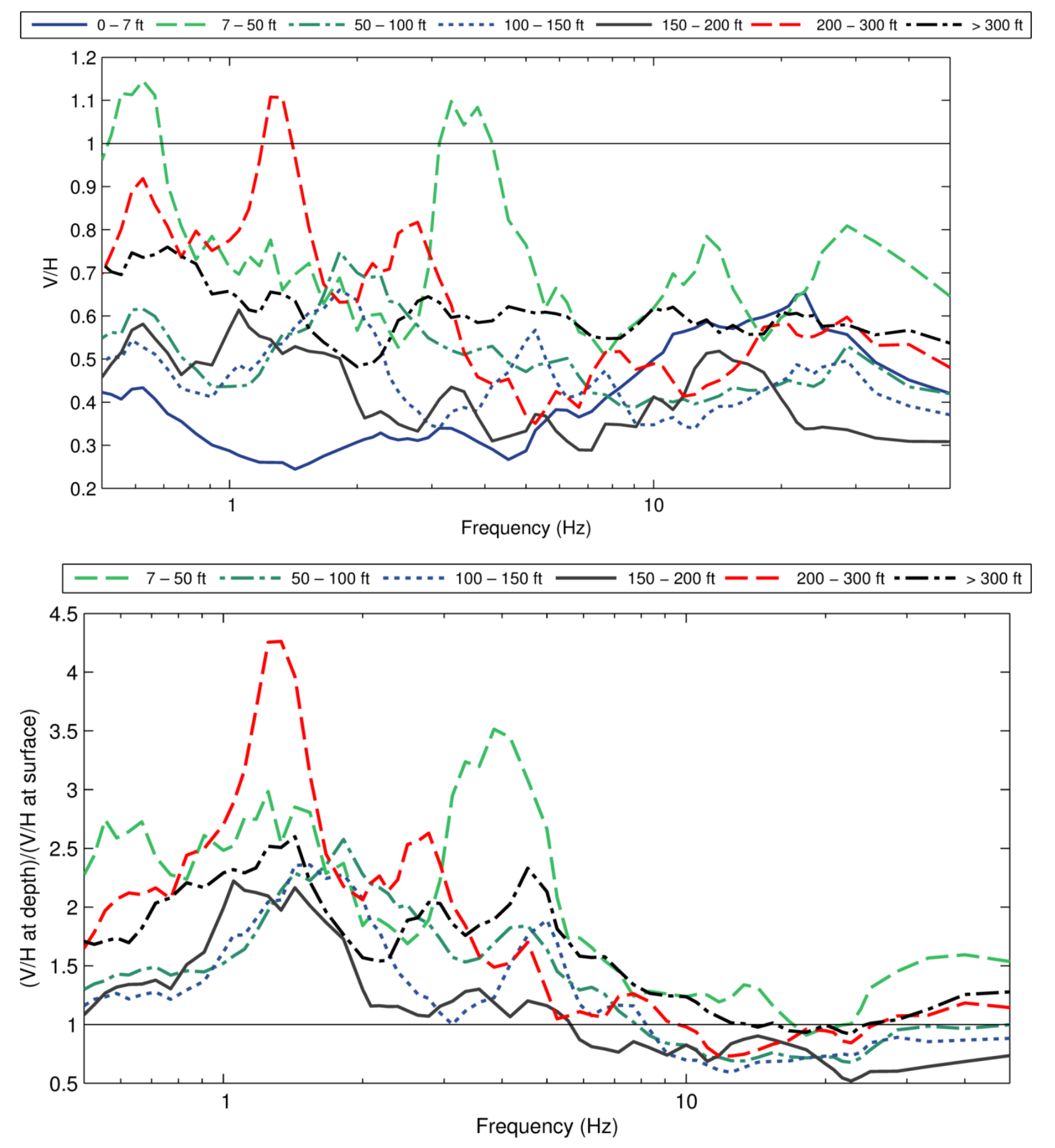

Figure $10 \mathrm{~V} / \mathrm{H}$ ratios of all records obtained from arrays in class D2 sites. Average V/H ratios (top) and normalized average $\mathrm{V} / \mathrm{H}$ ratios (bottom) for each of the seven depth bins:

0-7 ft (30 ratios), 7-50 ft (3 ratios), 50-100 ft (27 ratios), 100-150 ft (12 ratios), 150-200 ft (6 ratios), $200-300 \mathrm{ft}$ (14 ratios), and $>300 \mathrm{ft}$ (18 ratios). 


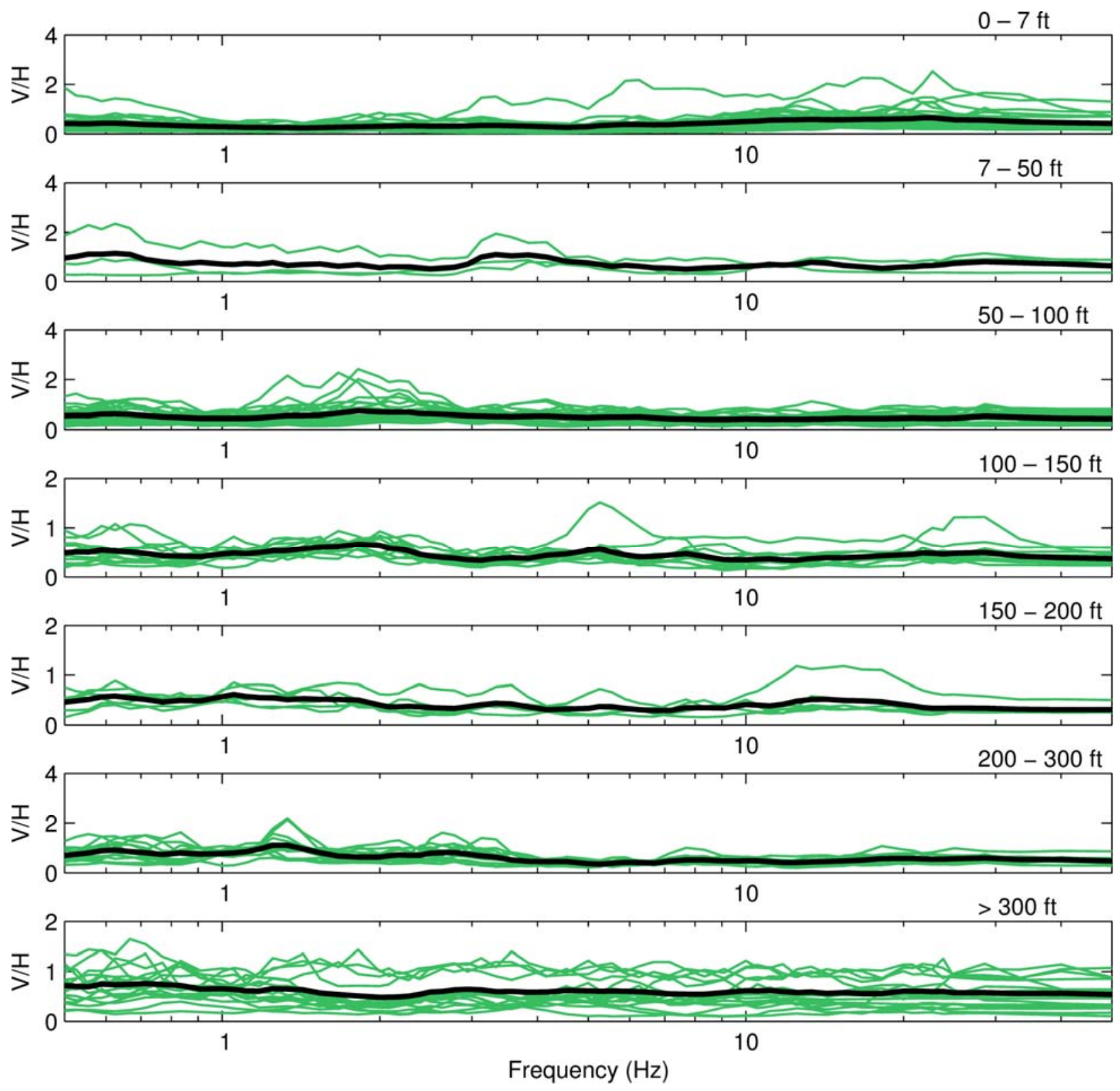

Figure $11 \mathrm{~V} / \mathrm{H}$ ratios of all records obtained from arrays in class D2 sites. Total of 110 V/H ratios plotted in their corresponding depth bins:

0-7 ft (30 ratios), 7-50 ft (3 ratios), 50-100 ft (27 ratios), 100-150 ft (12 ratios), 150-200 ft (6 ratios), $200-300 \mathrm{ft}$ (14 ratios), and $>300 \mathrm{ft}$ (18 ratios). The thick black lines correspond to the averages for each bin. 

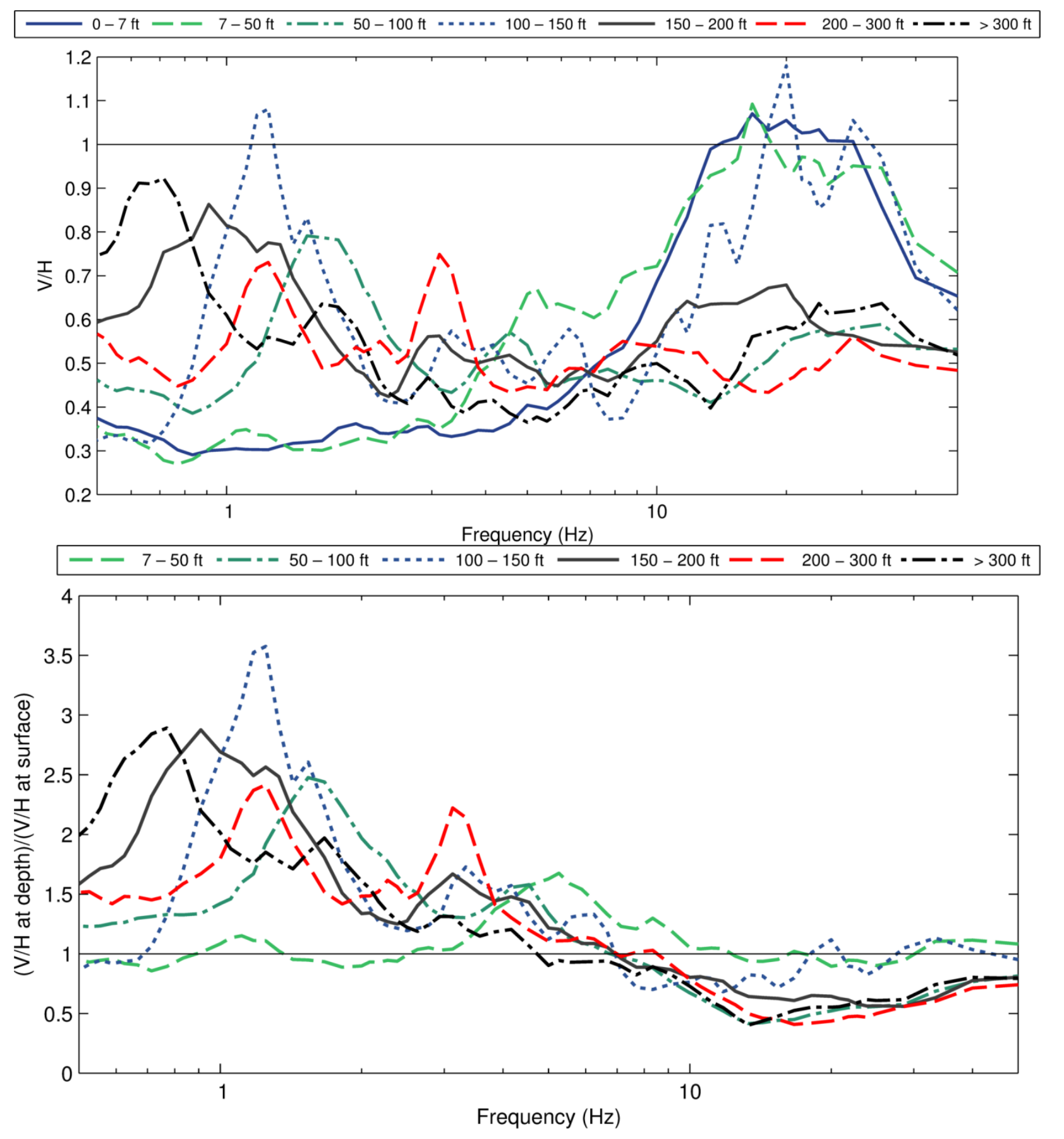

Figure $12 \mathrm{~V} / \mathrm{H}$ ratios of all records obtained from arrays in class D3 sites. Average V/H ratios (top) and normalized average V/H ratios (bottom) for each of the seven depth bins:

0-7 ft (69 ratios), 7-50 ft (69 ratios), 50-100 ft (58 ratios), 100-150 ft (6 ratios), 150-200 ft (19 ratios), $200-300 \mathrm{ft}$ (19 ratios), and $>300 \mathrm{ft}$ (29 ratios). 

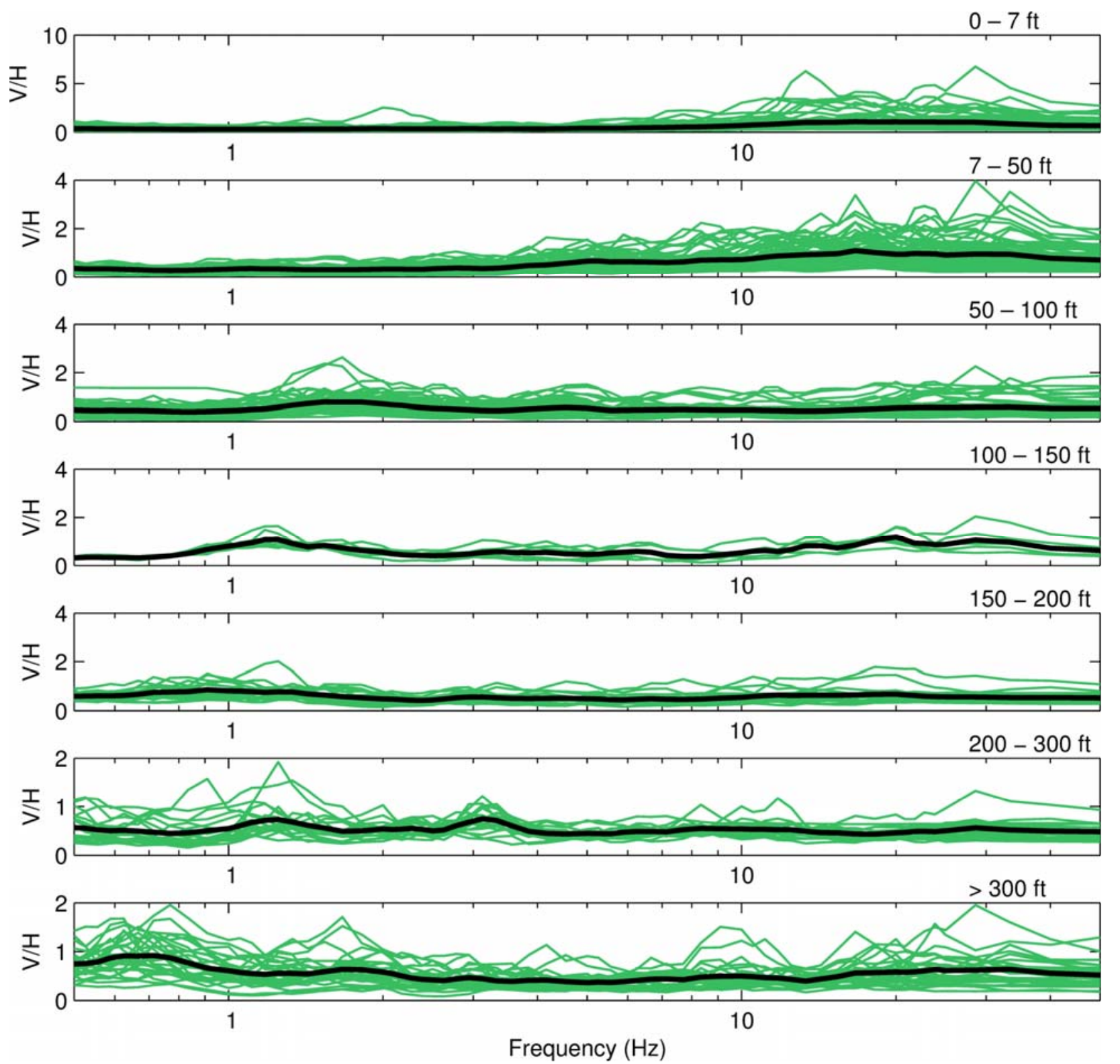

Figure $13 \mathrm{~V} / \mathrm{H}$ ratios of all records obtained from arrays in class D3 sites. Total of 269 V/H ratios plotted in their corresponding depth bins:

0-7 ft (69 ratios), 7-50 ft (69 ratios), 50-100 ft (58 ratios), 100-150 ft (6 ratios), 150-200 ft (19 ratios), $200-300 \mathrm{ft}$ (19 ratios), and $>300 \mathrm{ft}$ (29 ratios). The thick black lines correspond to the averages for each bin. 

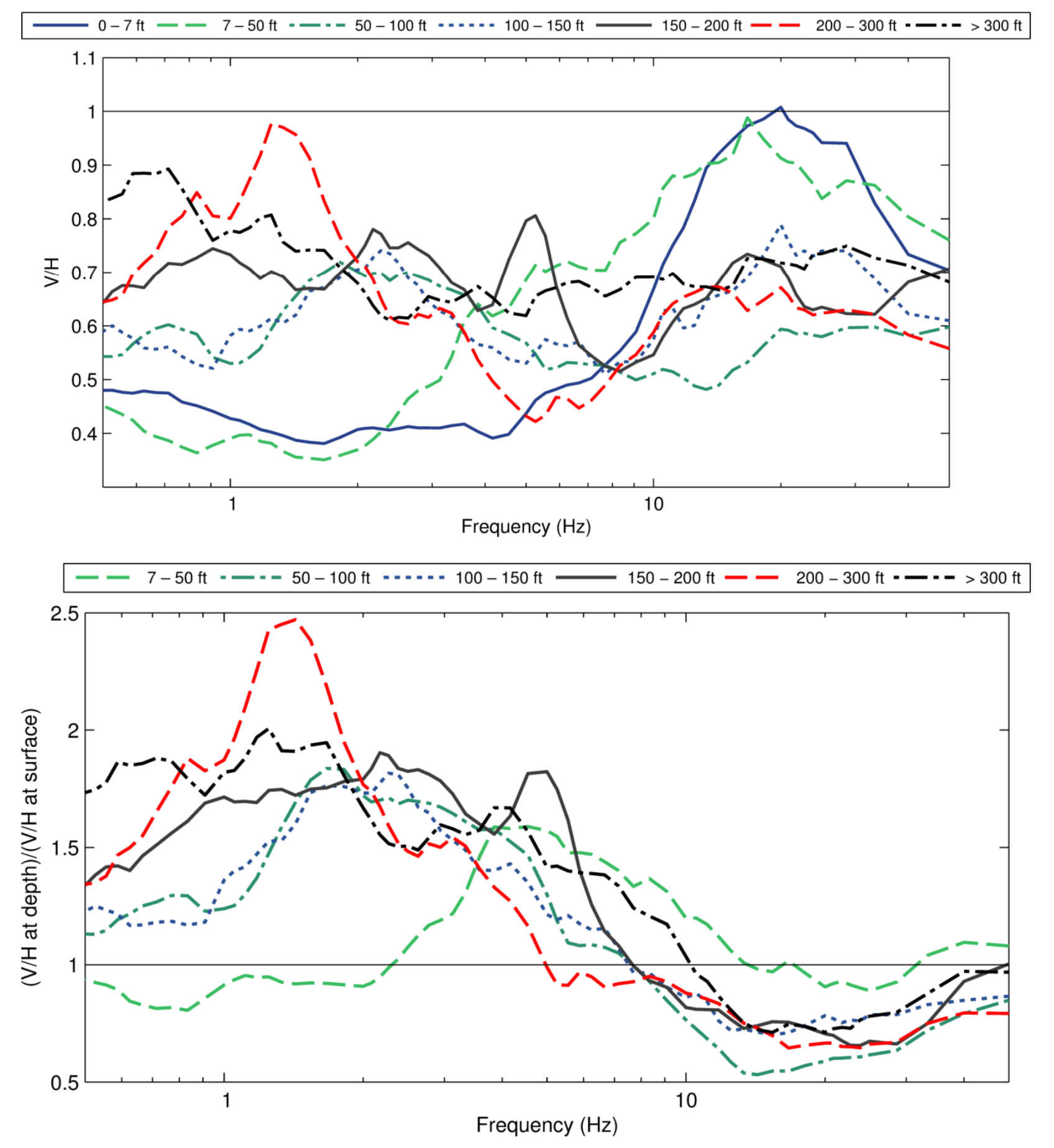

Figure $14 \mathrm{~V} / \mathrm{H}$ ratios of all records obtained from arrays in class D (D1, D2, and D3) sites. Average V/H ratios (top) and normalized average V/H ratios (bottom) for each of the seven depth bins:

0-7 ft (170 ratios), 7-50 ft (127 ratios), 50-100 ft (133 ratios), 100-150 ft (53 ratios), 150-200 ft (49 ratios), $200-300 \mathrm{ft}$ (66 ratios), and $>300 \mathrm{ft}$ (78 ratios). 

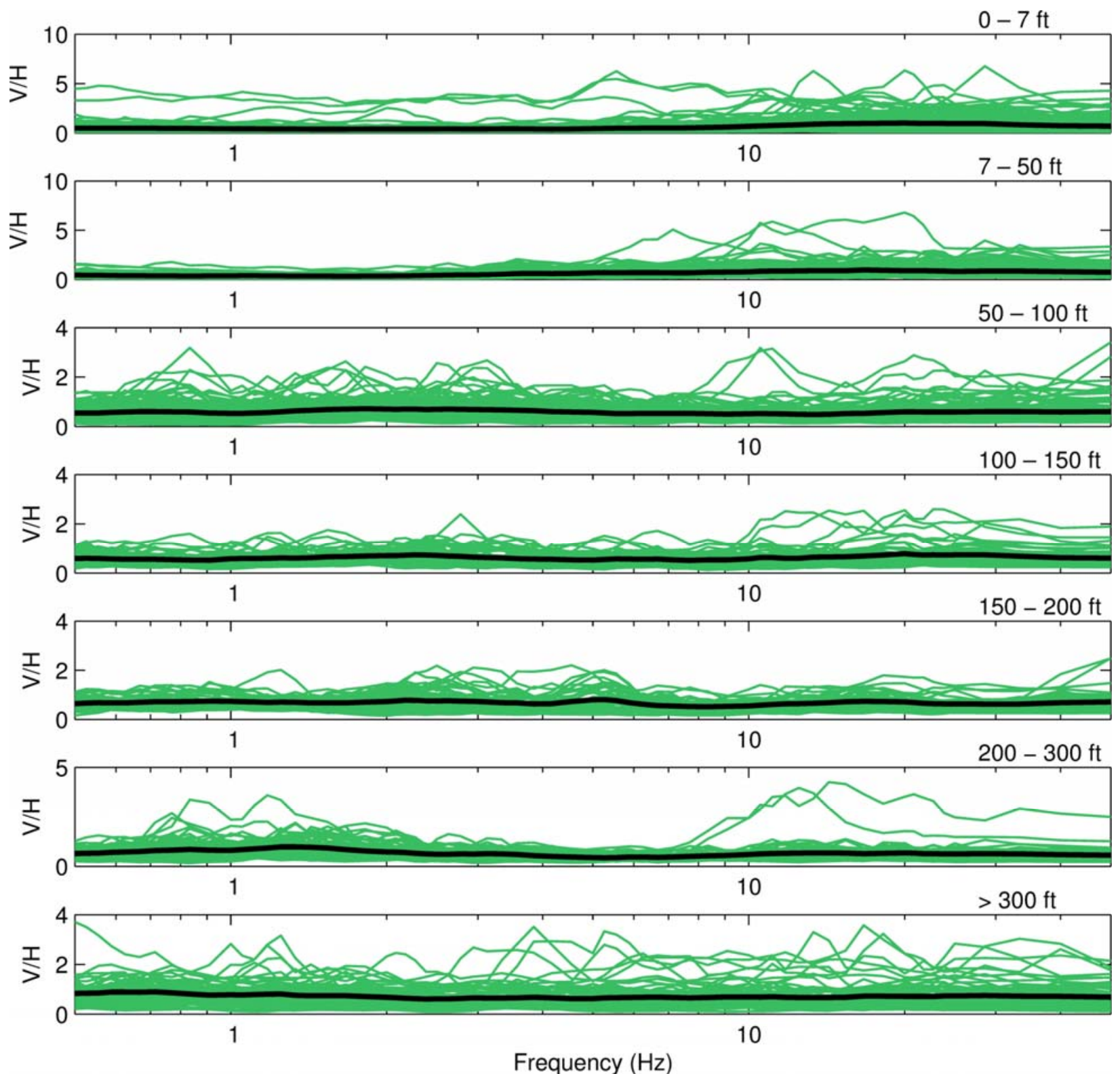

Figure 15 V/H ratios of all records obtained from arrays in class D (D1, D2, and D3) sites. Total of $676 \mathrm{~V} / \mathrm{H}$ ratios plotted in their corresponding depth bins:

0-7 ft (170 ratios), 7-50 ft (127 ratios), 50-100 ft (133 ratios), 100-150 ft (53 ratios), 150-200 ft (49 ratios), $200-300 \mathrm{ft}$ (66 ratios), and $>300 \mathrm{ft}$ (78 ratios). The thick black lines correspond to the averages for each bin. 

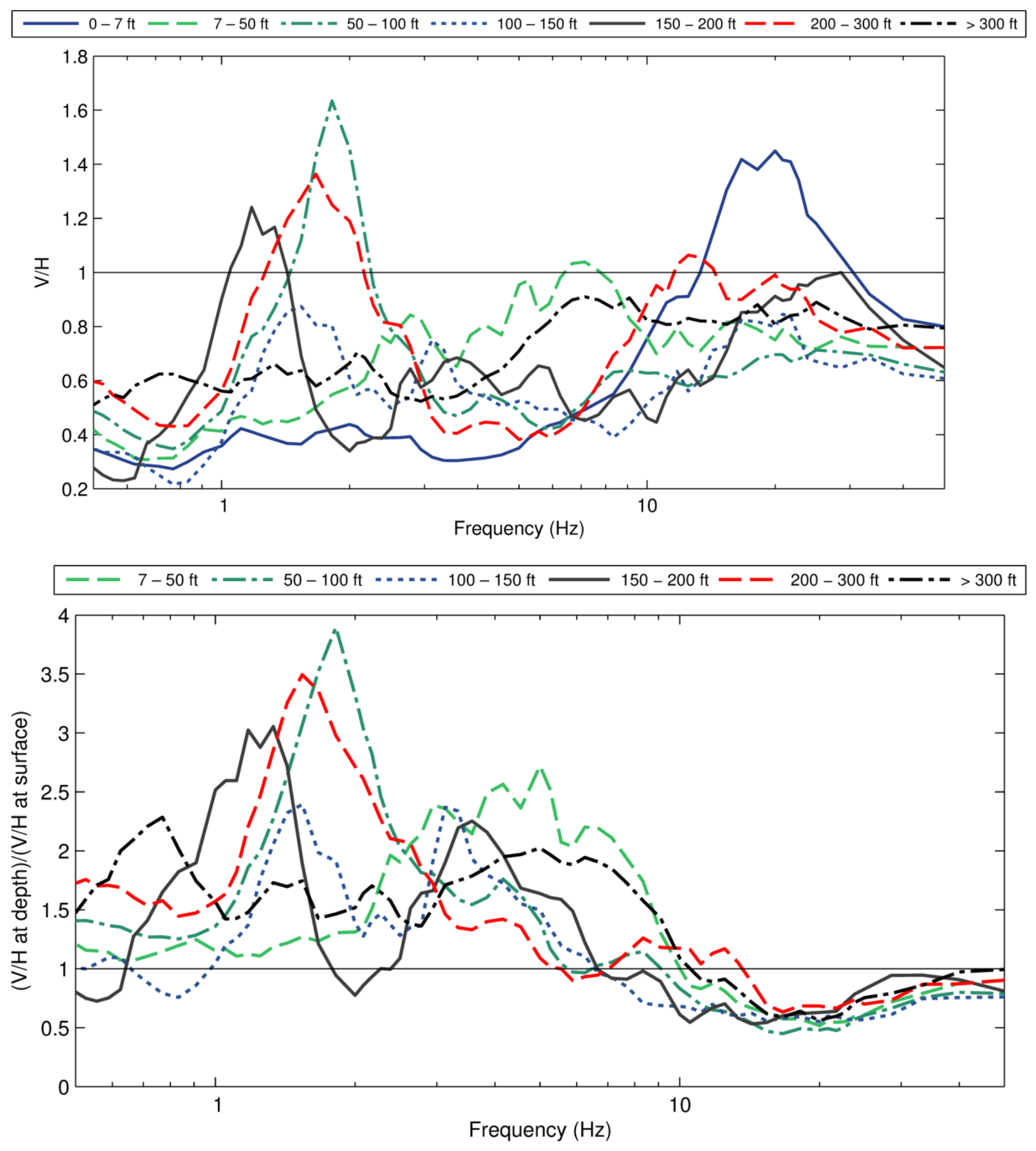

Figure $16 \mathrm{~V} / \mathrm{H}$ ratios of all records obtained from arrays in class $\mathrm{E}$ sites. Average V/H ratios (top) and normalized average $\mathrm{V} / \mathrm{H}$ ratios (bottom) for each of the seven depth bins:

0-7 ft (17 ratios), 7-50 ft (5 ratios), 50-100 ft (17 ratios), 100-150 ft (6 ratios), 150-200 ft (2 ratios), $200-300 \mathrm{ft}$ (12 ratios), and $>300 \mathrm{ft}$ (6 ratios). 

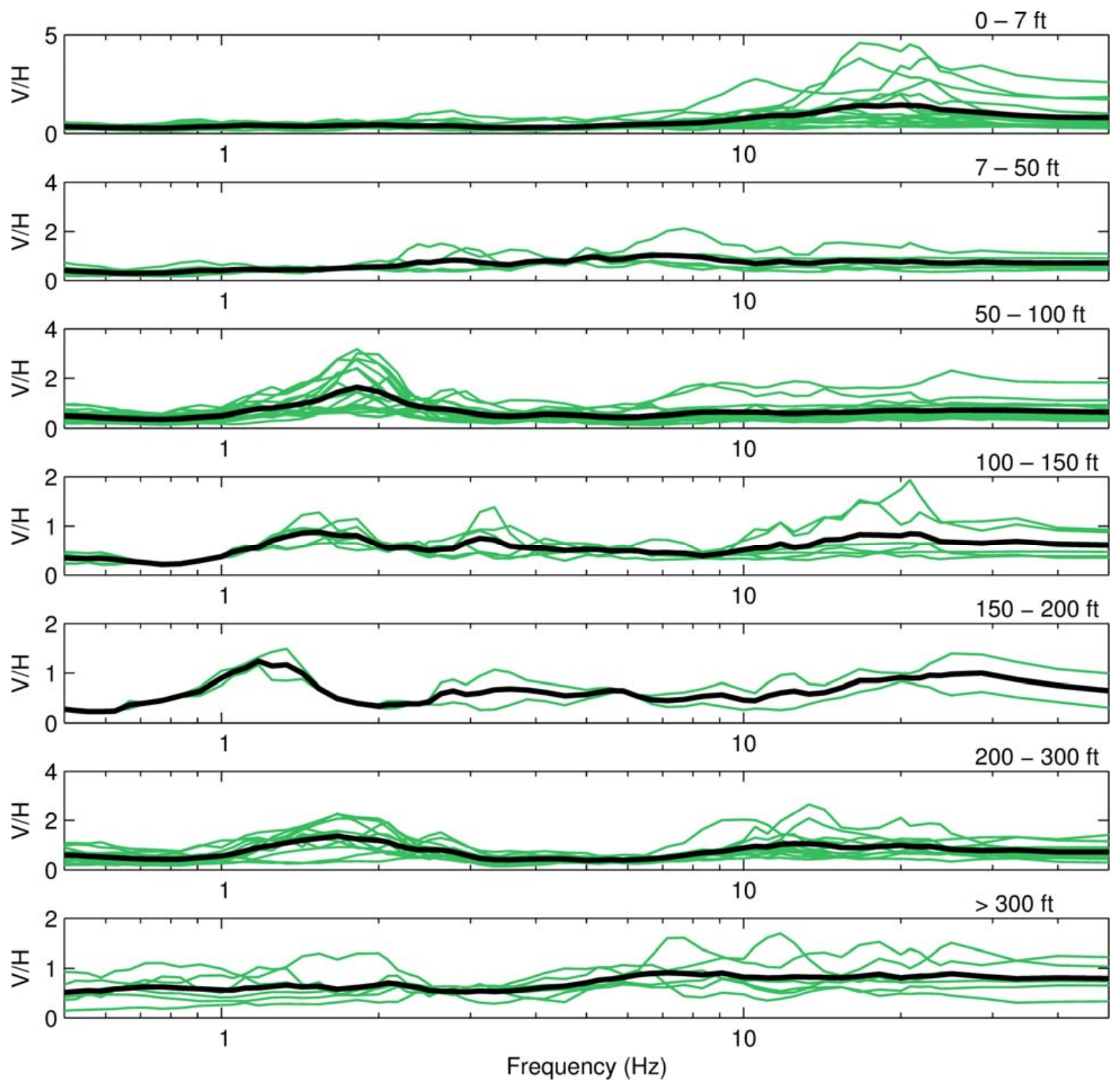

Figure $17 \mathrm{~V} / \mathrm{H}$ ratios of all records obtained from arrays in class E sites. Total of $65 \mathrm{~V} / \mathrm{H}$ ratios plotted in their corresponding depth bins:

0-7 ft (17 ratios), 7-50 ft (5 ratios), 50-100 ft (17 ratios), 100-150 ft (6 ratios), 150-200 ft (2 ratios), $200-300 \mathrm{ft}$ (12 ratios), and $>300 \mathrm{ft}$ (6 ratios). The thick black lines correspond to the averages for each bin. 

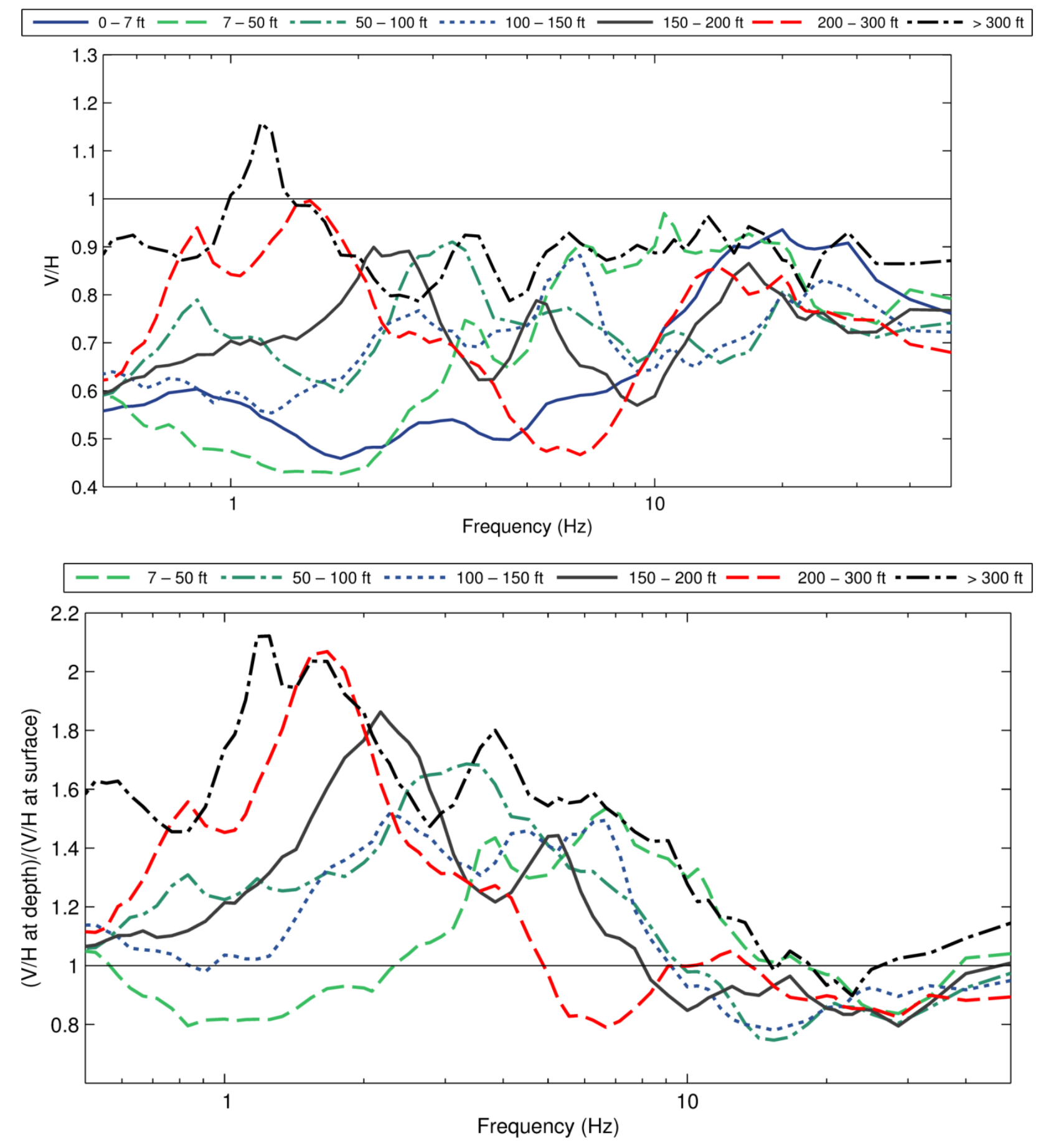

Figure $18 \mathrm{~V} / \mathrm{H}$ ratios of all records obtained from events with PGA in the range 0.01-0.10 g (from arrays in class B, C, and D1 sites only). Average V/H ratios (top) and normalized average $\mathrm{V} / \mathrm{H}$ ratios (bottom) for each of the seven depth bins:

0-7 ft (137 ratios), 7-50 ft (63 ratios), 50-100 ft (69 ratios), 100-150 ft (62 ratios), 150-200 ft (57 ratios), $200-300 \mathrm{ft}$ (50 ratios), and $>300 \mathrm{ft}$ (28 ratios). 

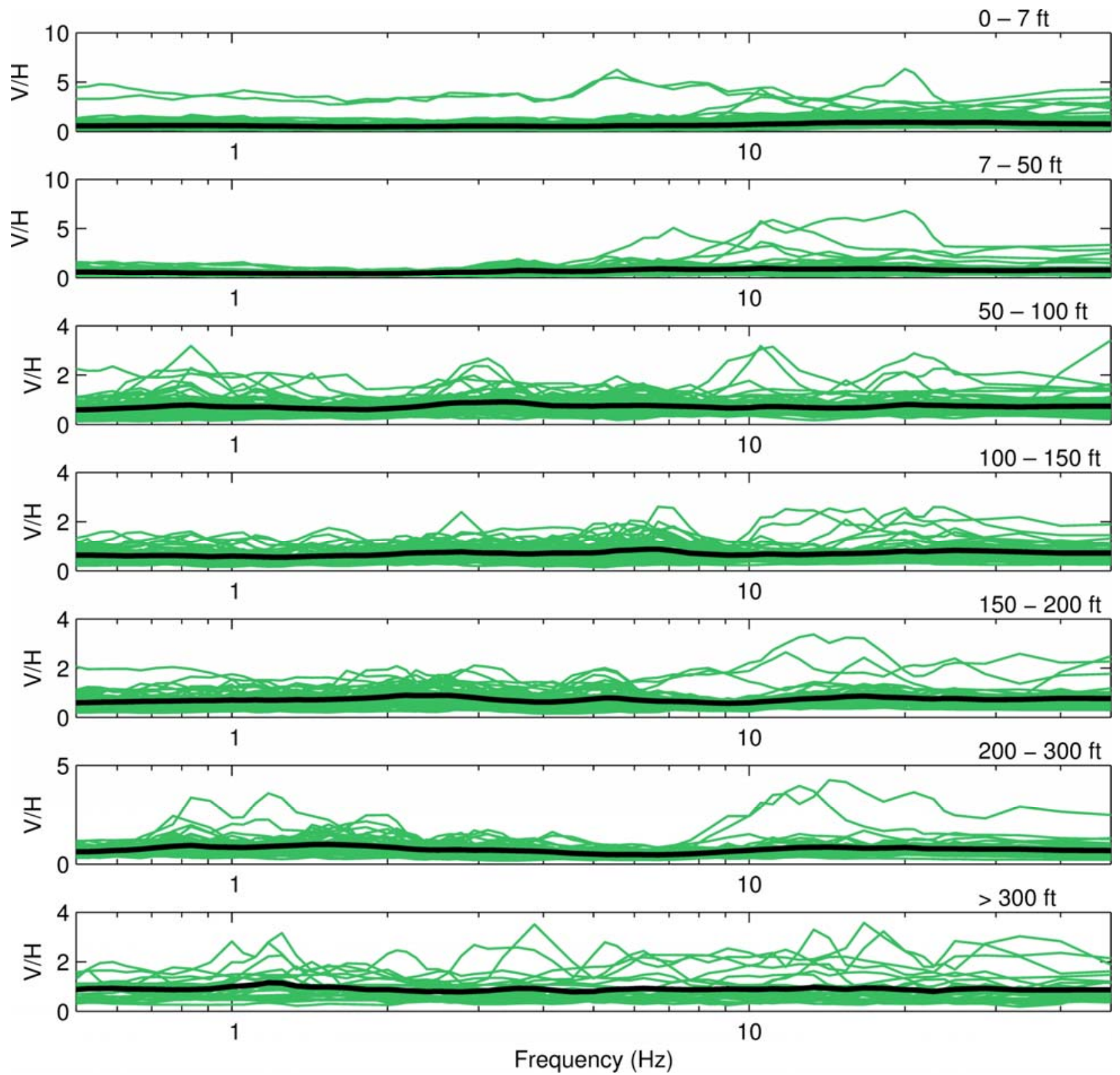

Figure $19 \mathrm{~V} / \mathrm{H}$ ratios of all records obtained from events with PGA in the range 0.01$0.10 \mathrm{~g}$ (from arrays in class B, C, and D1 sites only). Total of $466 \mathrm{~V} / \mathrm{H}$ ratios plotted in their corresponding depth bins:

0-7 ft (137 ratios), 7-50 ft (63 ratios), 50-100 ft (69 ratios), 100-150 ft (62 ratios), 150-200 ft (57 ratios), $200-300 \mathrm{ft}$ (50 ratios), and $>300 \mathrm{ft}$ (28 ratios). The thick black lines correspond to the averages for each bin. 

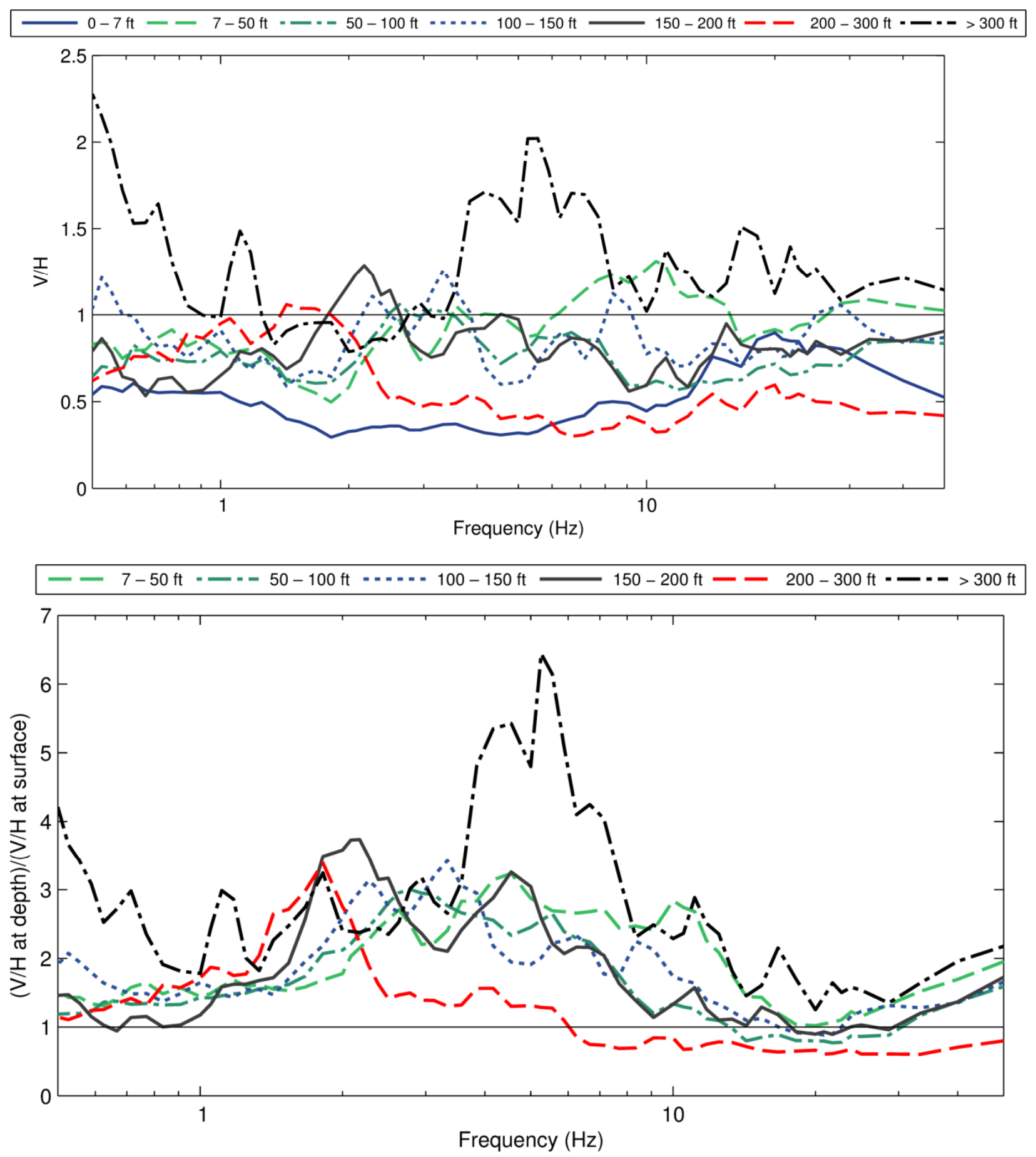

Figure $20 \mathrm{~V} / \mathrm{H}$ ratios of all records obtained from events with PGA in the range 0.10$0.20 \mathrm{~g}$ (from arrays in class B, C, and D1 sites only). Average V/H ratios (top) and normalized average $\mathrm{V} / \mathrm{H}$ ratios (bottom) for each of the seven depth bins:

0-7 ft (9 ratios), 7-50 ft (4 ratios), 50-100 ft (6 ratios), 100-150 ft (2 ratios), 150-200 ft (3 ratios), $200-300 \mathrm{ft}$ (4 ratios), and $>300 \mathrm{ft}$ ( 2 ratios). 

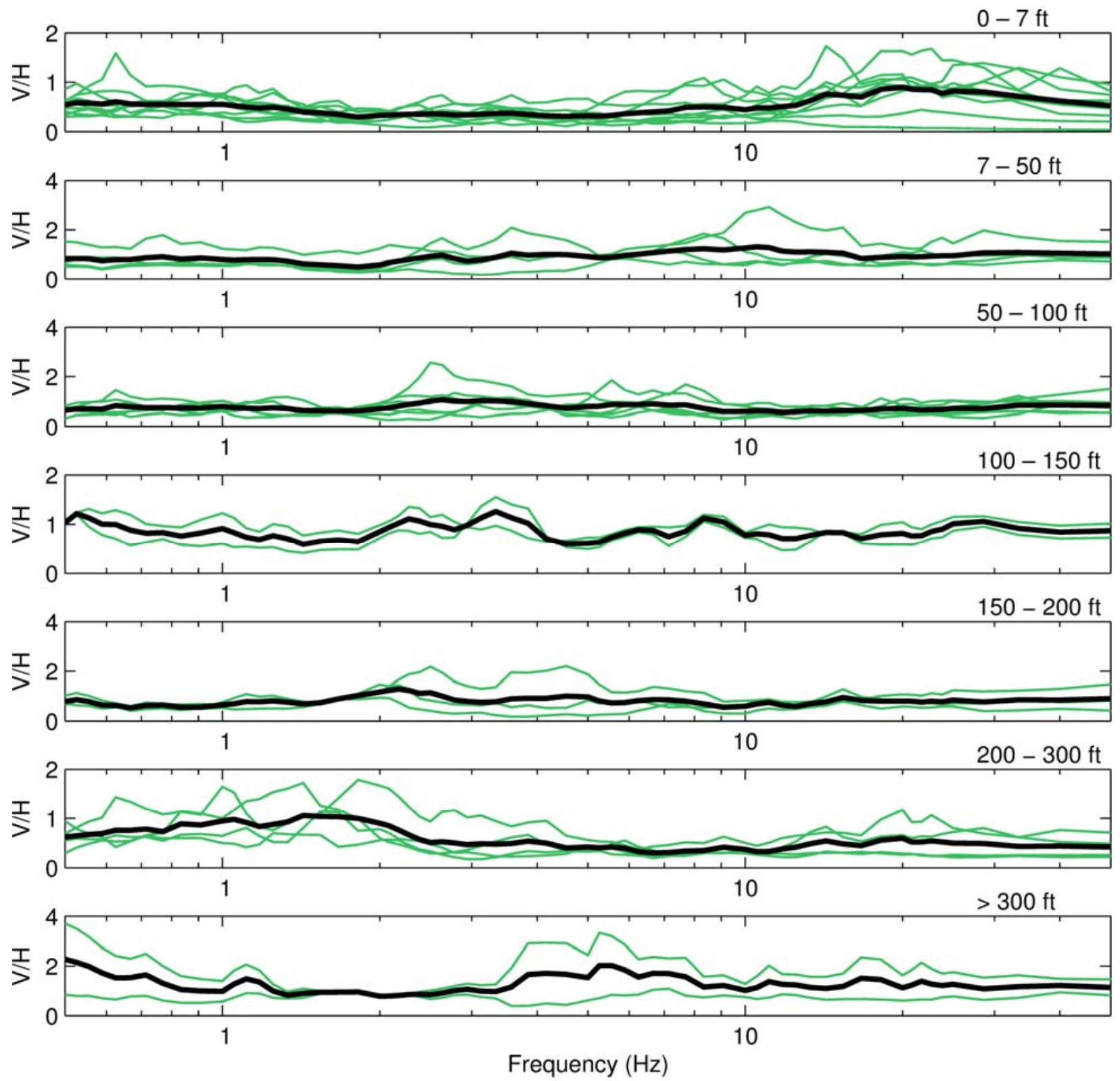

Figure 21 V/H ratios of all records obtained from events with PGA in the range 0.10$0.20 \mathrm{~g}$ (from arrays in class B, C, and D1 sites only). Total of $30 \mathrm{~V} / \mathrm{H}$ ratios plotted in their corresponding depth bins:

0-7 ft (9 ratios), 7-50 ft (4 ratios), 50-100 ft (6 ratios), 100-150 ft (2 ratios), 150-200 ft (3 ratios), 200-300 ft (4 ratios), and >300 ft (2 ratios). The thick black lines correspond to the averages for each bin. 

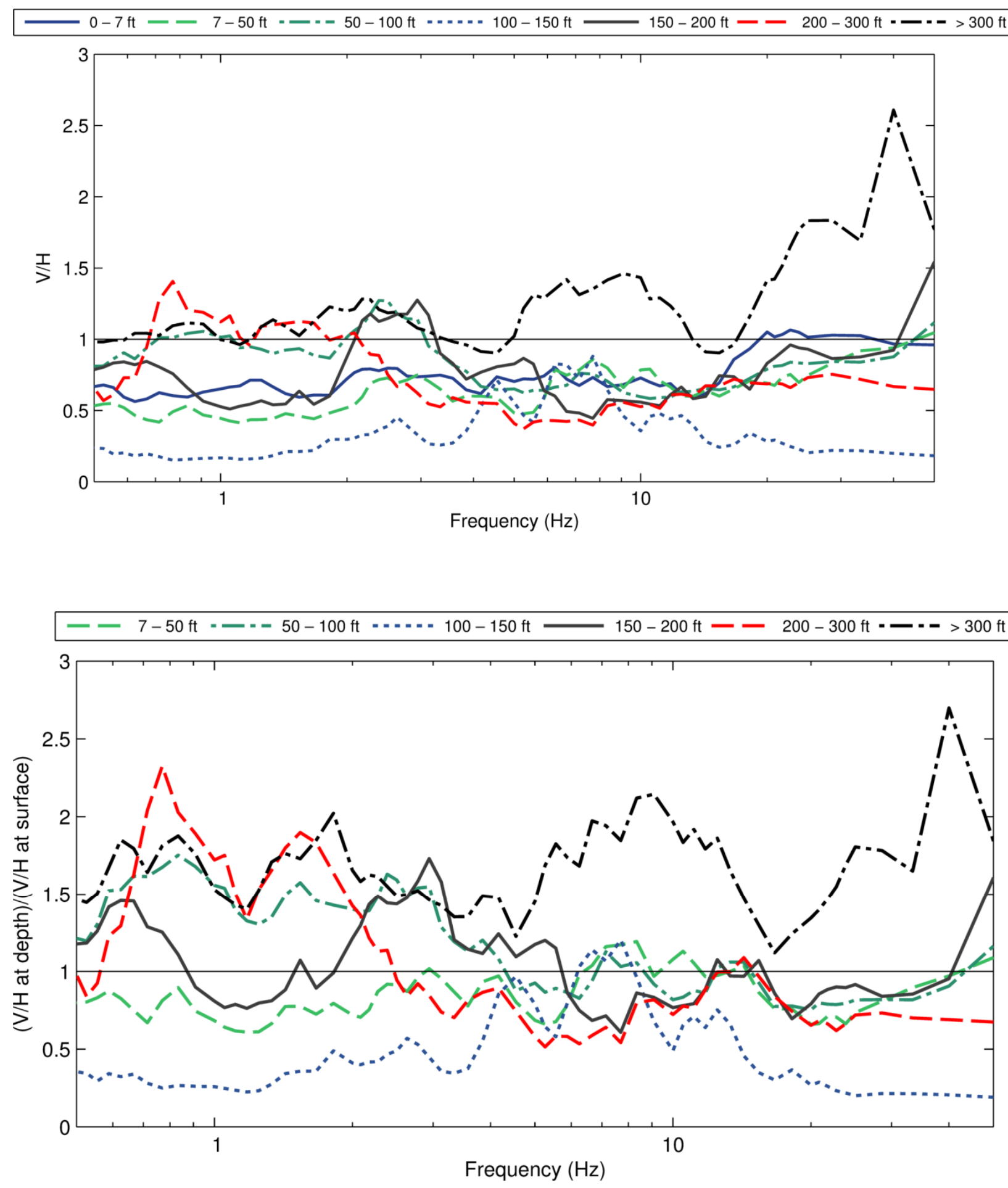

Figure $22 \mathrm{~V} / \mathrm{H}$ ratios of all records obtained from events with PGA in the range 0.20 $0.50 \mathrm{~g}$ (from arrays in class B, C, and D1 sites only). Average V/H ratios (top) and normalized average V/H ratios (bottom) for each of the seven depth bins:

0-7 ft (8 ratios), 7-50 ft (4 ratios), 50-100 ft (6 ratios), 100-150 ft (1 ratio), 150-200 ft (2 ratios), $200-300 \mathrm{ft}$ (3 ratios), and $>300 \mathrm{ft}$ (1 ratio). 

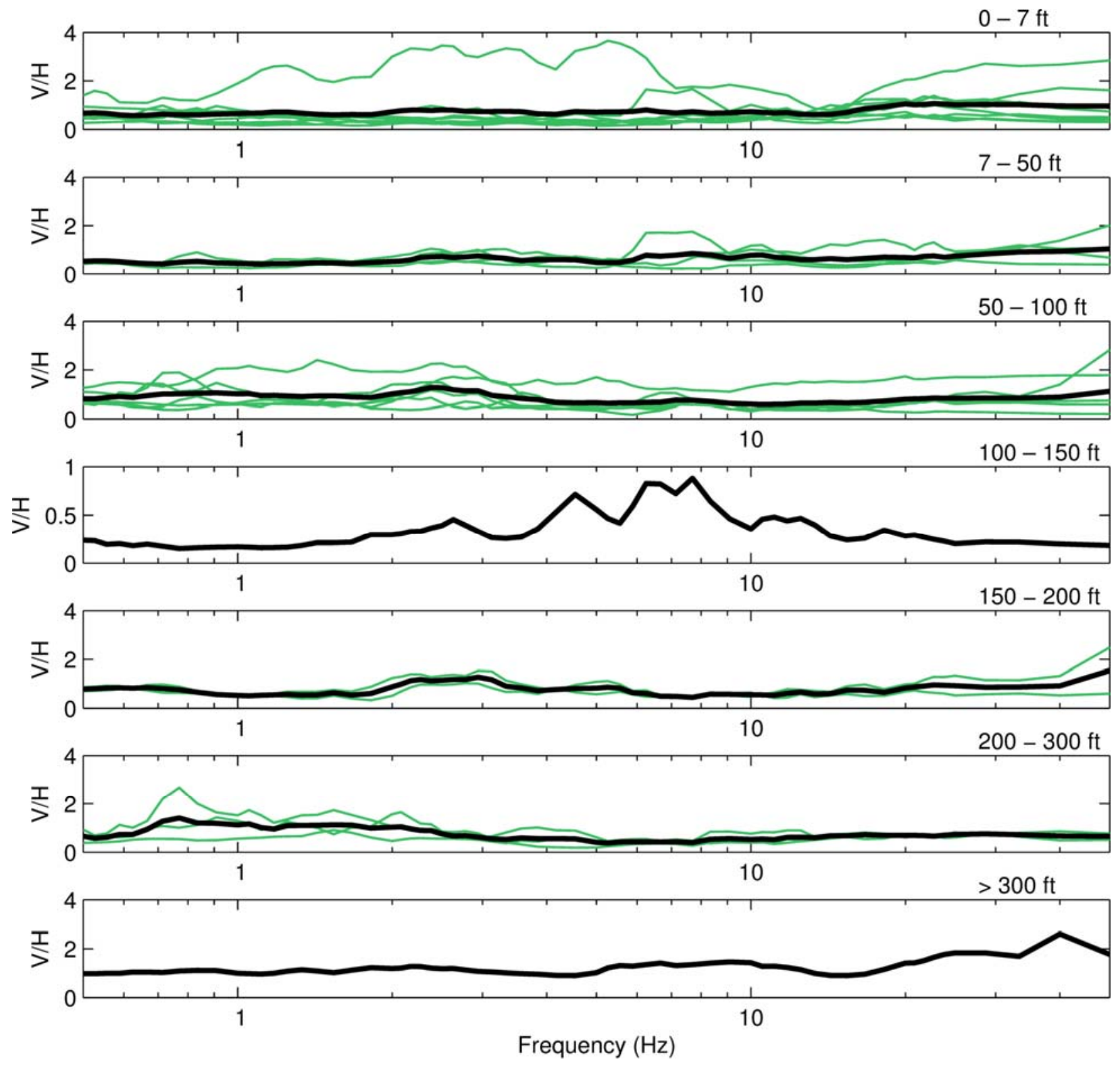

Figure $23 \mathrm{~V} / \mathrm{H}$ ratios of all records obtained from events with PGA in the range 0.20 $0.50 \mathrm{~g}$ (from arrays in class B, C, and D1 sites only). Total of $25 \mathrm{~V} / \mathrm{H}$ ratios plotted in their corresponding depth bins:

0-7 ft (8 ratios), 7-50 ft (4 ratios), 50-100 ft (6 ratios), 100-150 ft (1 ratio), 150-200 ft (2 ratios), 200-300 ft (3 ratios), and >300 ft (1 ratio). The thick black lines correspond to the averages for each bin. 

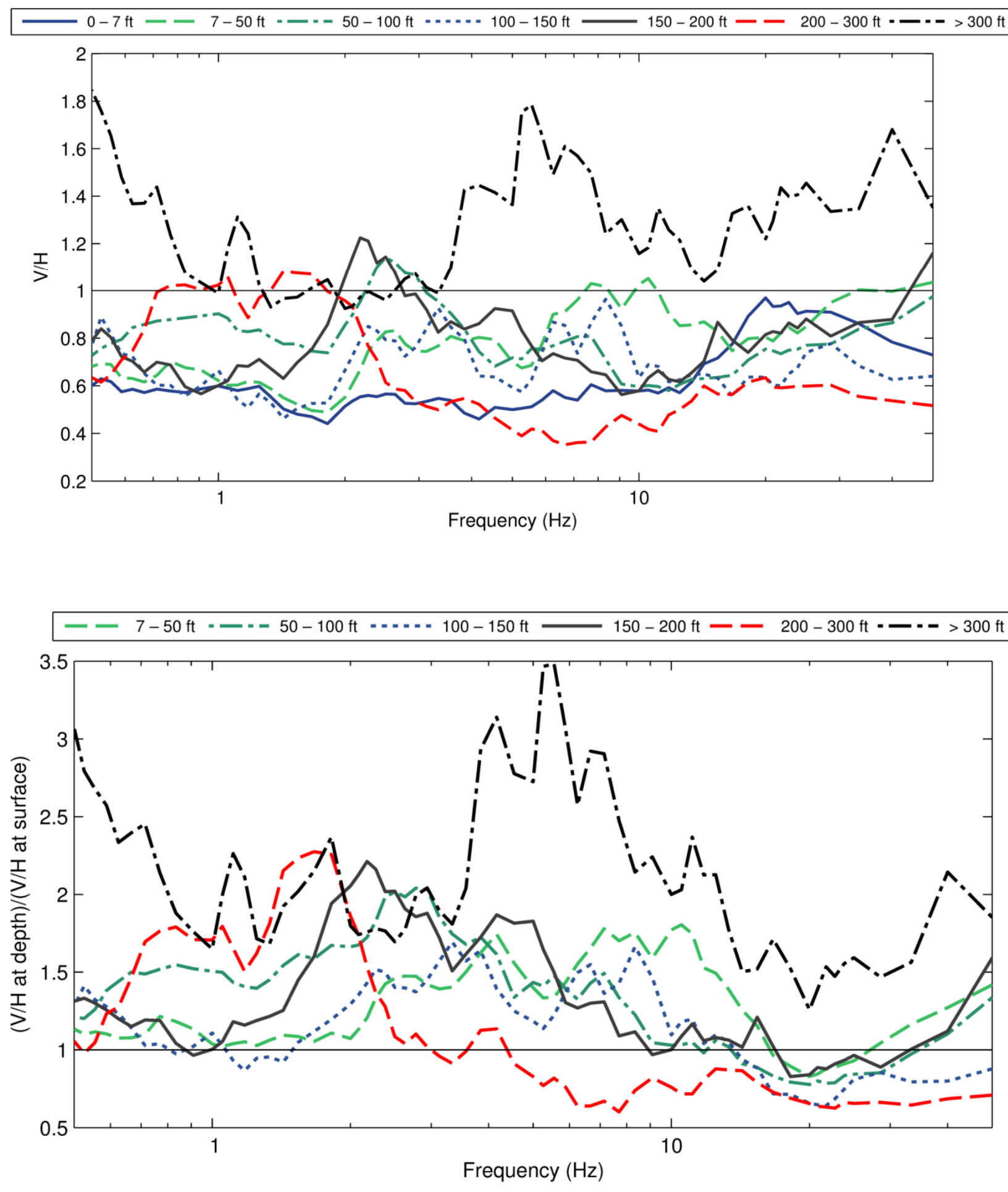

Figure $24 \mathrm{~V} / \mathrm{H}$ ratios of all records obtained from events with PGA in the range 0.10$0.50 \mathrm{~g}$ (from arrays in class B, C, and D1 sites only). Average V/H ratios (top) and normalized average V/H ratios (bottom) for each of the seven depth bins:

0-7 ft (17 ratios), 7-50 ft (8 ratios), 50-100 ft (12 ratios), 100-150 ft (3 ratios), 150-200 ft (5 ratios), $200-300 \mathrm{ft}$ (7 ratios), and $>300 \mathrm{ft}$ (3 ratios). 

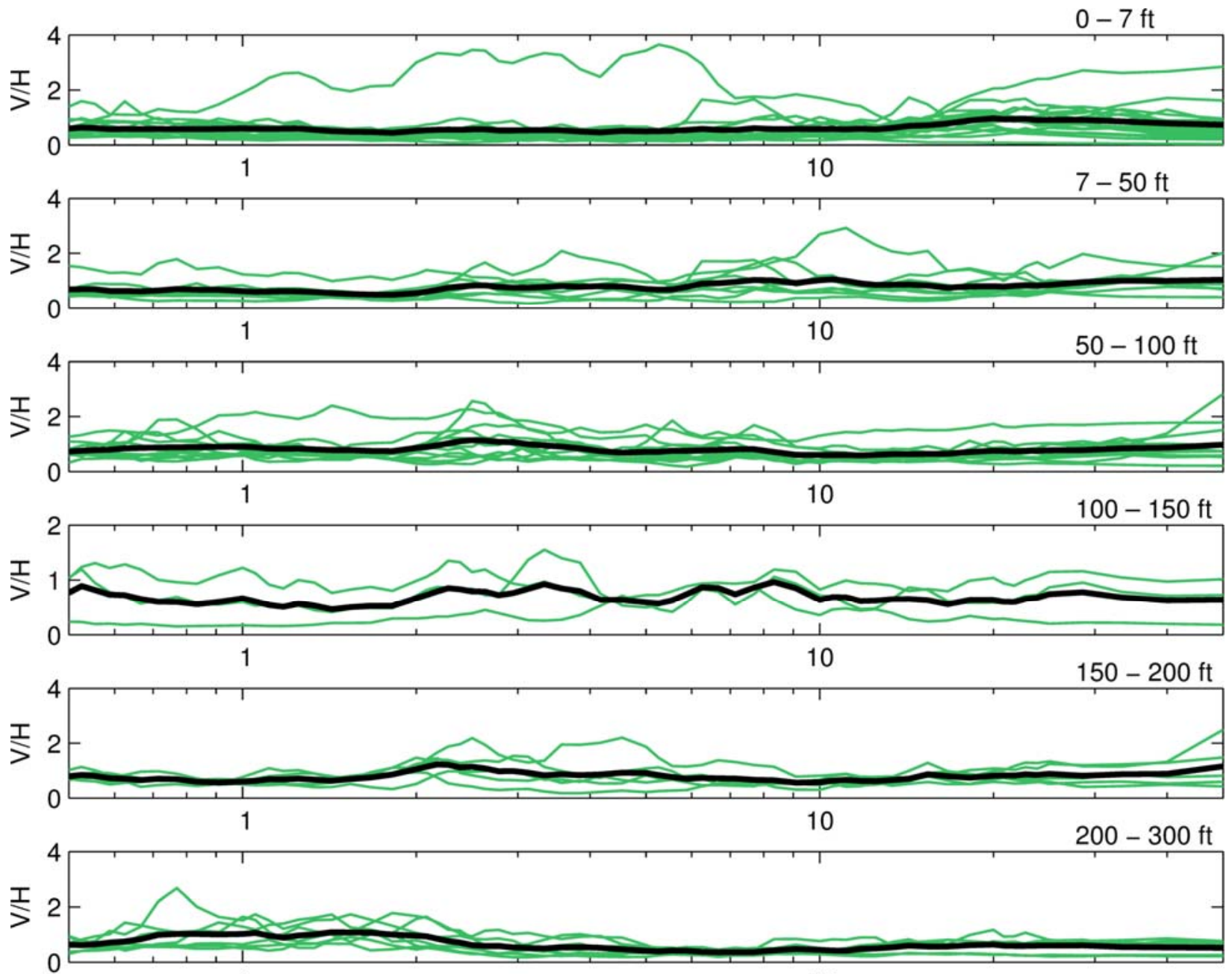

1210

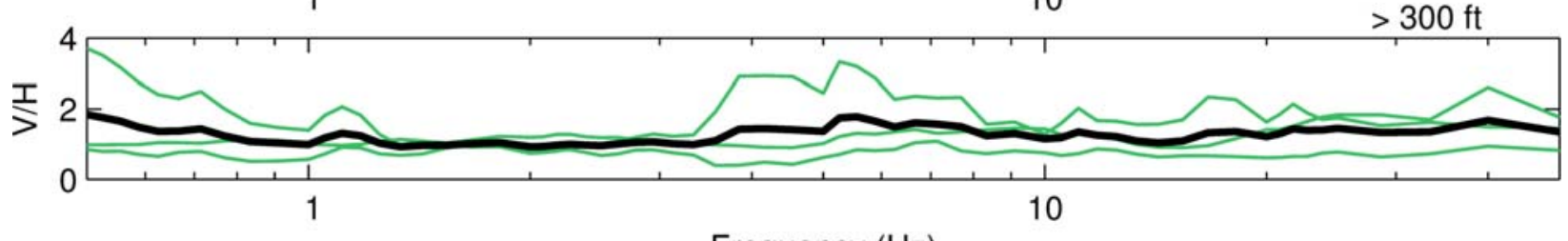

Frequency $(\mathrm{Hz})$

Figure $25 \mathrm{~V} / \mathrm{H}$ ratios of all records obtained from events with PGA in the range 0.10$0.50 \mathrm{~g}$ (from arrays in class B, C, and D1 sites only). Total of $55 \mathrm{~V} / \mathrm{H}$ ratios plotted in their corresponding depth bins:

0-7 ft (17 ratios), 7-50 ft (8 ratios), 50-100 ft (12 ratios), 100-150 ft (3 ratios), 150-200 ft (5 ratios), $200-300 \mathrm{ft}$ (7 ratios), and $>300 \mathrm{ft}$ (3 ratios). The thick black lines correspond to the averages for each bin. 

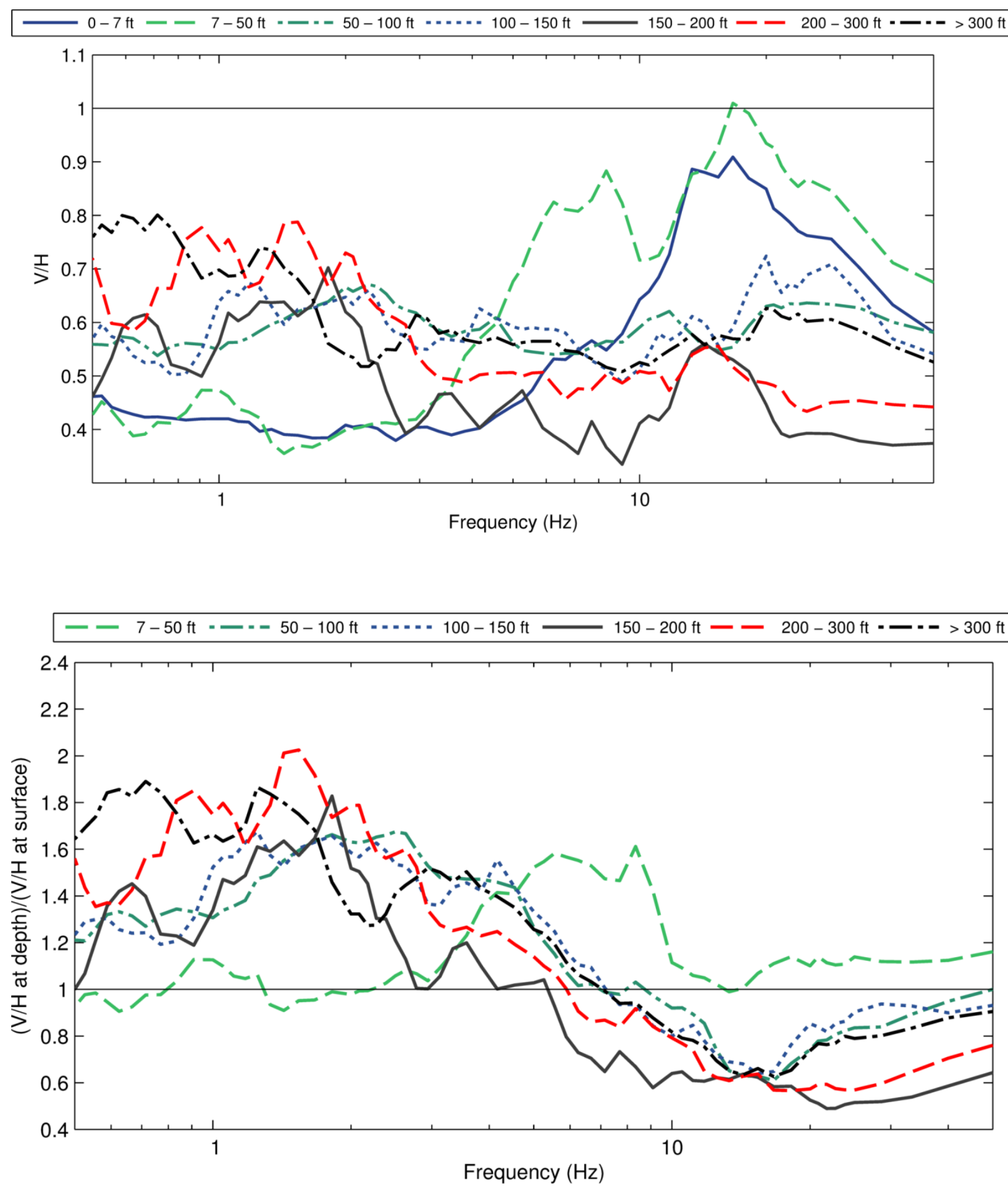

Figure $26 \mathrm{~V} / \mathrm{H}$ ratios of all records obtained from CGS-CESMD and USGS-NSMP sites in California (arrays in class B, C, and D sites only). Average V/H ratios (top) and normalized average $\mathrm{V} / \mathrm{H}$ ratios (bottom) for each of the seven depth bins:

0-7 ft (68 ratios), $7-50 \mathrm{ft}$ (28 ratios), 50-100 ft (48 ratios), 100-150 ft (31 ratios), 150-200 ft (7 ratios), 200-300 ft (9 ratios), and $>300 \mathrm{ft}$ (34 ratios). 


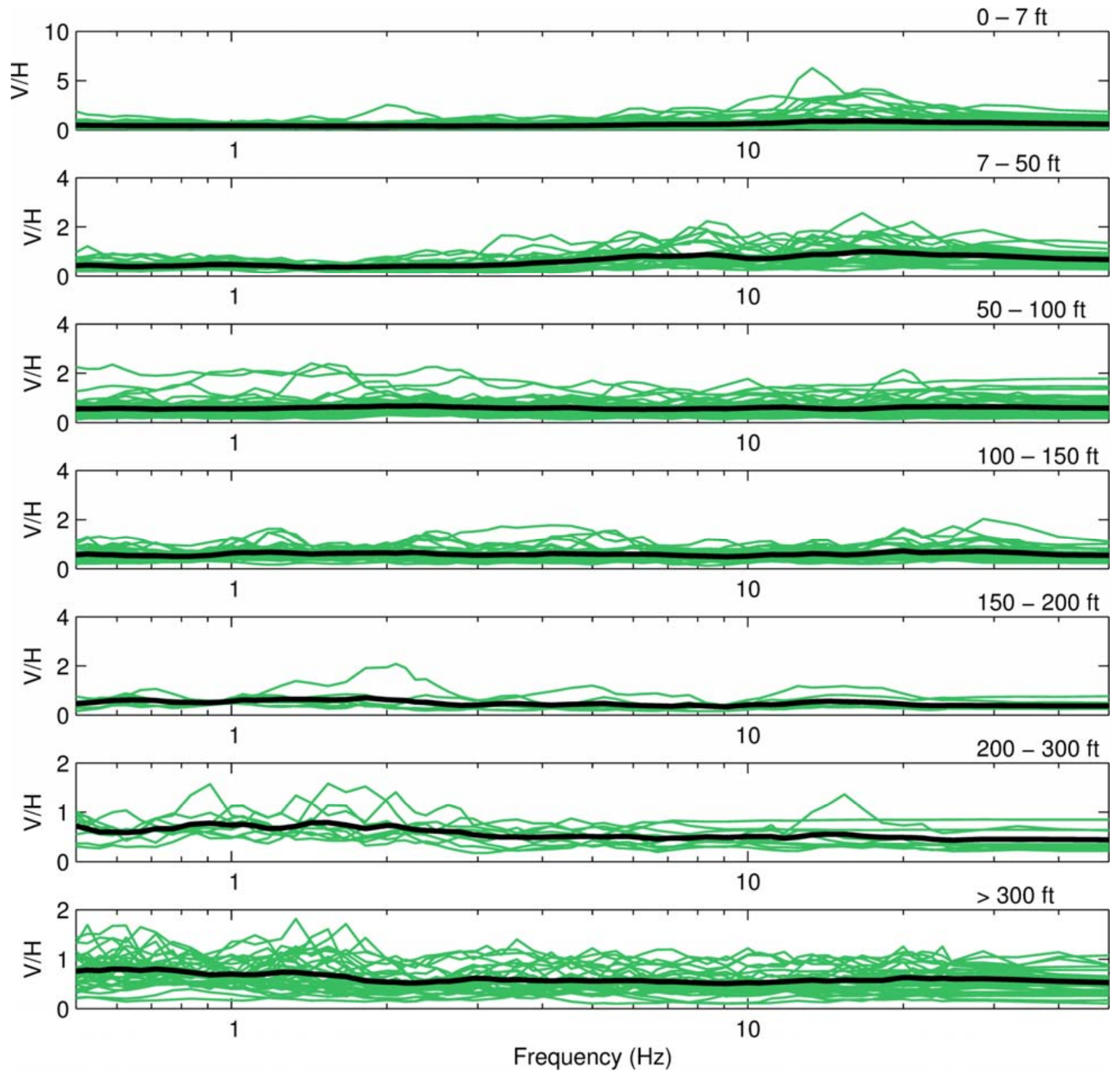

Figure $27 \mathrm{~V} / \mathrm{H}$ ratios of all records obtained from CGS-CESMD and USGS-NSMP sites in California (arrays in class B, C, and D sites only). Total of $225 \mathrm{~V} / \mathrm{H}$ ratios plotted in their corresponding depth bins:

0-7 ft (68 ratios), 7-50 ft (28 ratios), 50-100 ft (48 ratios), 100-150 ft (31 ratios), 150-200 ft (7 ratios), $200-300 \mathrm{ft}$ (9 ratios), and $>300 \mathrm{ft}$ (34 ratios). The thick black lines correspond to the averages for each bin. 

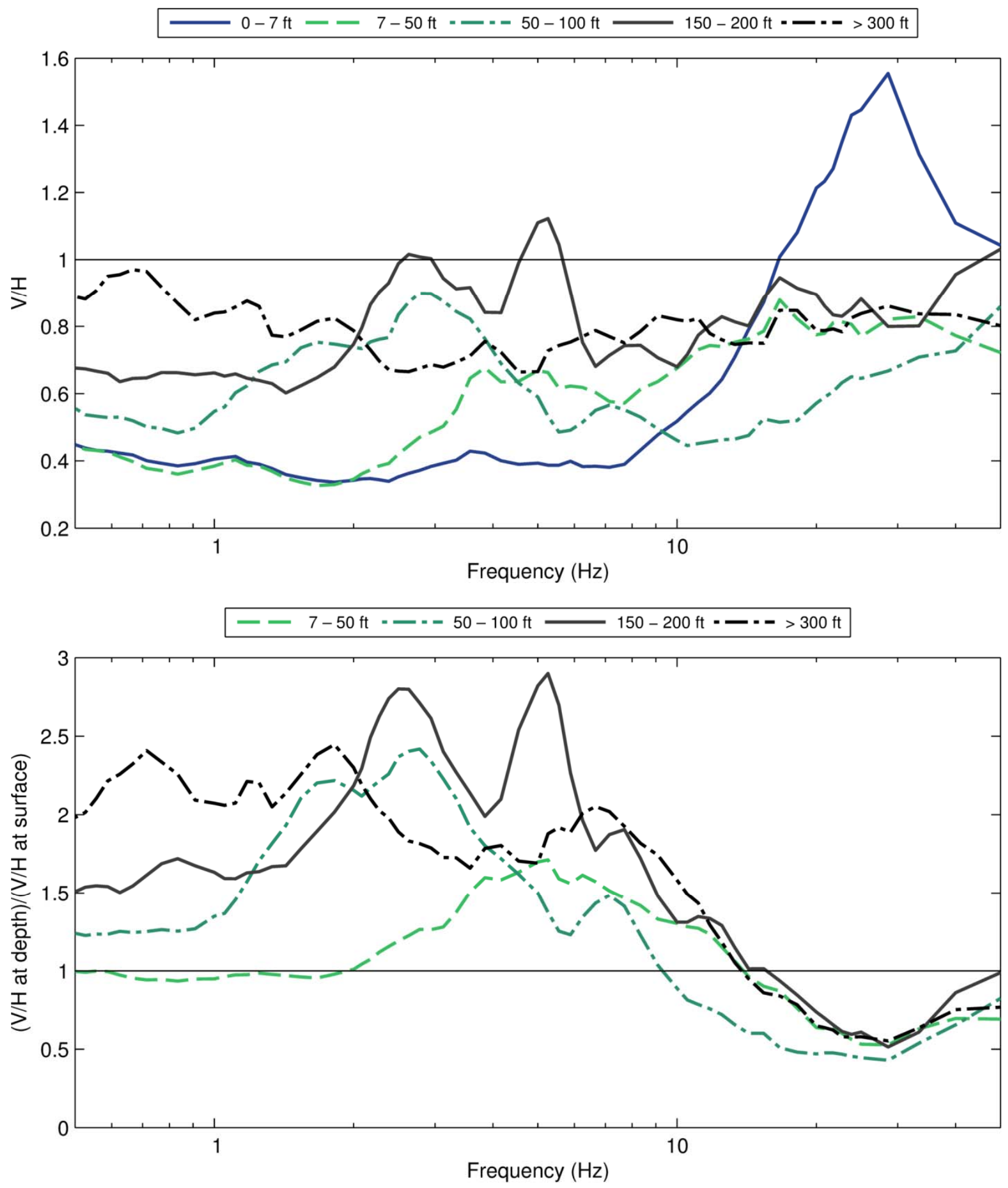

Figure $28 \mathrm{~V} / \mathrm{H}$ ratios of all records obtained from NEES at UCSB sites in California (arrays in class $\mathrm{C}$ and $\mathrm{D}$ sites only). Average $\mathrm{V} / \mathrm{H}$ ratios (top) and normalized average $\mathrm{V} / \mathrm{H}$ ratios (bottom) for each of the seven depth bins:

0-7 ft (43 ratios), 7-50 ft (86 ratios), 50-100 ft (34 ratios), 150-200 ft (23 ratios), and >300 ft (44 ratios). 

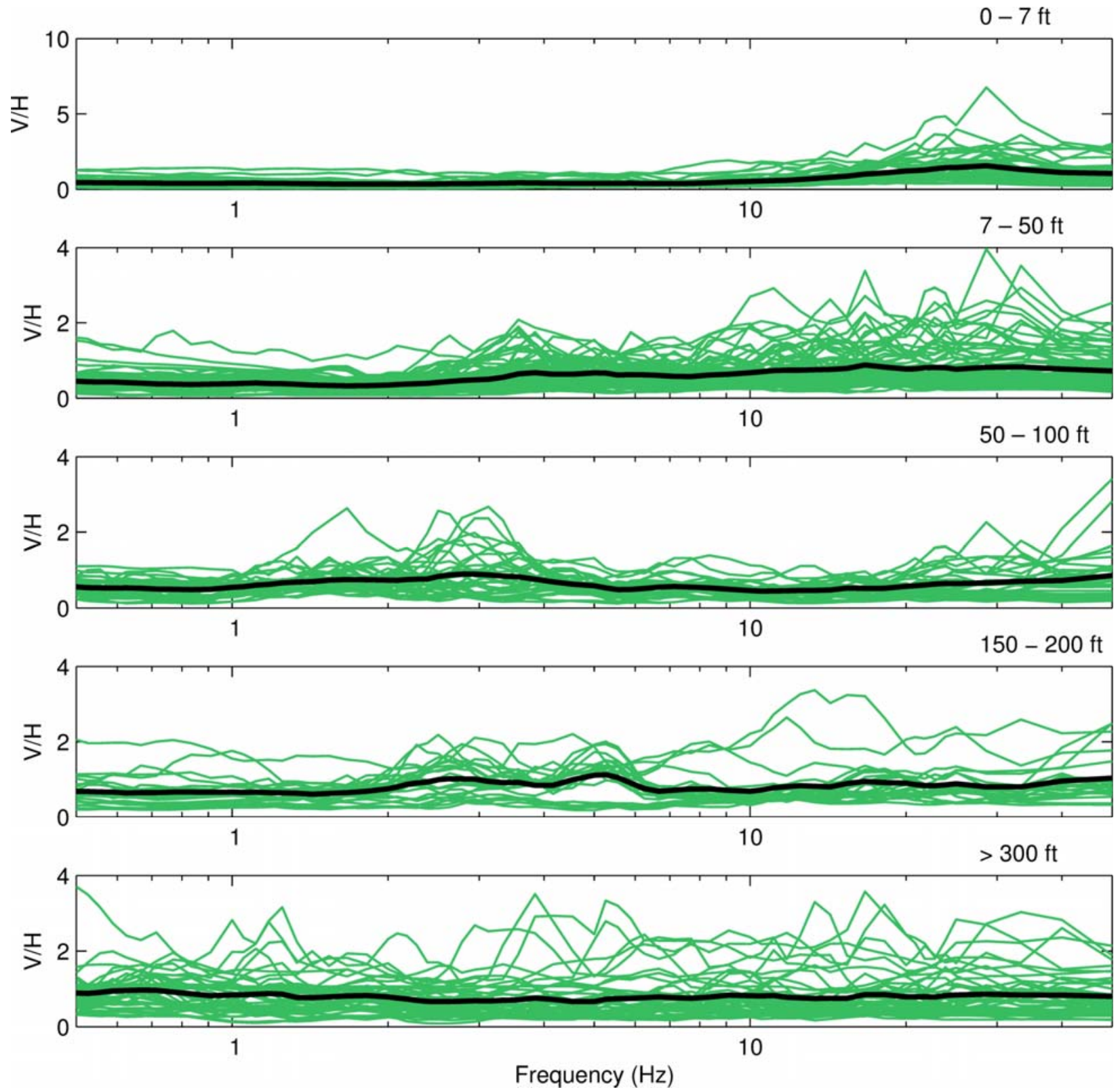

Figure $29 \mathrm{~V} / \mathrm{H}$ ratios of all records obtained from NEES at UCSB sites in California (arrays in class C and D sites only). Total of $230 \mathrm{~V} / \mathrm{H}$ ratios plotted in their corresponding depth bins:

0-7 ft (43 ratios), 7-50 ft (86 ratios), 50-100 ft (34 ratios), 150-200 ft (23 ratios), and >300 ft (44 ratios). The thick black lines correspond to the averages for each bin. 

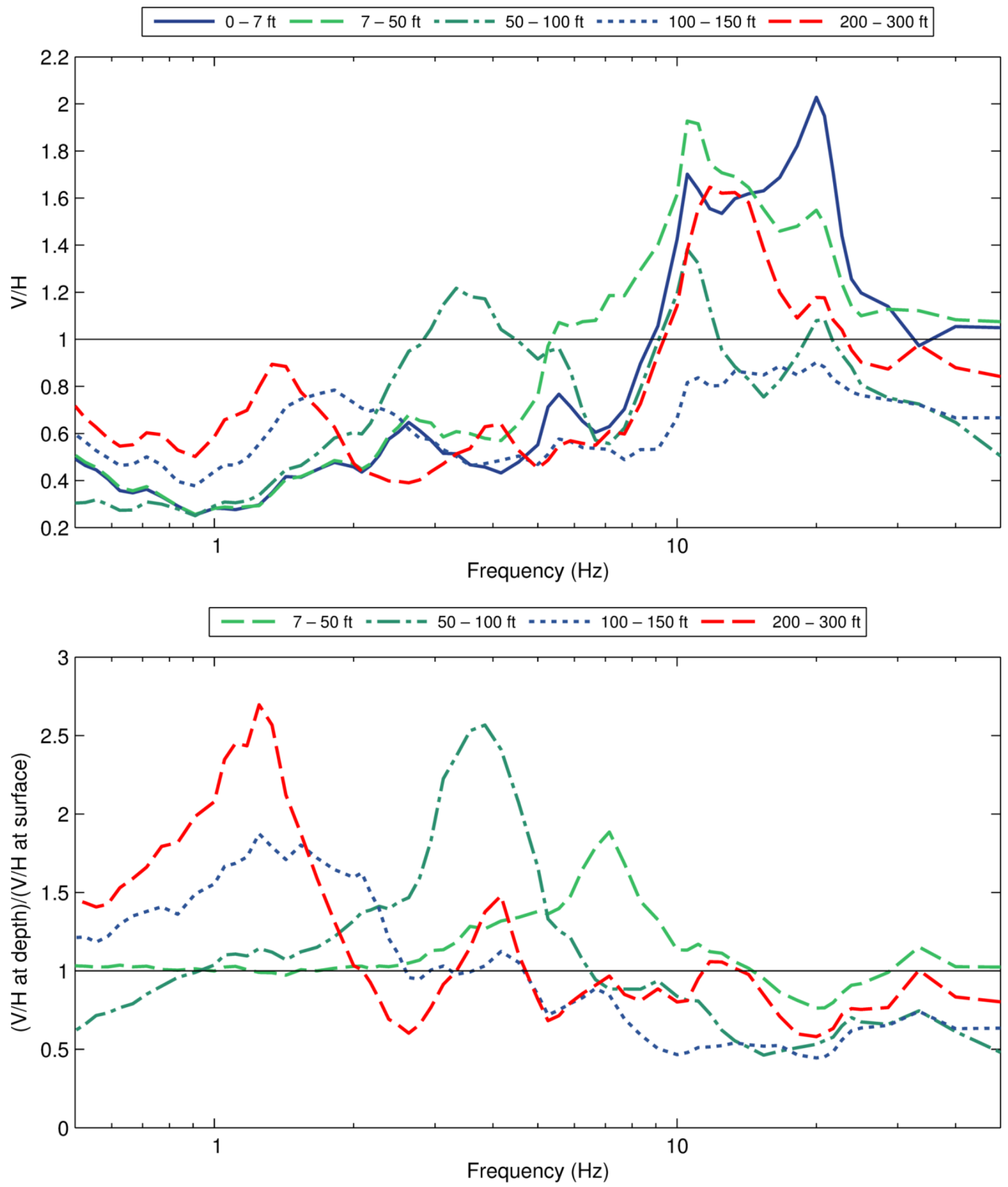

Figure $30 \mathrm{~V} / \mathrm{H}$ ratios of all records obtained from the NEES at UCSB site in Anchorage, Alaska (array in class D site). Average V/H ratios (top) and normalized average V/H ratios (bottom) for each of the seven depth bins:

0-7 ft (8 ratios), 7-50 ft (16 ratios), 50-100 ft (8 ratios), 100-150 ft (15 ratios), and 200-300 ft (8 ratios). 

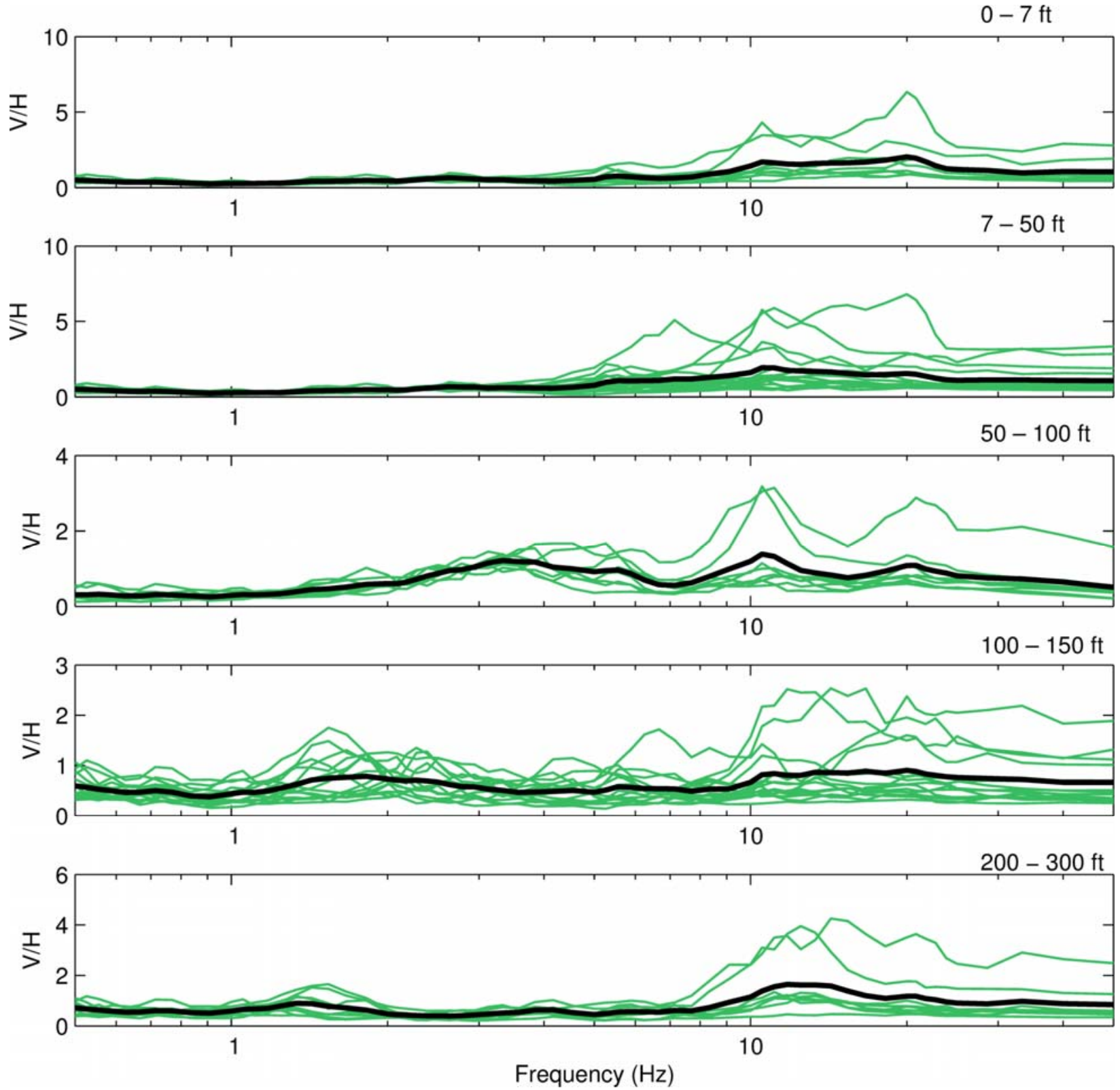

Figure $31 \mathrm{~V} / \mathrm{H}$ ratios of all records obtained from the NEES at UCSB site in Anchorage, Alaska (array in class D site). Total of $55 \mathrm{~V} / \mathrm{H}$ ratios plotted in their corresponding depth bins:

0-7 ft (8 ratios), 7-50 ft (16 ratios), 50-100 ft (8 ratios), 100-150 ft (15 ratios), and 200-300 ft (8 ratios). The thick black lines correspond to the averages for each bin. 

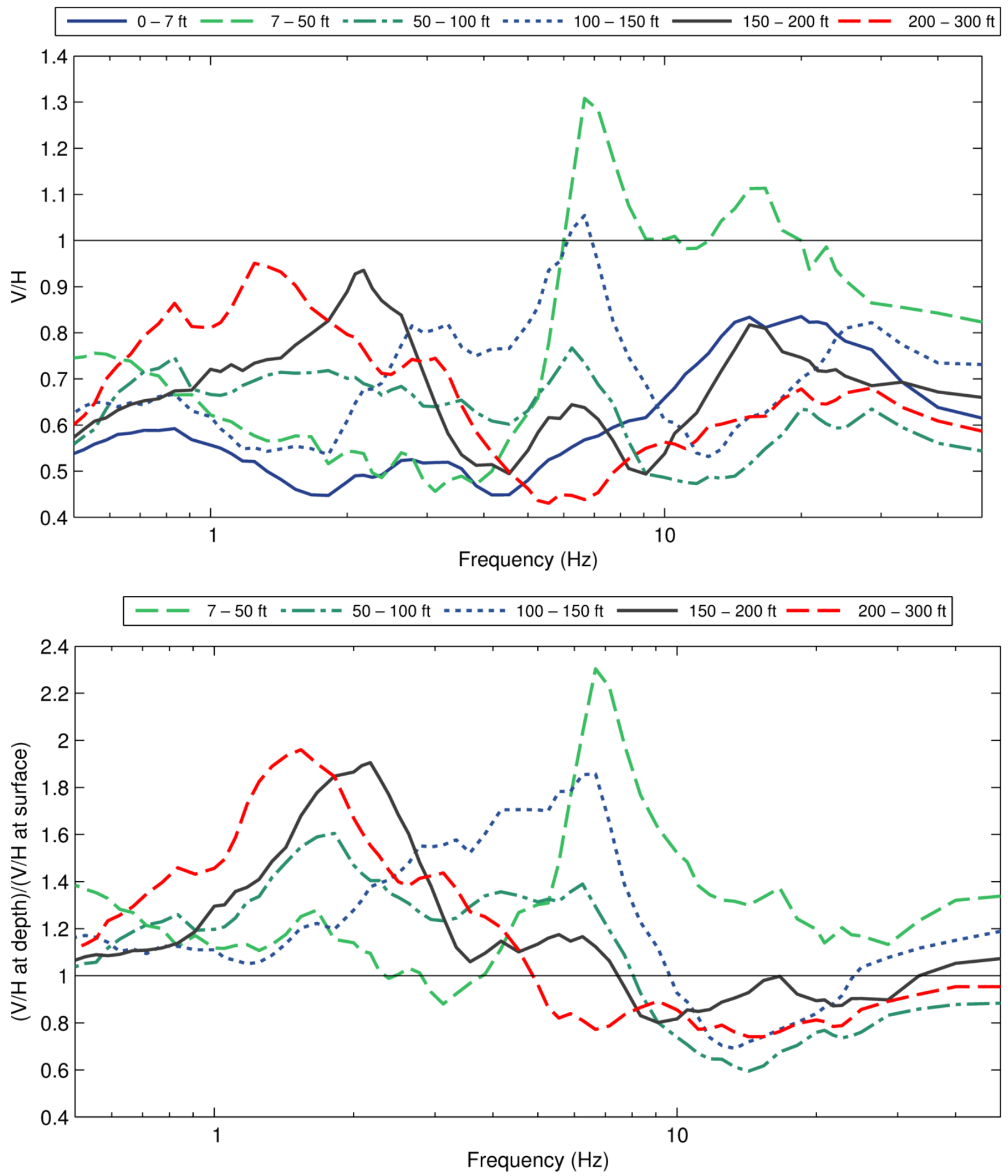

Figure $32 \mathrm{~V} / \mathrm{H}$ ratios of all records obtained from the Sendai District, Japan (arrays in class B, C, and D sites only). Average V/H ratios (top) and normalized average V/H ratios (bottom) for each of the seven depth bins:

0-7 ft (114 ratios), 7-50 ft (13 ratios), 50-100 ft (61 ratios), 100-150 ft (37 ratios), 150-200 ft (38 ratios), and $200-300 \mathrm{ft}$ (73 ratios). 

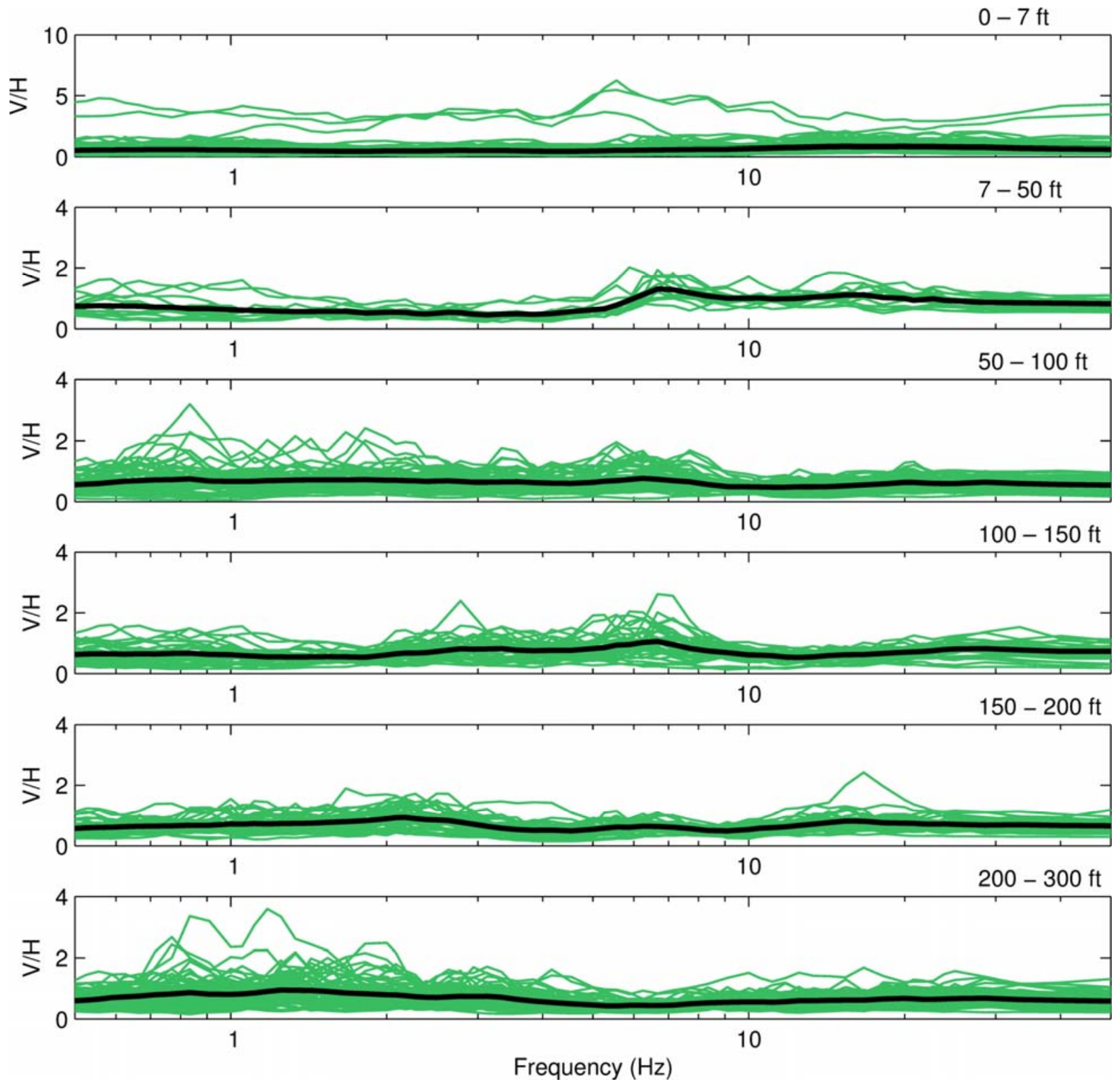

Figure $33 \mathrm{~V} / \mathrm{H}$ ratios of all records obtained from the Sendai District, Japan (arrays in class B, C, and D sites only). Total of $336 \mathrm{~V} / \mathrm{H}$ ratios plotted in their corresponding depth bins:

0-7 ft (114 ratios), 7-50 ft (13 ratios), 50-100 ft (61 ratios), 100-150 ft (37 ratios), 150-200 ft (38 ratios), and 200-300 ft (73 ratios). The thick black lines correspond to the averages for each bin. 

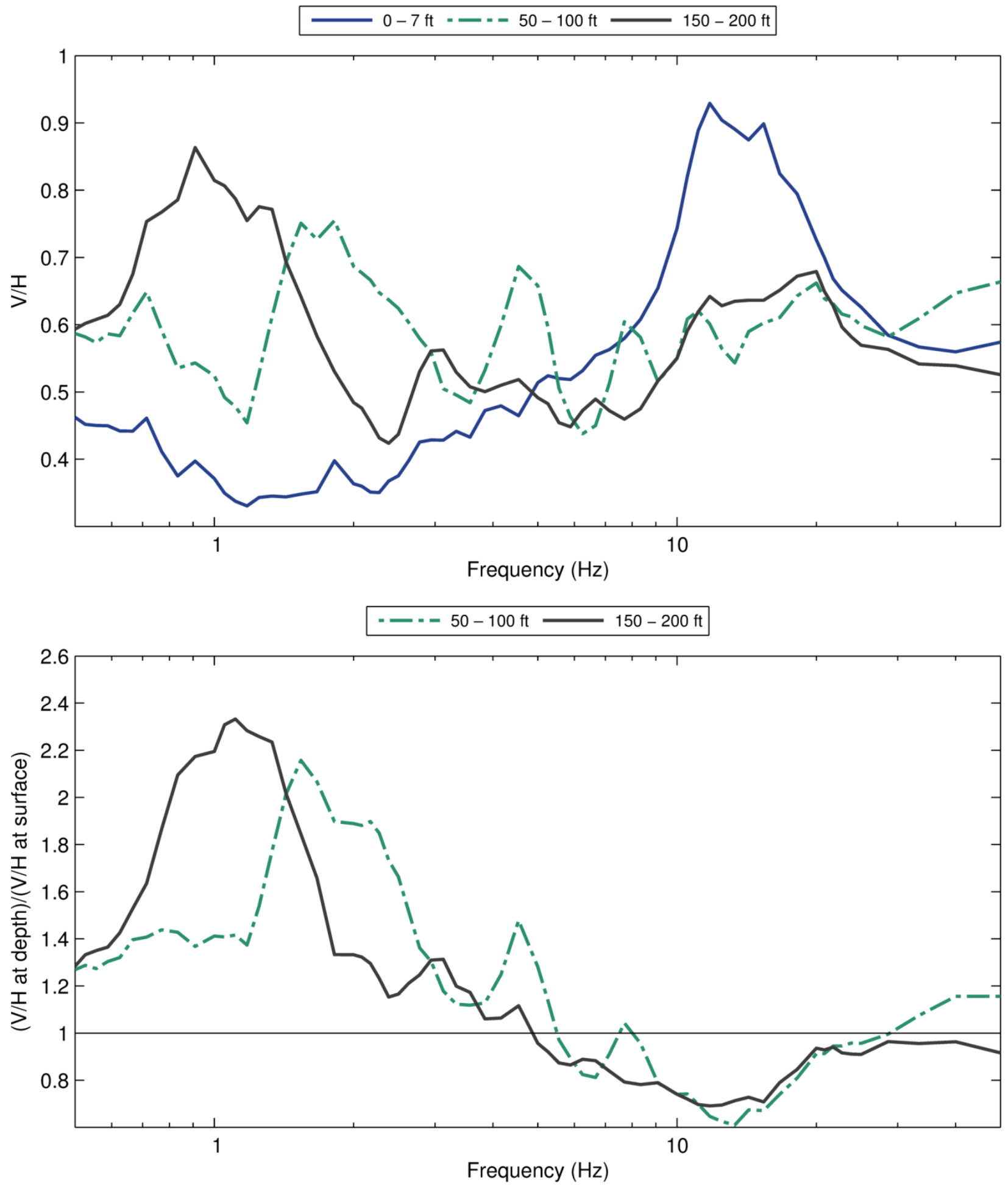

Figure $34 \mathrm{~V} / \mathrm{H}$ ratios of all records obtained from the Taipei Basin, Taiwan (arrays in class $\mathrm{D}$ sites only). Average $\mathrm{V} / \mathrm{H}$ ratios (top) and normalized average $\mathrm{V} / \mathrm{H}$ ratios (bottom) for each of the seven depth bins:

0-7 ft (20 ratios), 50-100 ft (15 ratios), and 150-200 ft (19 ratios). 
$0-7 \mathrm{ft}$

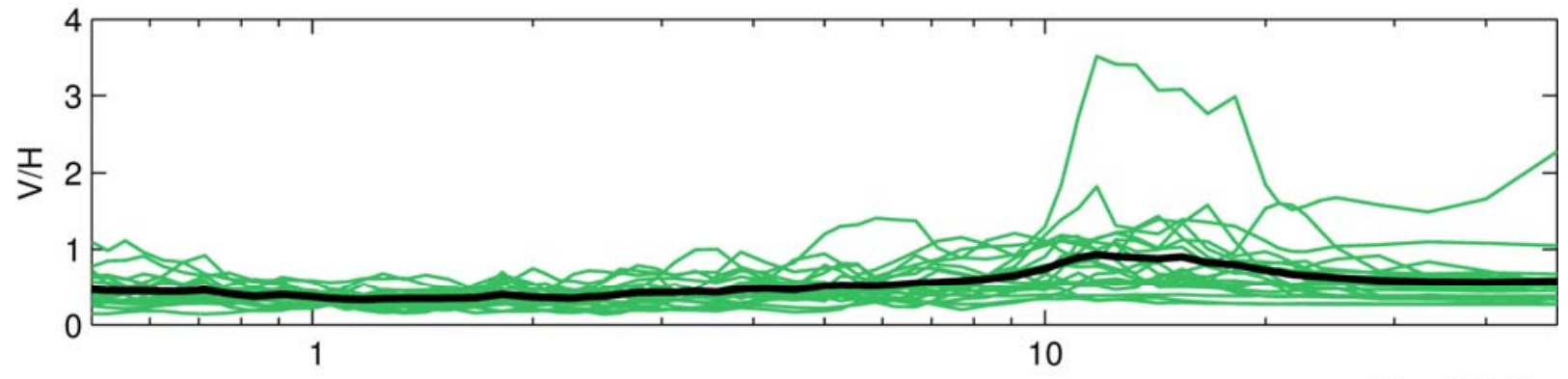

$50-100 \mathrm{ft}$
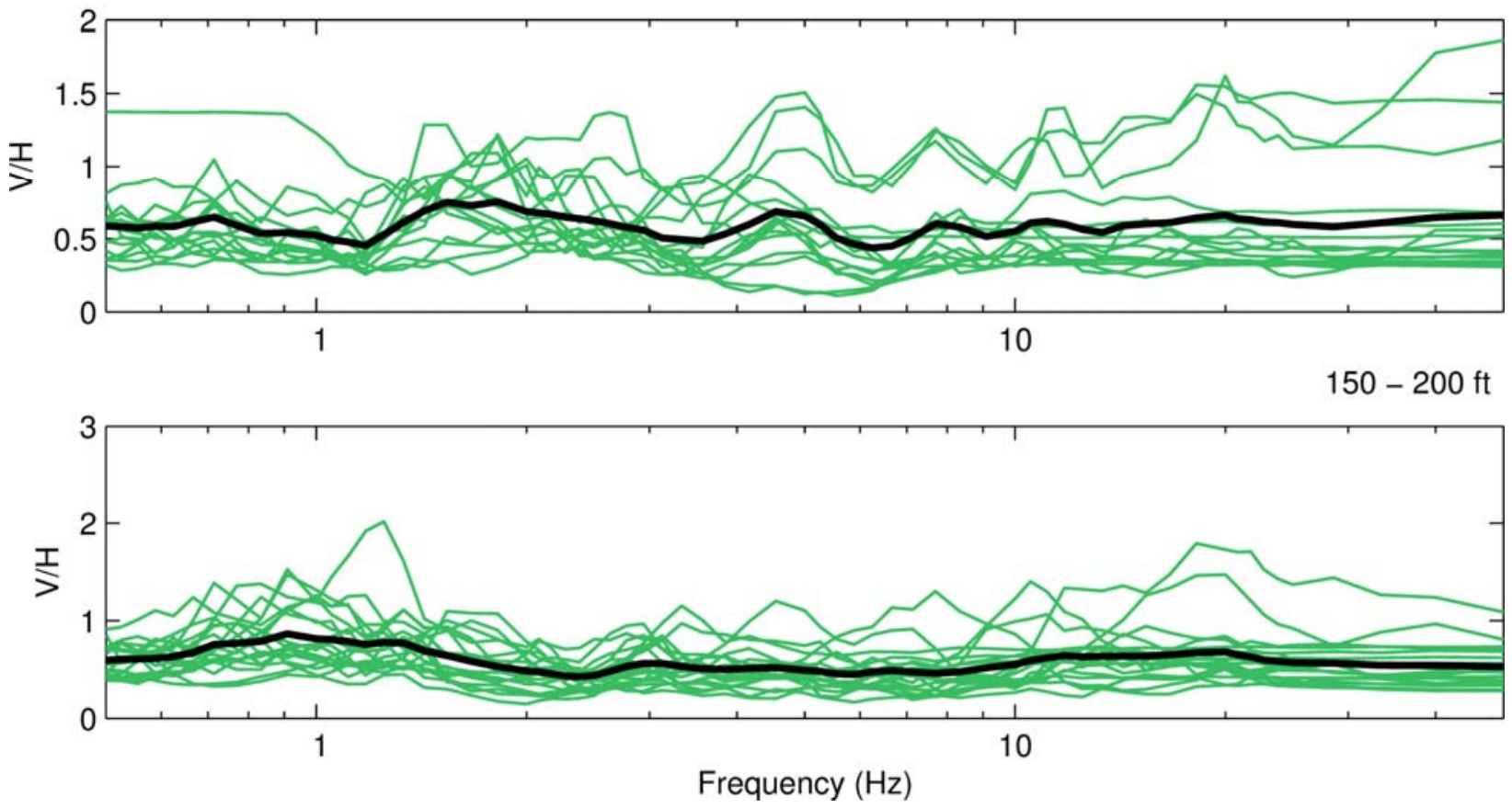

Figure $35 \mathrm{~V} / \mathrm{H}$ ratios of all records obtained from the Taipei Basin, Taiwan (arrays in class D sites only). Total of $54 \mathrm{~V} / \mathrm{H}$ ratios plotted in their corresponding depth bins:

0-7 ft (20 ratios), 50-100 ft (15 ratios), and 150-200 ft (19 ratios). The thick black lines correspond to the averages for each bin. 

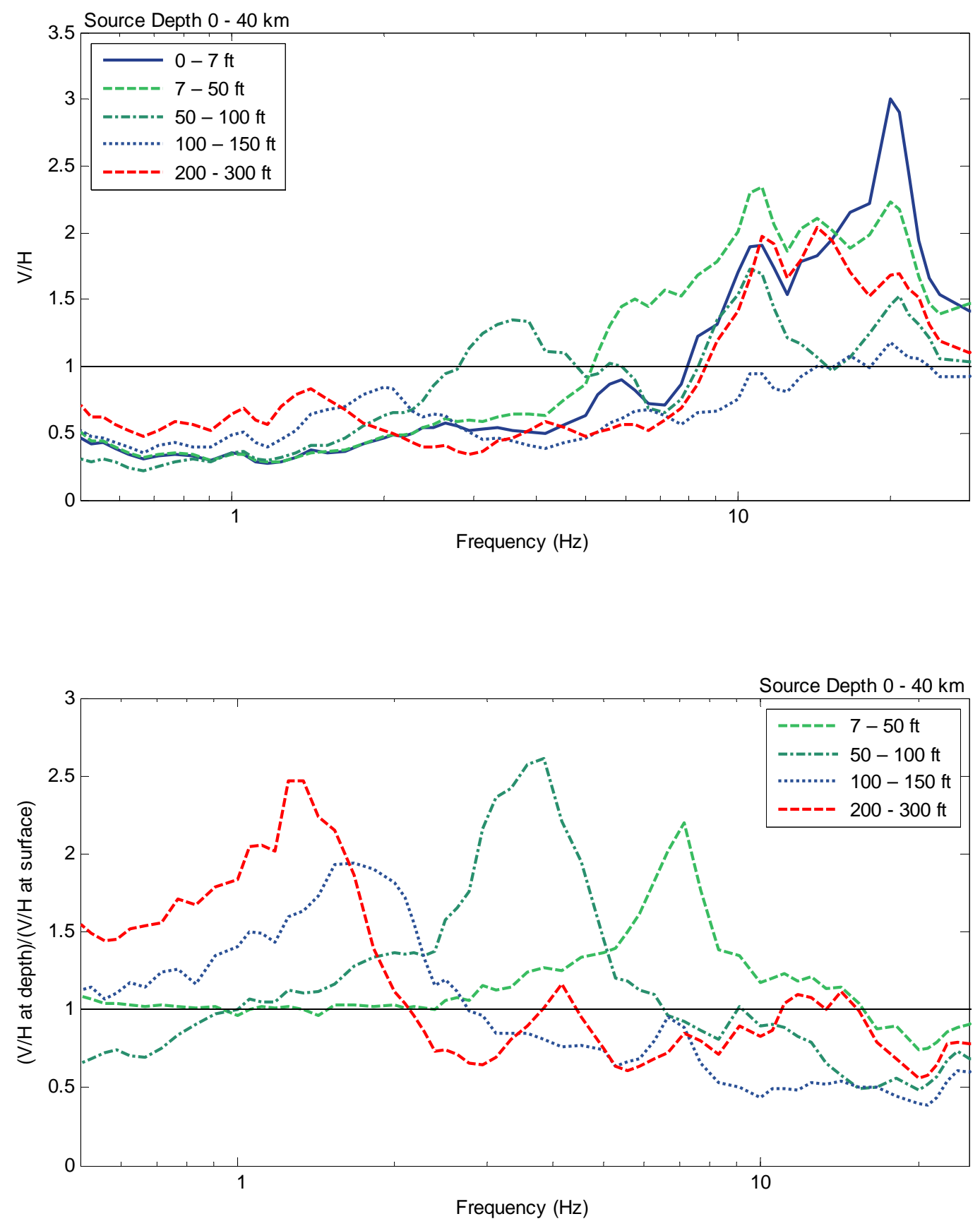

Figure $36 \mathrm{~V} / \mathrm{H}$ ratios of all records obtained from events with source depths between 0 $\mathrm{km}$ and $40 \mathrm{~km}$, from the NEES at UCSB site in Anchorage, Alaska (class D site)

Average $\mathrm{V} / \mathrm{H}$ ratios (top) and normalized average $\mathrm{V} / \mathrm{H}$ ratios (bottom) for each of the available depth bins. 

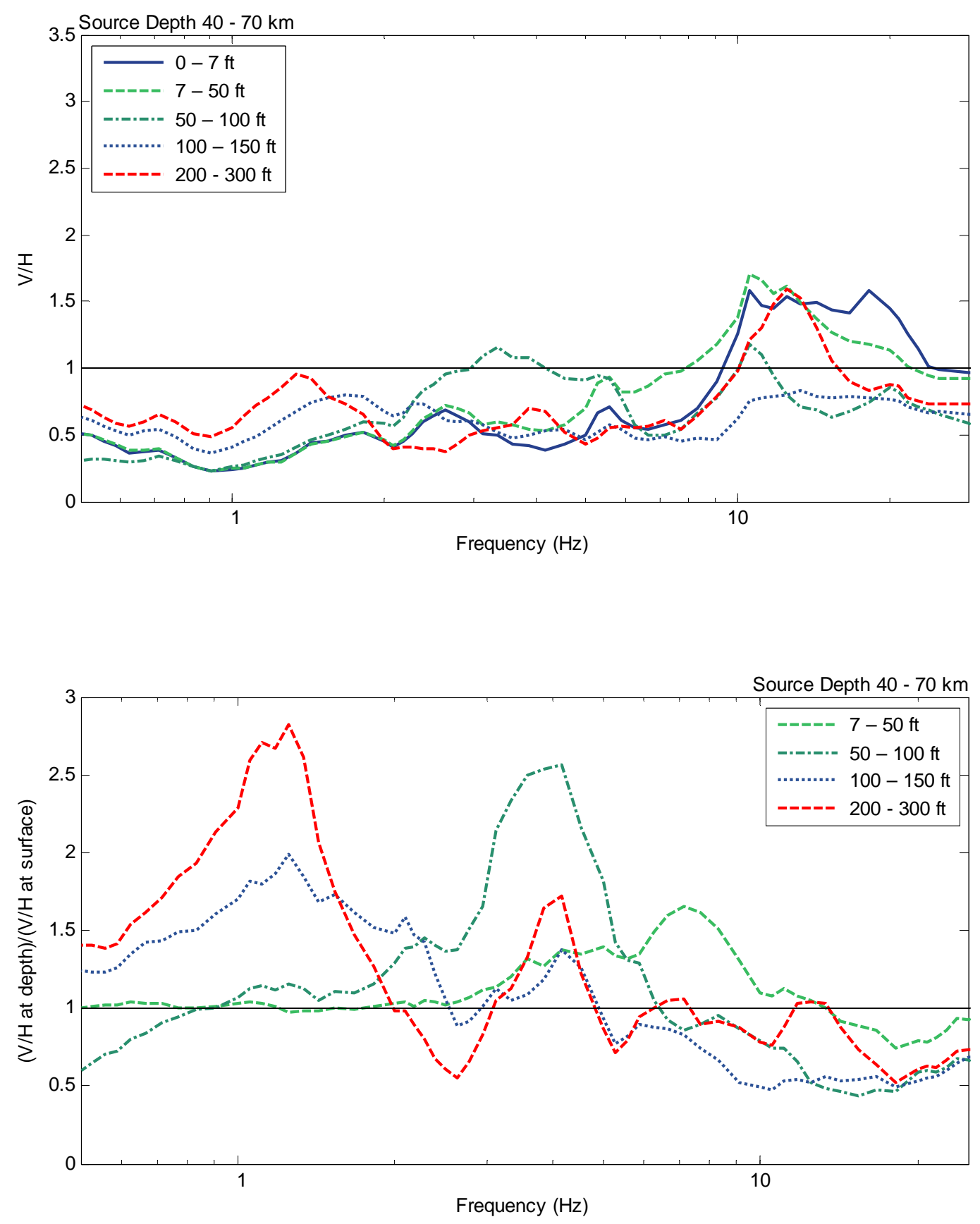

Figure $37 \mathrm{~V} / \mathrm{H}$ ratios of all records obtained from events with source depths between 40 $\mathrm{km}$ and $70 \mathrm{~km}$, from the NEES at UCSB site in Anchorage, Alaska (class D site) Average $\mathrm{V} / \mathrm{H}$ ratios (top) and normalized average $\mathrm{V} / \mathrm{H}$ ratios (bottom) for each of the available depth bins. 

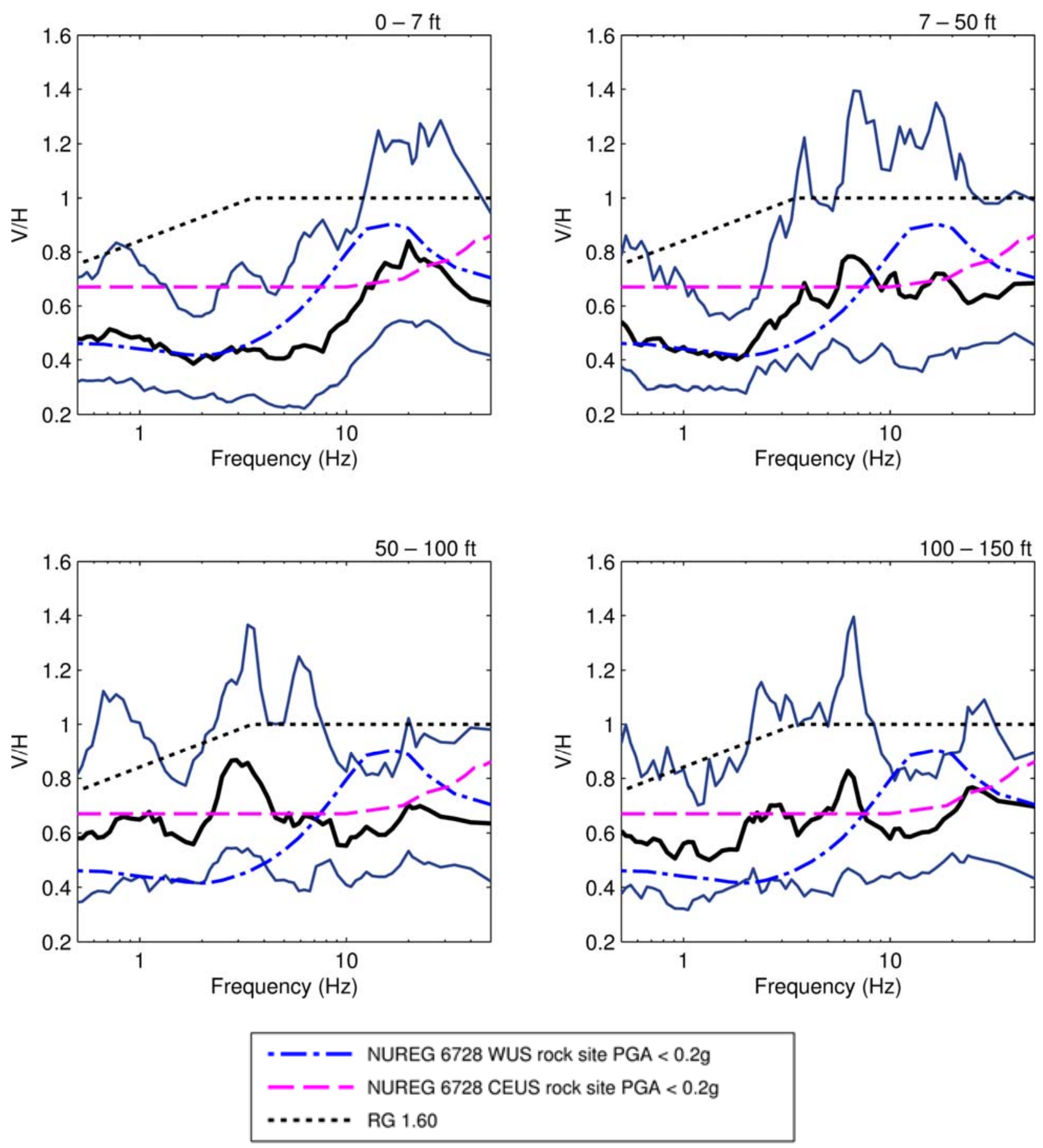

Figure 38 16th, 50th, and 84th percentiles of $\mathrm{V} / \mathrm{H}$ ratios of all records obtained from arrays in class B, C, and D1 sites, and comparison to V/H ratios recommended in NUREG 6728 and RG 1.60

$16^{\text {th }}, 50^{\text {th }}$, and $84^{\text {th }}$ percentiles are shown in solid lower blue, black, and upper blue lines, respectively. Figure shows depth bins 0-7 ft (top left), 7-50 ft (top right), 50-100 ft (bottom left), 100-150 ft (bottom right). 

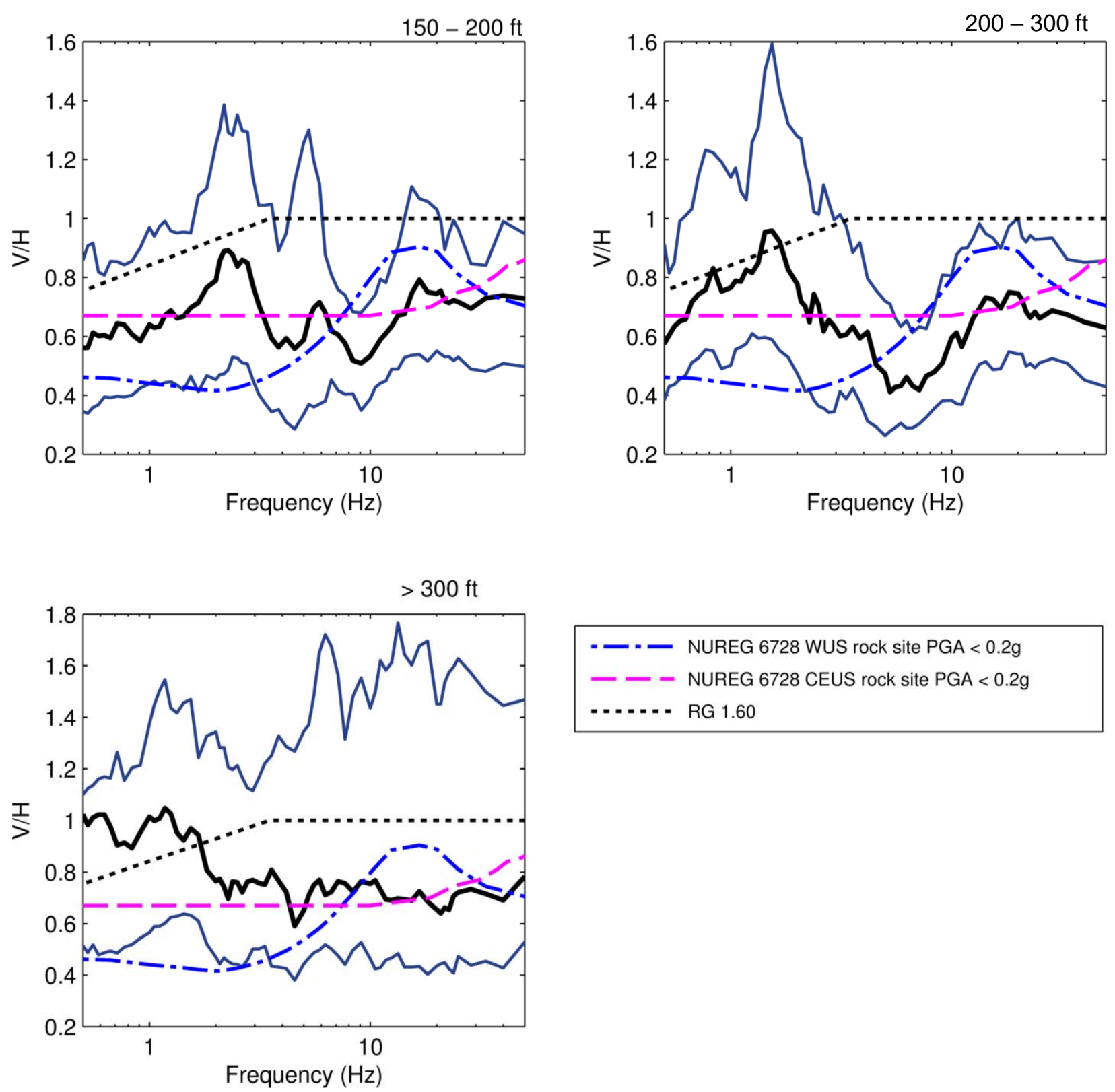

Figure 39 16th, 50th, and 84th percentiles of V/H ratios of all records obtained from arrays in class $B, C$, and D1 sites, and comparison to V/H ratios recommended in NUREG 6728 and RG 1.60

$16^{\text {th }}, 50^{\text {th }}$, and $84^{\text {th }}$ percentiles are shown in solid lower blue, black, and upper blue lines, respectively. Figure shows depth bins 150-200 ft (top left), 200-300 ft (top right), and >300 ft (bottom left). 